

Editorial: Smart Cities Iivari Kunttu

\title{
Smart Cities
}

Welcome to the September issue of the Technology Innovation Management Review. We welcome your comments on the articles in this issue as well as suggestions for future article topics and issue themes.

Towards Smart City Concept in Small Cities

Heikki Ruohomaa, Vesa Salminen \& Iivari Kunttu

Smart Mobility: Services, Platforms and Ecosystems

Jukka Pulkkinen, Jari Jussila, Atte Partanen, Igor Trotskii \& Aki Laiho

Open Data and Open Source Enabling Smart City Development: A Case

Study in Häme Region

Jari Jussila, Joni Kukkamäki, Mikko Mäntyneva \& Juuso Heinisuo

Open Strategy in a Smart City

Suvi Einola, Marko Kohtamäki \& Harri Hietikko

World Heritage meets Smart City in an Urban-Educational Hackathon

in Rauma

Anu Helena Suominen, Seija Halvari \& Jari Jussila

Author Guidelines 


\section{TII Technology Innovation Management Review}

\section{Publisher}

The Technology Innovation Management Review is a monthly publication of the Talent First Network.

ISSN

1927-0321

\section{Editor-in-Chief}

Stoyan Tanev

\section{Managing Editor \\ Gregory Sandstrom}

\section{International Advisory Board}

Dana Brown, Chair, Carleton University, Canada

Alexander Brem, Friedrich-Alexander-Universität

Erlangen-Nürnberg, Germany

K.R.E. (Eelko) Huizingh, University of Groningen, the Netherlands

\section{Associate Editors}

Martin Bliemel, University of Technology, Australia

Kenneth Husted, University of Auckland, New

Zealand,

Mette Priest Knudsen, University of Southern

Denmark, Denmark

Rajala Risto, Aalto University, Finland

Jian Wang, University of International Business and

Economics, China

\section{Review Board}

Tony Bailetti, Carleton University, Canada

Peter Carbone, Ottawa, Canada

Mohammad Saud Khan, Victoria University of

Wellington, New Zealand

Seppo Leminen, Pellervo Economic Research and

Aalto University, Finland

Colin Mason, University of Glasgow, United

Kingdom

Steven Muegge, Carleton University, Canada

Punit Saurabh, Nirma University, India

Sandra Schillo, University of Ottawa, Canada

Marina Solesvik, Nord University, Norway

Michael Weiss, Carleton University, Canada

Mika Westerlund, Carleton University, Canada

Blair Winsor, Memorial University, Canada

Mohammad Falahat, Universiti Tunku Abdul

Rahman, Malaysia

\section{(i)}

\section{Overview}

The Technology Innovation Management Review (TIM Review) provides insights about the issues and emerging trends relevant to launching and growing technology businesses. The TIM Review focuses on the theories, strategies, and tools that help small and large technology companies succeed.

Our readers are looking for practical ideas they can apply within their own organizations. The TIM Review brings together diverse viewpoints - from academics, entrepreneurs, companies of all sizes, the public sector, the community sector, and others - to bridge the gap between theory and practice. In particular, we focus on the topics of technology and global entrepreneurship in small and large companies.

We welcome input from readers into upcoming themes. Please visit timreview.ca to suggest themes and nominate authors and guest editors.

\section{Contribute}

Contribute to the TIM Review in the following ways:

- Read and comment on articles.

- Review the upcoming themes and tell us what topics you would like to see covered.

-Write an article for a future issue; see the author guidelines and editorial process for details.

- Recommend colleagues as authors or guest editors.

- Give feedback on the website or any other aspect of this publication.

- Sponsor or advertise in the TIM Review.

- Tell a friend or colleague about the TIM Review.

Please contact the Editor if you have any questions or comments: timreview.ca/contact

\section{About TIM}

The TIM Review has international contributors and readers, and it is published in association with the Technology Innovation Management program (TIM; timprogram.ca), an international graduate program at Carleton University in Ottawa, Canada.

(C) $2007-2019$

Talent First Network

www.timreview.ca 


\title{
Editorial: Smart Cities
}

\author{
Iivari Kunttu, Guest Editor
}

Welcome to the September issue of the Technology Innovation Management Review. As a guest editor, it is my pleasure to introduce this month's editorial theme Smart Cities. The first three papers included in this special issue originate from papers presented at the ISPIM Connects Ottawa event held in Ottawa, Canada, April 7-10, 2019. One of the focal topics of the event was innovating with government, to which the theme of this special issue brings new insights from the viewpoint of smart city development. As the smart city concept brings together technological development, government and different layers of society, it utilizes various technological enablers, such as the internet of things (IoT) and artificial intelligence (AI) to provide citizens with new kinds of services in their everyday living. However, in addition to technical innovation, the development of smart city areas involves the changing roles of citizens, service providers and city authorities. This, in turn, has innovative impact on business development, service development and administration in various layers of developing urban areas. All of this focuses nicely around the theme of innovating with government at the ISPIM Connects Ottawa event.

The first paper in this special issue gives an overview of some of the academic and practical research being made about smart cities. This paper, written by Ruohomaa et al., "Applying the Smart City Concept in Small Cities", has a particular focus in smart city development strategies adopted in small cities. In this effort, it presents three example cases of how small cities have participated in smart city activities in Finland.

The paper authored by Pulkkinen et al., "Smart Mobility: Services, Platforms and Ecosystems", considers the topic of service business development in terms of operating and maintaining a vehicle fleet in a smart city context. The paper focuses on smart mobility as an important and emerging area of service business development in smart cities. The authors conclude that to create a uniform environment for service business development in this context requires three main elements: a service ecosystem, relevant digital platform, and service portfolio that glues the ecosystem and platform together to create the business solution.

The paper by Jussila et al., "Open Data and Open Source Enabling Smart City Development: Case Study - Häme Region”, highlights the importance of utilizing open data and open source software development in the process of creating new and innovative city services. Open technologies provide opportunities for networked collaboration in service development between cities and third-party developers. The paper presents two practical case examples that utilize open technologies in smart city development, including a centralized open service to collect and publish event-related data in cities, and an open-source software-based smartphone application that provides citizens with the most common city services. Both examples have been implemented and piloted in the city of Hämeenlinna, Finland.

Einola et al. consider in their paper open and participatory strategy process in the smart city context. In "Open Strategy in a Smart City", the authors show how crowdsourcing can be used as an effective tool for citizen participation in developing city strategy. The study utilizes the data obtained from survey responses by almost 2000 Vaasa city citizens, who addressed the role of an open strategy in developing their smart city.

The paper of Suominen et al., "World Heritage meets Smart City in an Urban-Educational Hackathon in Rauma”, considers smart cities from the viewpoint of cultural heritage. The paper uses a UNESCO World Heritage city, Rauma, as a case example that integrates its historical uniqueness with modern city services. In their study, the authors present urban and educational hackathon as an innovative development method for smart city development.

There is a wide consensus among the research community on the need to develop the concept of smart cities because of growing urbanization, user expectations, technological development, and environmental challenges. The contributions included in this special issue of the TIM Review provide covering insights into smart city development not only from a technological perspective, but also with viewpoints about service business development, utilization of open technologies, participatory development processes, and inclusive strategizing. For this reason, I hope the content of this special issue will be of the interest to the TIM Review audience, as well as for scholars and practitioners contributing to smart city development. 


\section{Editorial: Smart Cities}

Iivari Kunttu

\section{About the Guest Editor}

Iivari Kunttu holds a PhD degree in Information Technology from the Tampere University of Technology (TUT, 2005), and a $\mathrm{PhD}$ degree in Economics (management) from the University of Vaasa, Finland (2017). Currently he acts as Principal Research Scientist in Häme University of Applied Sciences. In 2012-2017, he held an Assistant Professor position in Department of Management at the University of Vaasa. He has also held several $R \& D$ Manager and $R \& D$ process development specialist positions in the Nokia Corporation, and project manager positions in TUT. His current research interests include $R \& D$ and innovation management, data analysis, business development, as well as digital services. His works have been published in such international journals as Pattern Recognition Letters, Machine Vision Applications, Optical Engineering, Journal of Telemedicine and Telecare, Annals of Long-term Care, Technovation, Industry and Innovation, and Technology Innovation Management Review.

Citation: Kunttu, I. 2019. Editorial: Smart Cities.

Technology Innovation Management Review, 9(9): 3-4.

http://doi.org/10.22215/timreview/1263

Keywords: smart cities 


\title{
Towards Smart City Concept in Small Cities Heikki Ruohomaa, Vesa Salminen, Iivari Kunttu
}

\author{
"The greatest danger of turbulence is not \\ the turbulence - It is to act with yesterday's \\ logic." \\ Peter Drucker
}

\begin{abstract}
The smart city concept brings together technology, government and different layers of society, utilizing technological enablers, such as the internet of things (IoT) and artificial intelligence (AI). These enablers, in turn, facilitate development of various aspects of the smart city including, e.g., transportation, governance, education, safety and communications. However, the transition towards smarter cities involves not only technological development but also the changing and evolving roles of citizens, service providers and city authorities. In this transition, the key issue is creating and growing roles of collaboration, participation and coordination. Whereas mainstream research focuses on smart city transformation in big cities, aspects of this transformation in the context of small cities has been a widely neglected topic. This paper presents three cases of smart city development in small cities in Finland, each concentrating on a different aspect of smart city development. The cases reveal how a relatively small-sized city may take remarkable steps in smart city development by selecting a specific theme on which to build smart city activities. These examples also emphasize the critical role of public sector actors, showing that the public sector has a key role in creating the foundations for fruitful ecosystem-based development work.
\end{abstract}

\section{Introduction}

It is not just corporations that are seeing rapid changes due to major global challenges, such as globalization, climate change and digitalization. Societies, cities and regions are also experiencing these changes. Today, $55 \%$ of the world's population lives in urban areas, a proportion that is expected to increase to $68 \%$ by 2050 (United Nations, 2018). Thus, the speed and complexity of change also challenge leadership, organizational structures, $R \& D$ activities, education and training, and value chains. Ecosystem-based development is considered to be an option that will facilitate management of change at governmental, national, regional and company level.

The World Economic Forum report (Fourth Industrial Revolution for the Earth Series, 2018), following the work of Klaus Schwab, terms the period of accelerating innovation in science and technology as the "fourth industrial revolution". The technologies of the fourth industrial revolution have generated growing interest in the opportunities they offer as well as concern about governance, regulation and ethics (Fourth Industrial Revolution for the Earth Series, 2018). Combining artificial intelligence (AI) with big data - not to mention exponential accumulation of data itself - has created a fascinating world of communications, collaboration and interaction, not just between people but also between machines, as well as between people and machines (Salminen, Kantola and Ruohomaa., 2016). As a result, the industry 4.0 framework defines the context for digitalization and industrial IoT. This framework contains the connectivity of devices for effective value chain management using sophisticated data collection as well as data-based optimization and analysis. For this reason, industry 4.0 also provides a detailed and solid framework for development work related to smart cities (Lom, Pribyl and Svitek, 2016) because activities related to data collection, interpretation and analysis (in support of rational decision-making and planning) are central to creating smart city services in the value chain network.

The purpose of this paper is to make a practical contribution to the wide-ranging literature on smart city development by presenting three practical cases on smart city development in small Finnish cities. The cases reveal that the commitment of key stakeholders is essential to sustainable development work in this area. The results also underline the importance of providing a platform for new development and pilot studies of ecosystem-based development. The rest of the paper is organized as follows: section 2 describes a framework for smart cities, based on a concise review of literature in this field, with an emphasis on digital participation and 


\section{Towards Smart City Concept in Small Cities}

\section{Heikki Ruohomaa, Vesa Salminen, Iivari Kunttu}

collaborative processes enabled by digitalization. Section 3 presents three case studies about small city development in a rural region of Finland. Section 4 discusses the results and gives guidelines for further research in this field.

\section{Smart City Concept}

The smart city concept derives from the intersection of studies in urbanism and information and communication technology (ICT), combined with the dimensions of creativity and humanity (Nam and Pardo, 2011; Pereira et al., 2017). The smart city concept represents new ways of organizing city functions and urban life for environmental purposes, based on digitalization (Öberg, Graham and Hennelly, 2017). In the field of ICT, rapid development of software, hardware and networks has made it technologically possible to connect people and the facilities that serve their everyday needs in cities (Pereira et al., 2017). Thus, the smart city concept brings together technology, government and different layers of society, utilizing technological enablers, such as the internet of things (IoT) and artificial intelligence
(AI). These enablers, in turn, facilitate development of various aspects of the smart city, including, e.g., transportation, governance, education, safety and communications. Thus, different and often complementary aspects of asmart city encompass an efficience, technological advancement, sustainability and social inclusivity (Vanolo, 2014). General trends in this kind of development include the transition from global to local production and consumption, a change from competitive to collaborative manufacturing and service provision, and a move from shareholder-based businesses to multiple stakeholder viewpoints (Herrschel, 2013; Öberg, Graham and Hennelly, 2017).

Smart city development requires not only technological enablers but also a new way of thinking among cities, businesses, citizens and academia, which includes key development stakeholders. In this manner, close collaboration between universities and the private sector must be maintained, and the main objective should be shared learning (Ruohomaa, Mäntyneva and Salminen, 2018). This kind of long-term cooperation creates a background for new co-innovation and co-evolution.

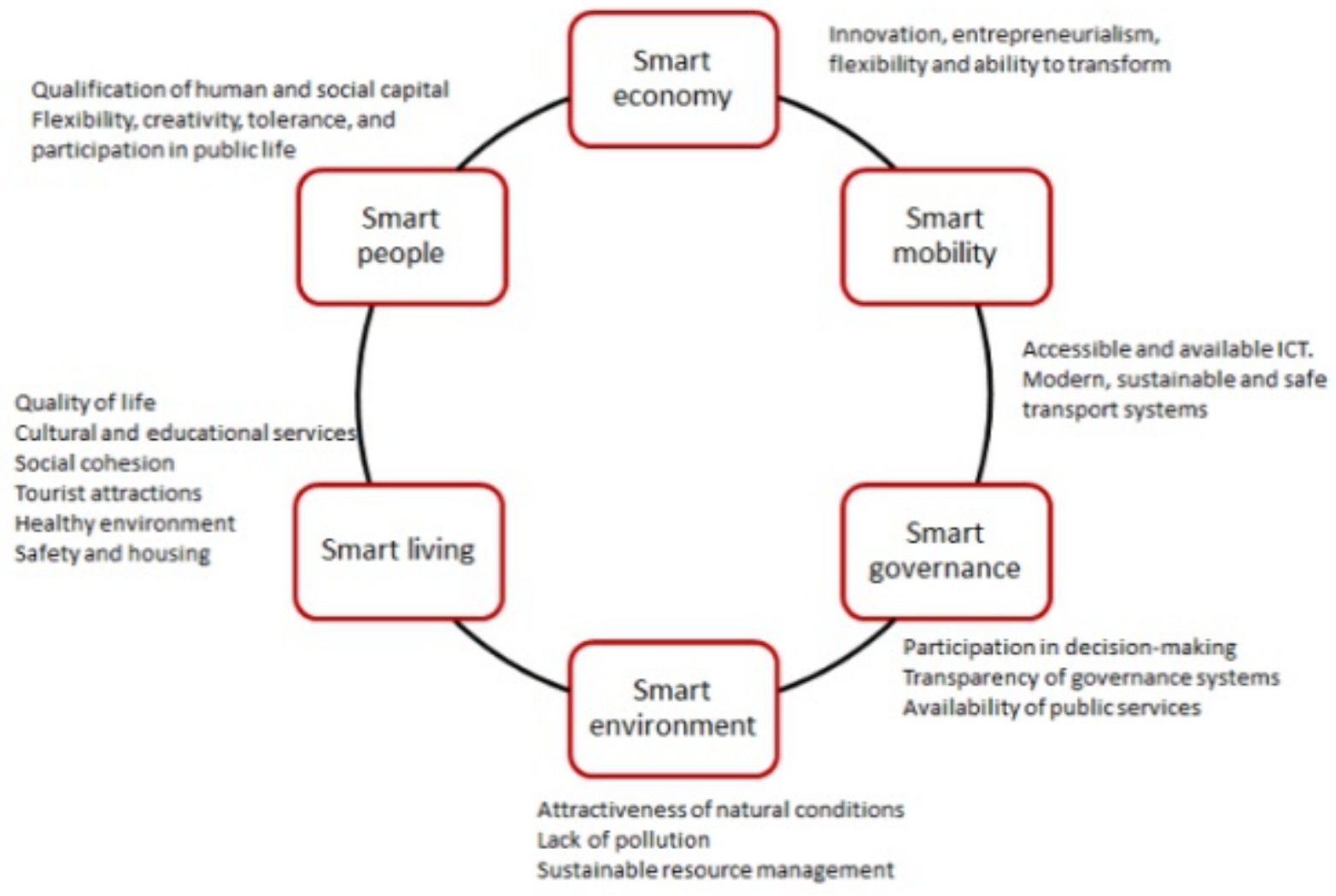

Figure 1. Dimensions of the smart city concept, adapted from Giffinger and Suitner (2015) 


\title{
Towards Smart City Concept in Small Cities
}

\author{
Heikki Ruohomaa, Vesa Salminen, Iivari Kunttu
}

The transition towards smarter cities involves changing and evolving stakeholder roles (Lom, Pribyl and Svitek, 2016). Citizens should no longer be considered as merely users but rather as stakeholders with an active role; as participants, collaborators and developers in the city's activities. In the same manner, technology should no longer be considered as an asset but as a dynamic enabler in smart city development. Moreover, in this framework, business is no longer viewed as a provider but rather as a collaborative partner. These new roles, together with the ecosystems formed by smart cities, establish a framework for a new kind of development in urban areas. In this framework, it is important to understand that smart city development does not mean merely providing new digital services for citizens. Rather, it is a transformative process involving city structures, governance and functions, as well as interaction and collaboration between city stakeholders (Vanolo, 2014).

Smart city initiatives have recently been merged into a model to make cities better places to live in. The smart city can thus be considered as an ideal of sustainable urban living. It is nevertheless a rather vague concept, defined in various ways depending on the context of smartness (Öberg, Graham and Hennelly, 2017). According to Giffinger and Suitner (2015), the concept of a smart city should incorporate at least one of the following dimensions (Figure 1): 1) a smart economy related to, e.g., innovation, entrepreneurship, flexibility or productivity; 2) smart mobility in the context of sustainable resource management and transport systems; 3) smart governance with implications for participation, decision-making and transparent governance structures; 4) a smart environment that is understood to provide attractive, natural conditions and a lack of pollution, as well as sustainable management of resources and energy; 5) smart living and quality of life; and 6) smart people in terms of qualifications, creativity, education and flexibility (Vanolo, 2014). In this manner, smartness in the smart city context can be associated with very different phenomena. One factor that these phenomena have in common is sustainability, which is included in one form or another in almost all of the above-mentioned dimensions (Öberg, Graham and Hennelly, 2017). Moreover, Herrschel (2013) suggests that the smartness of smart cities has come to include "innovativeness, participation, collaboration, and coordination". This highlights the role of smart processes, collaborative practices and ways of working as opposed to pure ICT-based technological development. The latter is seen as an enabler, rather than as a key element of the smart city concept. Despite this rather broadly defined framework, previous literature in the field of smart city development is relatively coherent in suggesting that digitalization and urbanization are making production and consumption less global and more local, thus changing manufacturing from competitive to collaborative and business from a single shareholder basis to multiple stakeholders (Öberg, Graham and Hennelly, 2017). In this context, data-driven service operation can be used to significantly improve service performance, by implementing the right data strategy (Pulkkinen, Jussila, Partanen and Trotskii, 2019).

Figure 2 displays the essential framework for a digital ecosystem in smart city transformation (Ruohomaa and Salminen, 2019). In this framework, the general

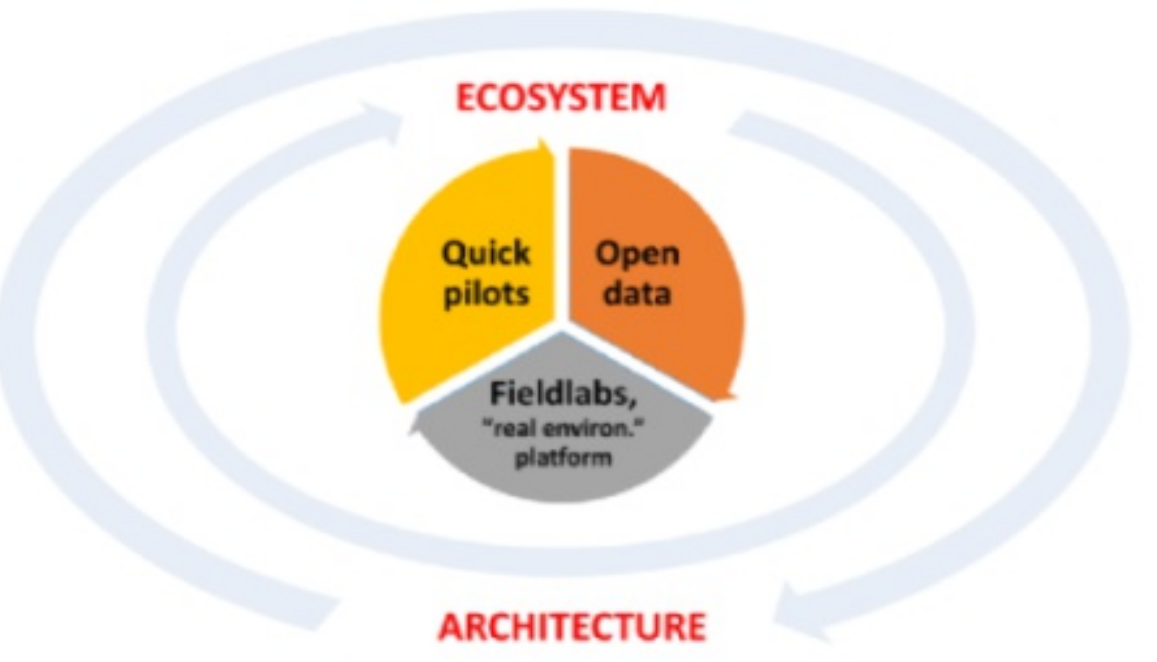

Figure 2. Digital ecosystem in a smart city context (Ruohomaa and Salminen, 2019) 


\section{Towards Smart City Concept in Small Cities}

\section{Heikki Ruohomaa, Vesa Salminen, Iivari Kunttu}

architectural layer enables the involvement of privatesector partners. At the same time, the players in this framework form an ecosystem that consists of inhabitants, tourists, companies and the city itself.

The concept of a city's 'smartness' can be understood on three conceptual levels (Lom, Pribyl and Svitek, 2016). Firstly, in the context of marketing, smartness involves user perspective. The smart services related to smart cities are linked to user-friendliness, which means that smart cities require conceptual adaptations to end user needs and interfaces with the city's inhabitants (Marsá Maestre et al., 2006). Secondly, in the context of strategic management and development, the smart city concept is directly related to the strategic and ideological directions taken by urban planning. This is because public actors, such as governments and cities, at all levels, utilize the concept of smartness to distinguish their new strategies, development programmes and policies, as a guideline for the development of urban areas in terms of economic growth, sustainable development and better quality of life. Smart governance (or e-governance) means that various key stakeholders are engaged in decisionmaking and public services through, e.g., social media, open data or other internet-based participation platforms (Pereira et al., 2017). A key issue in facilitating these kinds of participatory tools and services is collaboration across departments and communities; which tests the real user-centeredness of these services. Thirdly, in the context of technological development, enablers of the smart city concept utilize the methods of artificial intelligence (AI), the internet of things (IoT), and machine learning (which all rely on sophisticated data collection and analysis), to apply these commercially. These technological enablers facilitate the development and deployment of ICT-related aspects of smart cities, e.g., smart transportation, smart energy, smart education, smart safety and smart communication (Lom, Pribyl and Svitek, 2016). Together, these three levels of the smart city concept form a smart city ecosystem, which represents an extension of smart space from personal surroundings to the larger community and entire city. Table 1 illustrates the basic characteristics of the smart city ecosystem.

Table 1. Characteristics of a smart city ecosystem

\begin{tabular}{|c|c|c|c|}
\hline Context & General direction & User point of view & $\begin{array}{l}\text { Governance point } \\
\text { of view }\end{array}$ \\
\hline \multirow[t]{2}{*}{ Marketing } & & & Service process \\
\hline & $\begin{array}{l}\text { User pers pective is } \\
\text { emp has ized. }\end{array}$ & $\begin{array}{l}\text { Usable, accessible } \\
\text { and user-friendly } \\
\text { digital services. }\end{array}$ & $\begin{array}{l}\text { needs to be } \\
\text { adapted to user } \\
\text { needs and } \\
\text { interfaces. }\end{array}$ \\
\hline $\begin{array}{l}\text { Strategic } \\
\text { management } \\
\text { and } \\
\text { Governance }\end{array}$ & $\begin{array}{l}\text { Governments and cities } \\
\text { at all levels utilize the } \\
\text { concept of smartness to } \\
\text { engage various } \\
\text { stake holders in decision- } \\
\text { making. }\end{array}$ & $\begin{array}{l}\text { Citizens are } \\
\text { conside red as key } \\
\text { stake holders, } \\
\text { participating in } \\
\text { decision-making } \\
\text { and city } \\
\text { develop ment } \\
\text { through } \\
\text { participation tools. }\end{array}$ & $\begin{array}{l}\text { Cities facilitate } \\
\text { participatory } \\
\text { planning and } \\
\text { decision-making by } \\
\text { providing citizens } \\
\text { with digital } \\
\text { participation } \\
\text { options. }\end{array}$ \\
\hline Technology & $\begin{array}{l}\text { Utiliz ation of } \mathrm{AI}, \mathrm{IO} \mathrm{T} \text { and } \\
\text { machine learning } \\
\text { together with data } \\
\text { analysis to provide smart } \\
\text { services. }\end{array}$ & $\begin{array}{l}\text { Impro ving quality } \\
\text { of life through } \\
\text { smart services. }\end{array}$ & $\begin{array}{l}\text { Providing citizens } \\
\text { with relevant digital } \\
\text { services, facilitating } \\
\text { sus tainable living } \\
\text { in cities. }\end{array}$ \\
\hline
\end{tabular}




\section{Towards Smart City Concept in Small Cities}

\section{Heikki Ruohomaa, Vesa Salminen, Iivari Kunttu}

\section{Case Studies}

The purpose of this paper is to consider smart city transformation in small cities by focusing on selected areas. In this section, we present three cases, each focusing on one small city in Finland. In the first case, we present the case of Hämeenlinna. In its ecosystembased development work, this city has faced a cumulative increase of data, and has used new technologies to respond to the rapid change and complexity of the business environment. The case study is based on the smart mobility part of the framework in relation to bikes. The second case considers the town of Riihimäki. Riihimäki relies on smart specialization by adapting digitalization and robotics to improve the overall competitiveness of local business, society, educational environments and city services. The third case presented is that of Forssa. The Forssa case focuses on a circular economy in terms of industrial development and town services. In this manner, experience and understanding of the circular economy and industrial symbiosis have facilitated greater understanding of how to develop smart living, education and tourism in the Forssa region. Table 2 summarizes the key characteristics of each smart city development case.

\section{The Case of Hämeenlinna}

The city of Hämeenlinna has recently started ecosystem development work aimed at improving the town's competitiveness and sustaining its surrounding region. Key stakeholders involved in ecosystem work include city authorities, local companies, the local university and other educational institutions, as well as city inhabitants. Digitalization and developing smart city services are among the key targets of this ecosystem building work (Kunttu, 2019). Weveral pilot projects have been initiated to develop smart city services in Hämeenlinna.

The pilot project presented in this paper is an electronic bike service, which will be detailed along with data that can be collected for further use (Figure 3). As part of the smart mobility concept, the bike-share operators and cities in which they operate want bike-share travel to become a viable part of the transportation system for city residents. In this manner, bike sharing is a city transport solution and a smart answer to urban mobility, providing a competitive alternative to private cars and existing public transport services (Dennis, 2018). In the Hämeenlinna bike project, yellow-and-green bikes are made available in selected locations around the city (see Figure 4). Users can check the availability of the bikes and rent one by using a smartphone application. Open data provided by the bike-sharing service are utilized in several ways. In the direct data-based service, users are able to see the availability of bikes in the town. In the indirect services, data are used by the bike operators to ensure availability and also to maintain the bikes. The city authorities are also aiming to utilize the collected bike data to plan cycle routes and services for bikers.

\section{The Case of Riihimäki}

The town of Riihimäki bases its strategy on robotics for developing an attractive business environment. Since robotics has been selected as the strategic focus area for the town, the authorities are committed to long-term development and implementation of robotics in a wide range of life and working environments. Development

Table 2. Characteristics of each city in the case study

\begin{tabular}{l|lll}
\multicolumn{1}{c}{ Hämeen linna } & \multicolumn{1}{c}{ Forssa } & \multicolumn{1}{c}{ Riihimäki } \\
\hline $\begin{array}{l}\text { Number of } \\
\text { inhabitants } \\
\text { Focus areas }\end{array}$ & 67,000 & 20,000 & 28,000 \\
& $\begin{array}{l}\text { Education, local } \\
\text { governance, military } \\
\text { base }\end{array}$ & Circular economy & $\begin{array}{l}\text { Manufacturing } \\
\text { industry }\end{array}$ \\
$\begin{array}{l}\text { Focus area in } \\
\text { smart city } \\
\begin{array}{l}\text { development } \\
\text { Smart city } \\
\text { pilots }\end{array}\end{array}$ & Smart mobility & $\begin{array}{l}\text { Smart enviro nment } \\
\text { (circular economy) }\end{array}$ & $\begin{array}{l}\text { Smart living } \\
\text { (service robotics) }\end{array}$ \\
& Bike-sharing service & $\begin{array}{l}\text { Recycling and } \\
\text { waste management } \\
\text { services }\end{array}$ & $\begin{array}{l}\text { Robotics in } \\
\text { education and } \\
\text { elderly care }\end{array}$
\end{tabular}




\section{Towards Smart City Concept in Small Cities}

Heikki Ruohomaa, Vesa Salminen, Iivari Kunttu

activities in Riihimäki are interlinked, and follow the European industry 4.0 framework to ensure crossjurisdictional comparability and compatibility. An industry 4.0 framework with robotics can also be used to indicate intent to the European Digital Single Market, and thus attract new business to the town. To ensure implementation, it is necessary to have an open atmosphere so that stakeholders, including citizens, business actors and town authorities, can participate in robotics development and innovation activities. By involving multiple stakeholders, it is possible to reduce resistance to change, increase commitment, and obtain new development ideas.

Utilization of robotics and digitalization requires new skills (not only technical but also multidisciplinary) and a broad approach. For this reason, the town of Riihimäki has invested heavily in educational robotics activities, ranging from nurseries and elementary schools, to university level and lifelong learning for adults, integrating this with the needs of various sectors, including industry, health care, education, and traffic. Education is not only seen as a way of building know-how, but also of reducing resistance to change, speeding up implementation and promoting a positive attitude to robotics. Education is also fundamental to innovation when it takes place in "real-life" environments, in pilots and quick trials. The town has also arranged several events related to robotics, including competitions and development challenges for students. The city has also collaborated closely with the local university on these activities.

The three main areas of robotics development in Riihimäki are production robotics (focusing on industrial automation and manufacturing), service robotics and the robotics of health care. The pilots for these three aspects are being undertaken in various parts of the city. For example, care associations are running pilots for service robotics in the field of elderly care (Bäck et al., 2012; Bäck, Mäkela and Kallio, 2013) in collaboration with the local university.

\section{The Case of Forssa}

The town of Forssa is in the middle of the Finnish agricultural landscape, located within a triangle formed by the three largest cities in Finland, and with good transportation connections. The largest national research institute for agriculture and bioeconomy is also located in the Forssa region. In addition, the bioeconomy and agriculture departments of the regional university of applied sciences are located there.

The history of the Forssa circular economy business ecosystem dates to the 1990s, when the first EU waste treatment directive was launched. Because of this,

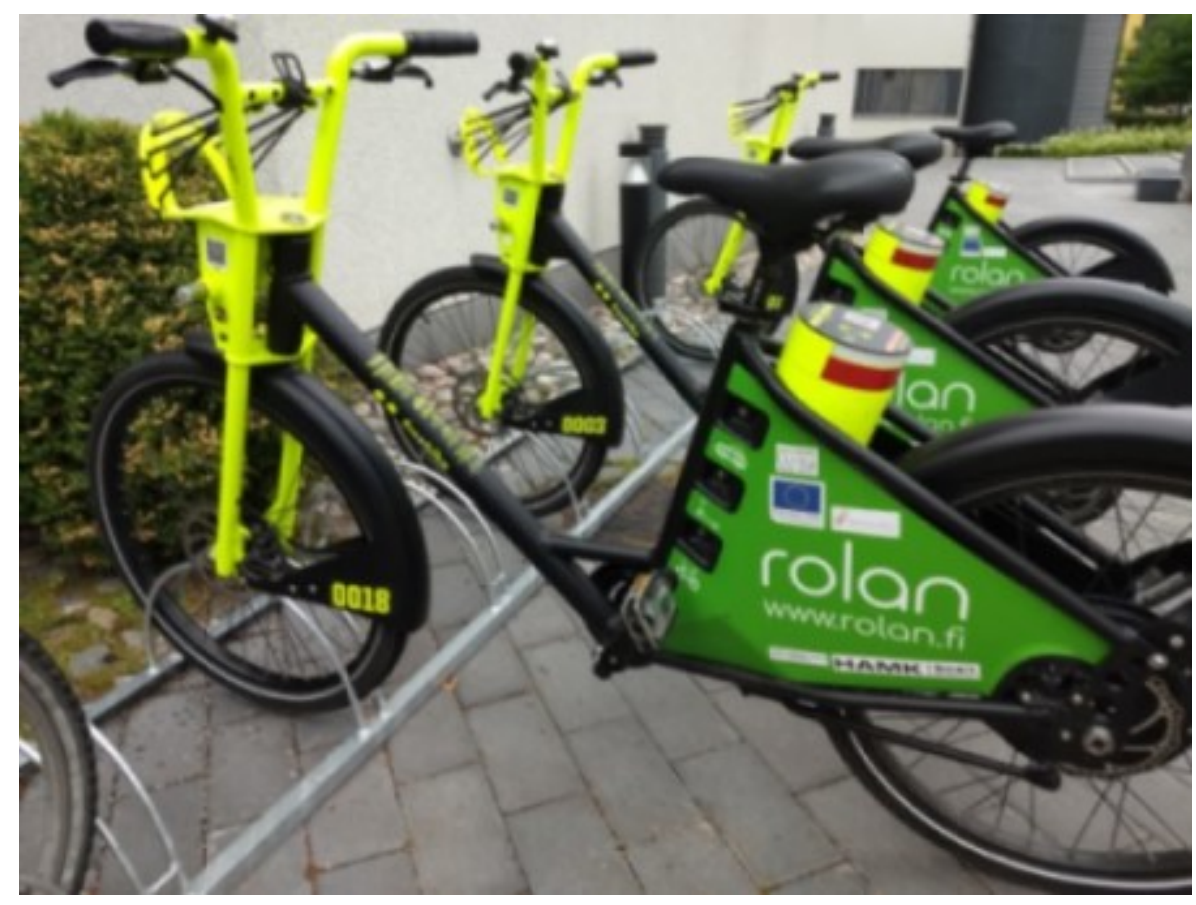

Figure 3. Bike-sharing service at Hämeenlinna railway station 


\section{Towards Smart City Concept in Small Cities}

\section{Heikki Ruohomaa, Vesa Salminen, Iivari Kunttu}

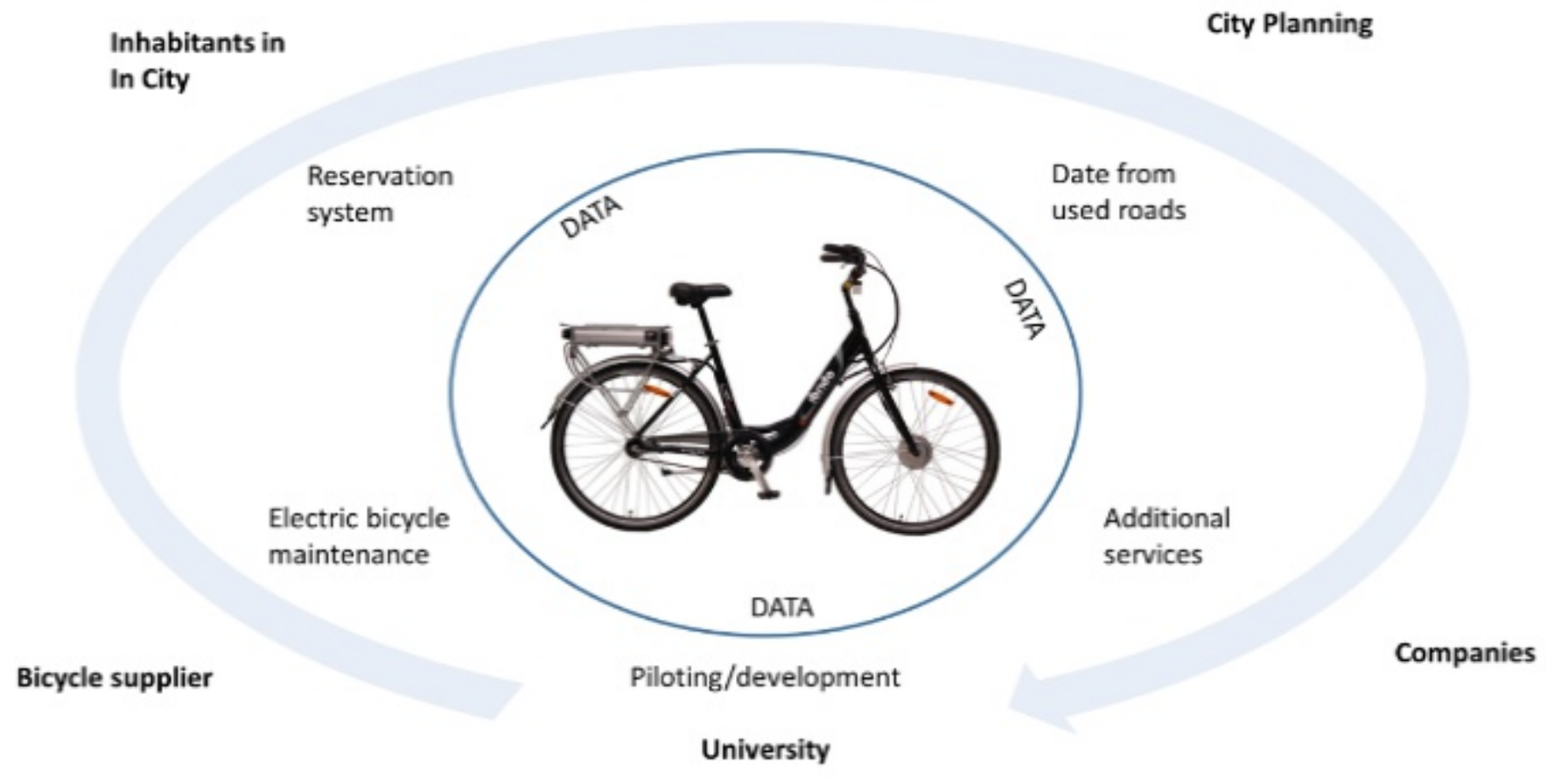

Figure 4. Pilot of the electric bicycle digital ecosystem

Forssa and the surrounding municipalities decided to create a large landfill area, where all the companies involved with waste handling or treatment could be located. Since then, several companies operating in the waste management business have moved to this area. Their close proximity makes it easy for these companies to cooperate with one another, and in this way an ecosystem has been created for a circular economy and industrial symbiosis. The circular economy ecosystem in Forssa is currently ranked the best in Finland.

Nowadays, in the Forssa region, strategic focus is placed on a circular economy. R\&D funding is used for the development of this circular economy, and the local university has adapted its degree programmes to support circular economy education. The local authorities are highly supportive of ecosystem-based development, and new start-ups focusing on circular economy activities. Figure 5 presents a visualization of industrial symbiosis of the circular economy ecosystem in Forssa. Based on this, the town of Forssa and its surrounding regions are being branded as the "Smart Green Forssa Region". Also related, Forssa hosts an annual circular economy event for start-ups and growth enterprises (FRUSH) to make its activities visible, attract investors and promote circular economy-related startups.
The city of Forssa has also selected the circular economy and smart city development as part of its strategic focus. The reason behind this is the fact that although the circular economy and industrial symbiosis were largely driven by industry at the outset, these developments have had a marked impact on the of city of Forssa, and have led to increased understanding and thinking among its citizens generally. Thus, the city strongly supports resource efficiency and circular economy development in its everyday activities. Circular economy thinking has had a major impact on education, environment, living, services and tourism. A concrete example of this is the local waste management facility, which continuously produces new user innovations for smart recycling and effective resource utilization.

\section{Conclusion}

In the existing literature related to smart city development, a wide consensus exists on the need to build new smart city solutions because of urbanization, user expectations, technological development, and environmental challenges. This paper presented practical viewpoints, cases and experiences relating to the planning of smart cities, and the availability of services. We also considered how these examples could 


\section{Towards Smart City Concept in Small Cities}

\section{Heikki Ruohomaa, Vesa Salminen, Iivari Kunttu}

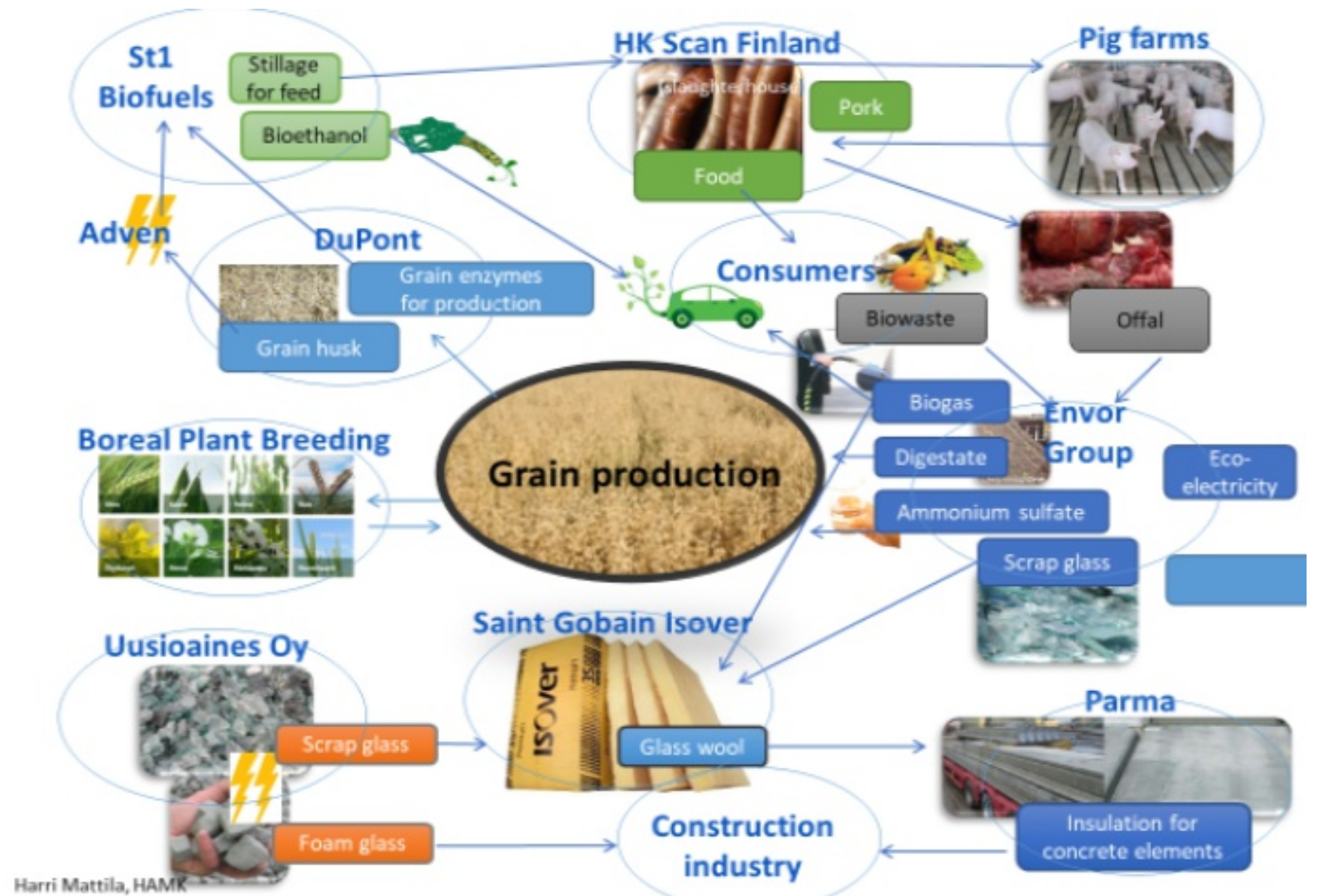

Figure 5. Efforts made in the Forssa region to visualize local bio-based industrial symbiosis

be used as a tool for city planning in a smart city context. In this way, the paper may provide helpful information based on "lessons learned", relevant to all the actors involved and interested to participate in smart city development (and the fundamental services themselves).We presented a case study of three small cities in southern Finland, all of which had selected to undertake smart city development in a clearly defined area directly related to the strategic focus of the city or region. In this manner, a common denominator for the cases was that each town is basing its smart city activities in key strategic areas. In all three cases, the towns were actually platforms for smart city development projects, which enable inhabitants and other stakeholders to participate in planning and development, and thus become part of the ecosystem.

These case studies show that the public sector has a fundamental role in fruitful ecosystem-based development. They reveal larger initiatives where towns are moving their development activities towards ecosystem-orientation. This is changing what it means to be organized so that an ecosystem can be more responsive to the impact of digitalization and increasing amounts of data. 


\section{Towards Smart City Concept in Small Cities}

\section{Heikki Ruohomaa, Vesa Salminen, Iivari Kunttu}

\section{References}

Dennis, A. L. 2018. Case Study: Artificial Intelligence Helps Bike-Share Programs Get Smart. https://www.dataversity.net/case-study-bike-shareprograms-get-smart-artificialintelligence/?fbclid=IwAR3adaqrjlFnRlnmKTEVd7XS EsVwe0ny tLWLZI4L97OgRmX8_pAowDrTK9

Bäck, I. et al. 2012. Monitoring of nursing home residents using a humanoid robot. Journal of Telemedicine and Telecare, 18: 357-361.

Bäck, I., Mäkela, K. and Kallio, J. 2013. Robot-guided exercise program for the rehabilitation of older nursing home residents. Annals of Long-Term Care, 21(6): 38-41.

Fourth Industrial Revolution for the Earth Series. 2018. Harnessing the Fourth Industrial Revolution for Life on Land -Towards an Inclusive Bio-Economy. World Economic Forum, January 2018, Geneva, Switzerland.

Giffinger, R. and Suitner, J. 2015. Polycentric metropolitan development: from structural assessment to processual dimensions. European Planning Studies, 23(6): 1169-1186.

Herrschel, T. 2013. Competitiveness AND Sustainability: Can "Smart City Regionalism" Square the Circle? Urban Studies, 50(11): 2332-2348. doi: $10.1177 / 0042098013478240$

Kunttu, I. 2019. Developing smart city services by mobile application. ISPIM Connects, Ottawa, Innovation for Local and Global Impact, 7th-10th April 2019.

Lom, M., Pribyl, O. and Svitek, M. (2016). Industry 4.0 as a Part of Smart Cities. 2016 Smart Cities Symposium Prague (SCSP). IEEE.

doi: $10.1109 /$ SCSP.2016.7501015

Marsá Maestre, I. et al. (2006) Mobile Personal Agents for Smart Spaces. In IEEE International Conference on Pervasive Services: 299-302.

doi: 10.1109/PERSER.2006.1652247

Nam, T. and Pardo, T. A. (2011). Conceptualizing smart city with dimensions of technology, people, and institutions. The Proceedings of the 12th Annual International Conference on Digital Government Research: 282-291. doi:

10.1007/978-3-540-68894-5_7

Öberg, C., Graham, G. and Hennelly, P. 2017. Smart cities: a literature review and business network approach discussion on the management of organizations. IMP Journal, 11(3): 468-484.

doi: 10.1108/IMP-06-2015-0024

Pereira, V. G. et al. 2017. Increasing collaboration and participation in smart city governance: a cross-case analysis of smart city initiatives. Information Technology for Development, 23(3): 526-553.

Pulkkinen, J., Jussila, J., Partanen, A. and Trotskii, I. 2019. Data strategy framework in servitization: Case study of service development for a vehicle fleet.
Research and Innovation Forum, Rome, 24th-26th April 2019.

Ruohomaa, H. and Salminen, V. 2018. Regional Development in Modern Robotic Education on Industrial and Society Context. AHFE 2018, Florida, 21st-25th June 2019.

Ruohomaa, H. and Salminen, V. 2019. Mobility as a service in small cities - new concept for smart mobility in Industry 4.0 framework. ISPIM Connects, Ottawa, Innovation for Local and Global Impact, 7th-10th April 2019.

Ruohomaa, H., Mäntyneva, M. and Salminen, V. 2018. Renewing a University to Support Smart Manufacturing within a Region. Digital Transformation in Smart Manufacturing, chapter 8, IntechOpen.

Salminen, V., Kantola, J. and Ruohomaa, H. 2016. Digitalization and Big Data Supporting Responsible Business Co-Evolution. 2nd International Conference on Human Factors, Business Management and Society (inside the AHFE 2016), Orlando, USA, 27th-31st July 2016.

United Nations. 2018. 68\% of the world population projected to live in urban areas by 2050 .

https://www.un.org/development/desa/en/news/po pulation/2018-revision-of-world-urbanizationprospects.html

Vanolo, A. 2014. Smartmentality: The Smart City as Disciplinary Strategy. Urban Studies, 51(5): 883-898. doi: $10.1177 / 0042098013494427$ 


\section{Towards Smart City Concept in Small Cities}

\section{Heikki Ruohomaa, Vesa Salminen, Iivari Kunttu}

\section{About the Authors}

Mr. Heikki Ruohomaa is currently as research manager in the HAMK Smart Research Centre at Häme University of Applied Science. He is involved with various research activities, education ja (?) industrial implementation. His areas of expertise include ecosystem-based development, circular economy and Industry 4.0. He has also worked actively for regional development.

Dr. Vesa Salminen is currently acting as research director in the HAMK Smart Research Centre at Häme University of Applied Sciences. He is involved with various research activities, education and industrial implementation. His areas of expertise include innovation leadership, the data-to-service process, industrial service business, competence management and strategic management of business transitions. He previously worked as industrial professor at Lappeenranta University of Technology and spent two years as senior research scientist at the Massachusetts Institute of Technology, MIT, Boston. He has over 25 years' industrial experience, which includes being managing director of Spiral Business Services Corp., technology expert at Technology Industries of Finland, and marketing/sales/project expert at Valmet Corp. Salminen has published over 200 refereed journal articles, book chapters and conference articles, e.g., through Springer Publishing, Elsevier Publishing, Intech Media, IEEE Publishing, ASME Publishing, IST Publishing and IGI Global Publishing.
Dr. Iivari Kunttu holds a PhD degree in Information Technology from the Tampere University of Technology (TUT, 2005), and a PhD degree in Economics (management) from the University of Vaasa, Finland (2017). Currently he acts as Principal Research Scientist in Häme University of Applied Sciences. In 2012-2017, he held an Assistant Professor position in Department of Management at the University of Vaasa. He has also held several R\&D Manager and $R \& D$ process development specialist positions in the Nokia Corporation, and project manager positions in TUT. His current research interests include $R \& D$ and innovation management, data analysis, business development, as well as digital services. His works have been published in such international journals as Pattern Recognition Letters, Machine Vision Applications, Optical Engineering, Journal of Telemedicine and Telecare, Annals of Long-term Care, Technovation, Industry and Innovation, and Technology Innovation Management Review.

Citation: Ruohomaa, H, Salminen, V, \& Kunttu. I. 2019. Towards Smart City Concept in Small Cities. Technology Innovation Management Review, 9(9): 5-14.

(cc) BY

Keywords: smart city; regional development; industry 4.0; ecosystem-based development; mobility; robotic; circular economy. 


\title{
Smart Mobility: Services, Platforms and Ecosystems
}

\author{
Jukka Pulkkinen, Jari Jussila, Atte Partanen, Igor Trotskii, Aki Laiho
}

\author{
"If everyone is moving forward together, \\ then success takes care of itself." \\ Henry Ford, \\ Founder of Ford Motor Company
}

\begin{abstract}
In this study, we provide novel insight into building and managing growth in a new emerging market: the operation and maintenance of a heterogeneous and expanding vehicle fleet in a smart city environment. There are several different types of players in this emerging market and a dominant player is still missing. Based on our empirical findings, we identified three key characteristics of a growing business and the ability to reach a leading position: 1) co-creation through resource integration and service exchange is preferable for responding to market demands; 2) a digital platform is critical to create the necessary knowledge for resource integration and service exchange; and 3) smart services glue the ecosystem and platform together and create the outcome that solves the defined business problem. Most importantly, all three elements- ecosystem, platform and smart services- create a uniform environment in which to grow the business in a new emerging market.
\end{abstract}

\section{Introduction}

Smart mobility is booming and comprises an important part of the development of smart cities. City bikes are already widely used in many cities and new types of vehicles, such as scooters, are entering the market. This opens new niche markets for vehicle fleet operation and maintenance, and creates challenges for effective services, due to the existence of expanding heterogeneous vehicle fleets located in large geographical areas, and the inclusion of new types of vehicles with operation and maintenance requirements.

The market for smart mobility is increasing rapidly. Mobility as a service (MaaS) (Docherty, Marsden \& Anable, 2018) is becoming an increasingly popular model that is changing transportation chains for people in many cities (Loidl, Witzmann-Müller \& Zagel, 2019). This transportation disruption creates a new niche market for commercial actors operating and maintaining the whole vehicle fleet on behalf of a city. Currently, there are several different types of companies trying to gain a share in this market, starting from local small maintenance providers and ending with global technology companies that provide smart mobility systems, such as city bike systems. The winner in the new growing market will be the player who is capable of managing service operations at lower cost, while at the same time ensuring a sufficiently high quality for a fast-growing vehicle fleet (Pulkkinen, Jussila, Partanen \& Trotskii, 2019). Therefore, utilizing data to fulfil the above-mentioned requirements will be one critical success factor in achieving a significant market share. In current-day practice, there are several challenges in operating and managing an expanding vehicle fleet. Small local companies cannot easily expand to other cities, and big technology companies that deliver one type of smart mobility system, may encounter problems in operating and managing other vendors' systems, among other examples.

We draw on service-dominant (S-D) logic, defined as dynamic, continuing value co-creation through resource integration and service exchange, which has been constructed by an increasingly large number of academics (Lusch, Vargo \& Fisher, 2014; Vargo \& Lusch, 2017). "Resources", in this context, refers to broad knowledge and skills. S-D logic is moving toward a general theory of marketing and requires more midrange theoretical frameworks and practical use cases. One S-D logic diffusion is ecosystem services (Vargo \& Lusch, 2017). Business ecosystem development has been the focus of many researchers over recent decades (Järvi \& Kortelainen, 2017). The development of information and communications technology (ICT) has come to be seen as a cornerstone of the digital business ecosystem (DBE), in which a digital platform is used to create 


\section{Smart Mobility: Services, Platforms and Ecosystems}

Jukka Pulkkinen, Jari Jussila, Atte Partanen, Igor Trotskii, Aki Laiho

knowledge from data, and this knowledge is then utilized in business ecosystems (BEs) value co-creation (Senyo, Liu \& Effah, 2019). The ecosystem can either expand or shrink, depending on the decision-making and behaviour of all of the individual actors belonging to the ecosystem. Therefore, ecosystem dynamics has been the focus of several researchers (Senyo et al., 2019; Tsujimoto, Kajikawa, Tomita \& Matsumoto, 2018).

In the literature, there is a research gap relating to the operation and maintenance of smart mobility systems, due to the previous focus on developing ecosystems that connect users to smart mobility systems (Docherty et al., 2018; Faber, Rehm, Hernandez-Mendez \& Matthes, 2018; Ji, Cherry, Han \& Jordan, 2014; Loidl et al., 2019). On the other hand, empirical evidence on how to manage knowledge and the stability of BEs remains limited (Jacobides, Cennamo \& Gawer, 2018). Accordingly, this paper aims to address service development for commercial actors operating and maintaining vehicle fleets and to consider how the ecosystem should be utilized to gain a significant share in the new growing market. Building on existing research, we aim to answer the following research question: "What is the most effective way to build and manage a sustainable and expanding ecosystem for vehicle fleet operation and maintenance?" An ecosystem is presented in Fig. 1. The paper explores service business development that utilizes an ecosystem to improve the business' competitive position in a new market. Service business development creates artefacts to maintain and operate the expanding and heterogeneous vehicle fleet, in a way that enables the commercial actor to gain a significant market share. The results also present new practical guidelines generally to ecosystem actors for the creation of an expanding ecosystem, and some specific practical learning in this specific new market. As well, the results present one practical use case that more effectively bridges practice and theory in the area of ecosystem services, as one subdiscipline in S-D logic.

\section{Theoretical Background}

Smart Mobility

The development of a sharing economy is reshaping a

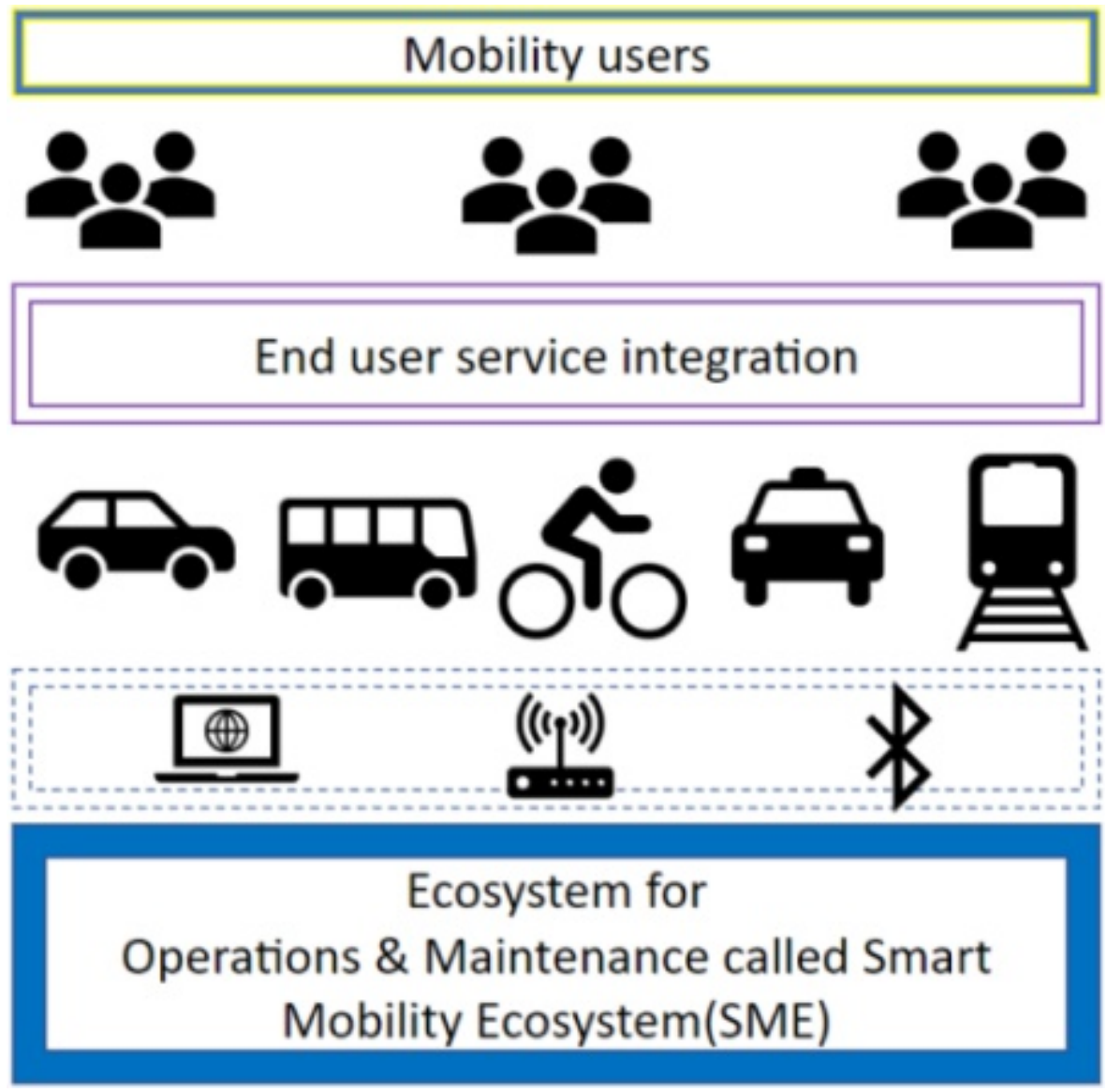

Figure 1. Smart Mobility Ecosystem to operate and maintain the vehicle fleet 


\section{Smart Mobility: Services, Platforms and Ecosystems Jukka Pulkkinen, Jari Jussila, Atte Partanen, Igor Trotskii, Aki Laiho}

large number of economic sectors, simultaneously offering new business opportunities and potentially disrupting traditional sectors (Acquier, Carbone \& Massé, 2019). New business models that utilize a sharing economy model in the mobility market have gained momentum in many cities (Hamari, Sjöklint \& Ukkonen, 2016; Yin, Qian \& Shen, 2018). One example of a sharing economy model is the so-called MaaS model, in which consumers do not own vehicles, but are provided with transport through a service provider. A bike-sharing system is another example of a sharing economy, and this system has experienced a tremendous boom in many cities (Loidl et al., 2019). Additional mobility solutions are expected to penetrate into markets. Already, the first shared electric scooters are in commercial use and drones have been piloted for package transport in Finland. Consequently, we can state that the market for different mobility solutions using a sharing economy model is growing rapidly.

Naturally, this opens up new business opportunities. One such opportunity is vehicle fleet operation and maintenance, since companies providing transport services do not always have the capability to operate and maintain their vehicle fleet effectively. The core competence for the transport service providers is different from that required for the technical operation and maintenance of the fleet. Consequently, there are companies focusing on this new niche market, providing vehicle fleet operation and maintenance. In the literature, there are several studies on managing mobility as part of a sharing economy for mobility users, along with methods of mobility system planning (Docherty et al., 2018; Faber et al., 2018; Ji et al., 2014; Loidl et al., 2019). On the other hand, there is a gap in the literature relating to the successful operation and maintenance of mobility systems. The operation and maintenance of a vehicle fleet fits well into the platform economy model, because there are consumers for the maintenance (vehicles) and providers of the maintenance (maintenance personnel).

\section{Digital Business Ecosystem}

The origin of the term "ecosystem" comes from biology. Tsujimoto et al. (2018) define it as "a biological system composed of all the organisms found in a particular physical environment, interacting with it and each other". Later it was also applied in business, in which a "business ecosystem" is an economic community of individuals and organizations, operating outside of their traditional industry boundaries (Moore, 1993; Senyo et al., 2019). According to Iansiti and Levien (2004), the three critical success factors in a business ecosystem are productivity, robustness and the ability to create niches and opportunities for new firms (Korpela, Kuusiholma, Taipale \& Hallikas, 2013).

Due to the emergence and exploitation of digital technology, new ways of co-creating value in the $\mathrm{BE}$ have been created. This has led to the development of the "digital business ecosystem" (DBE) concept, which combines the two main tiers of digital platforms and BEs, and is defined as a "sociotechnical environment of individuals, organizations and digital technologies with collaborative and comparative relationships, aiming to co-create value through shared digital platforms" (Senyo et al., 2019).

DBEs consist of different individuals and organizations known as actors. Typically, there are different types of actors with different goals for an ecosystem, and their different decision-making and behavioural principles are important for creating a sustainable DBE. This behaviour creates the dynamic of a DBE, which leads to either expansion or shrinkage of the system (Tsujimoto et al., 2018). If one actor has a strategic intention to design the whole ecosystem, then this actor is called the designing actor. The designing actor can manage the ecosystem strategically if the person or organization understands and manages the behaviour of the ecosystem dynamics (Tsujimoto et al., 2018).

The sustainability of restricted DBEs has been the focus of many studies. When the designing actors have tight control over other actors, the leader-follower relationship weakens the sustainability of the ecosystem (Joo \& Shin, 2018). On the other hand, there are different target goals for different actors, such as those relating to shared costs, shared risks, increases in flexibility, etc. (Graça \& Camarinha-Matos, 2017). In a collaborative DBE, where the behaviour and decisionmaking of different actors fits naturally into a common goal, the ecosystem behaviour is coherent, supporting the sustainability and expansion of the system (Tsujimoto et al., 2018). The customers in this ecosystem are also actors and their participation varies according to business characteristics (Joo \& Shin, 2018). The digital platform is used to create and share knowledge in the ecosystem. The interoperability of data and knowledge among all actors is therefore critical for a sustainable DBE (Figay, Ghodous, Khalfallah \& Barhamgi, 2012; Selma et al., 2012; Vernadat, 2009). Finally, we can state that a sustainable and expanding DBE must have a collaboration target as a common output of the whole ecosystem, and the individual behaviour and decision-making of all actors must be aligned with that collaboration target. The designing actor has a leading role in managing the 


\section{Smart Mobility: Services, Platforms and Ecosystems}

Jukka Pulkkinen, Jari Jussila, Atte Partanen, Igor Trotskii, Aki Laiho

dynamics of the ecosystem to ensure that the behaviour of all actors supports a coherent ecosystem.

\section{Service Ecosystem}

S-D logic represents dynamic value co-creation through resource integration and service exchange. This has attracted a great deal of attention from a large number of academics from various disciplines (Vargo \& Lusch, 2017). "Resources" refers to the broad knowledge and skills used to create a benefit. This conceptualization of a service using S-D logic reflects resource integration for the creation of value through a network with a common purpose, rather than only connections of resources, people or product flows. This approach shifts the focus from the firm-centric production of outputs, to activities and processes in which different actors' resources are integrated to reach their common collaboration target (KetonenOksi \& Valkokari, 2019; Wieland, Hartmann \& Vargo, 2017).

The development of ICT enables new models for cooperation in the design, production, delivery and consumption of services (Anttiroiko, Valkama \& Bailey, 2014). Organizations are increasingly digitally connected to each other, leading to the construction of digital ecosystems that form the basis for new service ecosystems and BEs (Nachira, Dini \& Nicolai, 2007).
One area of smart services concerns mediating the roles between providers and end customers of a service ecosystem. Digitally connected resources and organizations boost this development (Alt, Demirkan, Ehmke, Moen \& Winter, 2019).

The conceptual exploration of service ecosystems has just begun, and evidence-gathering and real applications are needed to deepen the understanding of these ecosystems in different circumstances (Vargo \& Lusch, 2017).

\section{Methodology}

This research aims to develop new services by creating artefacts as a solution to an unsolved business problem. As well, it uses the developed new services as the use case in a coherent ecosystem, to define the guidelines needed to create a sustainable and growing ecosystem. The research strategy was thus, quite naturally, to use design science, in which interests are critical and emancipatory, with a practical orientation. Design science seeks to extend the boundaries of human and social capabilities, i.e., knowledge and skills, by creating new and innovative artefacts (Hevner, Chatterjee, Park \& Ram, 2004). The most important criteria for wellconducted design science research include the requirements that an artefact is created to address a

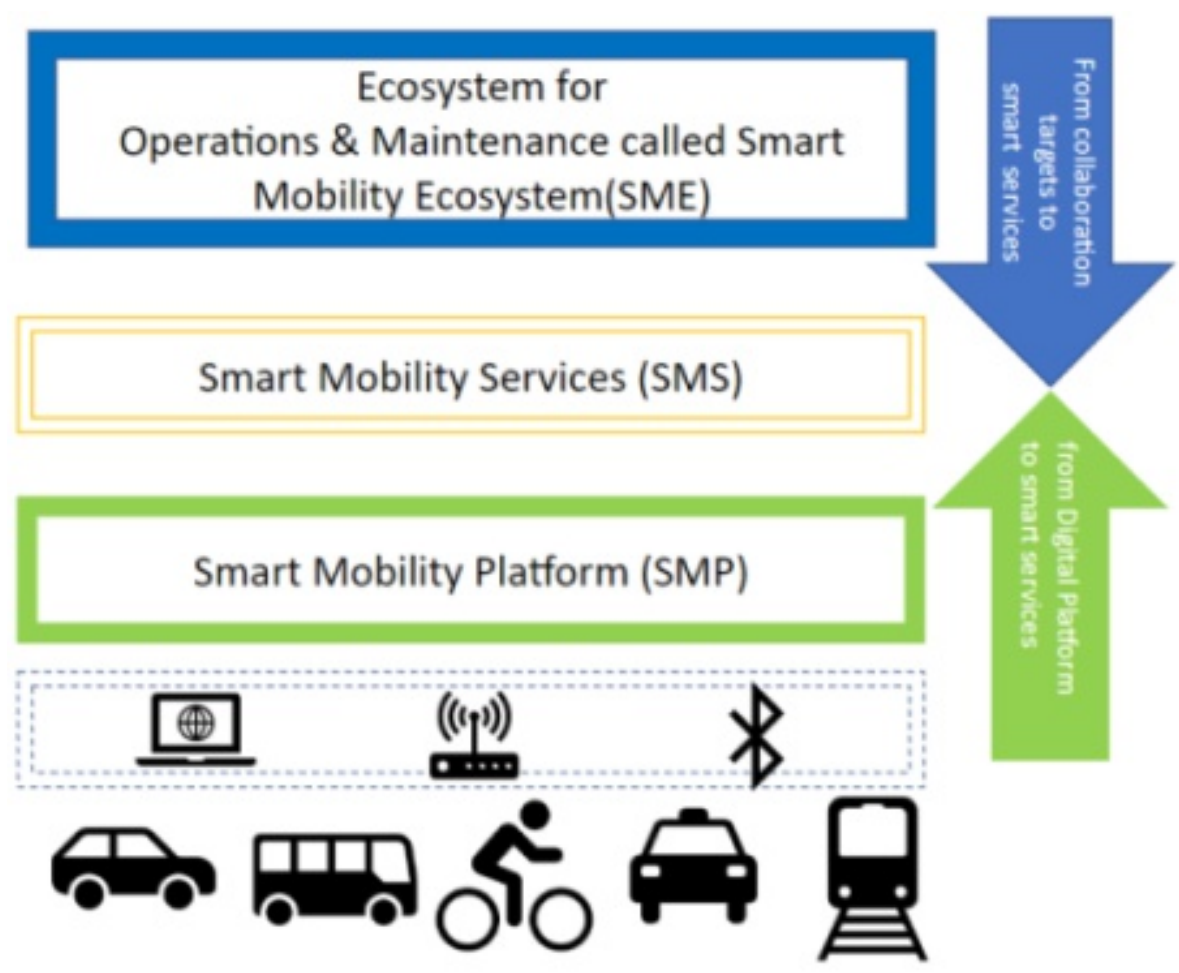

Figure 2. The Artifacts: Smart Mobility Ecosystem, Smart Mobility Services and Smart Mobility Platform 


\section{Smart Mobility: Services, Platforms and Ecosystems}

\section{Jukka Pulkkinen, Jari Jussila, Atte Partanen, Igor Trotskii, Aki Laiho}

problem, should be relevant to the solution of an unsolved and important business problem, and that research should present a verifiable contribution, with rigour applied both in the development and evaluation of the artefact (Peffers, Tuunanen, Rothenberger \& Chatterjee, 2007).

The relevance and importance of the business problem is opportune, as smart mobility is currently booming in Finland. Bike-sharing systems are already in use in the capital region (Helsinki), and in the cities of Turku and Kuopio. A new, full-scale system is coming to the city of Oulu. A bike-sharing pilot scheme for research purposes is starting in the city of Hämeenlinna (Ruohomaa \& Salminen, 2019). Additionally, an electric scooter-sharing system is already in use in Helsinki. On the other hand, all sharing systems require certain infrastructure, such as stations and ticket machines, to run the overall system. All of the vehicles and the infrastructure must be maintained, creating a growing market for the operation and maintenance of these systems.
In order to determine the answer to the research question, a more detailed objective was defined. This was done in collaboration with commercial actors operating and maintaining a vehicle fleet of more than 2,000 vehicles and other infrastructure equipment in 19 cities. The objective was to find a new way of providing services that is more efficient, easy to expand, fulfils defined quality requirements, and utilizes knowledge created by a digital platform. A data strategy framework (Pulkkinen et al., 2019) was rigorously utilized to develop a new way of providing services. The development of new services resulted in three new artefacts: a Smart Mobility Ecosystem (SME), a Smart Mobility Platform (SMP) and Smart Mobility Services (SMS) as described in Fig. 2. SMP functionalities were subjected to technical testing and a few iterations were made to develop the final functionalities. This process resulted in the structure of the SMP presented in Fig. 3, and in general requirements for the SMP. Following a design science methodology (Peffers et al., 2007), we also present a more general theoretical framework for smart services in a DBE environment.
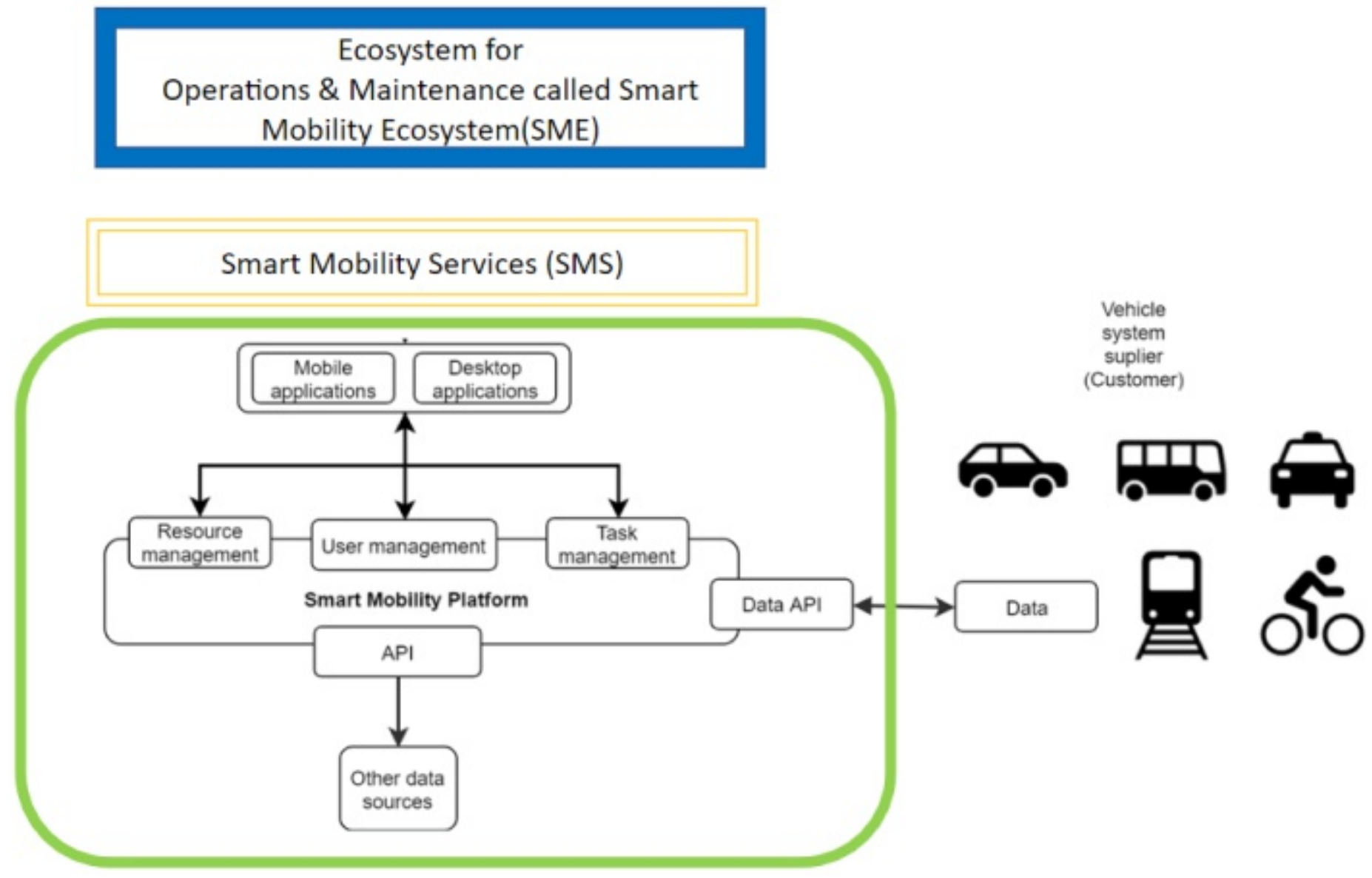

Figure 3. Smart Services needs to reach the collaboration targets by utilizing the knowledge created from data 


\section{Smart Mobility: Services, Platforms and Ecosystems \\ Jukka Pulkkinen, Jari Jussila, Atte Partanen, Igor Trotskii, Aki Laiho}

\section{Evaluation}

The evaluation was performed to ensure that the developed artefacts fulfil the defined objective, which was to develop a new way of providing services that is more efficient, easy to expand and fulfils defined quality requirements. In practice, the evaluation was performed in workshops, where researchers and personnel from a commercial company verified the services. Personnel from the company have extensive experience in providing operation and maintenance services for different types of vehicle systems. A new method of providing services utilizing the SMP was also tested by researchers and maintenance personnel, using the idea of a "proof of concept" in the field. Additionally, the roadmap to create the SME was rigorously discussed and analysed by the senior management of the commercial actors.

\section{Results}

The development of new services that fulfil the defined objective above, resulted in three new artefacts: the SME, SMP and SMS. The next objective was to find a new, more efficient and easy way to expand provision of services that fulfil the defined quality requirements, and which utilize knowledge created by the SMP.

\section{Smart Mobility Ecosystem}

A sustainable and expanding SME requires a leading company, which is the designing actor in a bounded or restricted ecosystem. The designing actor needs to create a coherent ecosystem in which the behaviour of all actors is aligned with their collaboration target. In this case, the designing actor is a commercial actor operating and maintaining the vehicle fleet. Other actors include the customer, the local maintenance providers, the vehicle system suppliers, and the consumers.

For the creation of a coherent SME by the designing actor, the following design criteria must be fulfilled by each actor.

The customer is typically the city owning the vehicle system. The customer defines the service scope and quality requirements in the service level agreement (SLA), and selects an operation and maintenance provider through competitive bidding. Accordingly, the customer's requirement with regard to the collaboration target is for services which fulfil the SLA requirements at the lowest price.
The designing actor must have the capability to operate and maintain a heterogeneous vehicle fleet over a geographically large area. The service scope and quality requirements are defined in the SLA separately by each customer and will vary, which increases the complexity. The collaboration targets services that fulfil the SLA requirements, at a cost level that represents the lowest price in competitive bidding, repeatedly, in order to gain a significant market share.

The local maintenance providers typically have first priority to directly service their customer, who will typically be in the same city. They may have some advantages such as local knowledge and relationships, but their capability to scale up operations to new types of vehicle, and especially to expand to new locations is limited. This makes their chances of growing to become a major player relatively small. Should they lose the contract to the designing actor, they may become a subcontractor to the designing actor and in this way, they become a member of the ecosystem and therefore the SMP is available to support their local operation. The basis of a coherent SME is a service operation that is effective enough to be competitive with regard to cost while simultaneously fulfilling the SLA's scope and quality requirements, with the help of the SMP. This defines the high technical requirements for an SMP and is a mandatory requirement for creating a coherent SME. If the SLA requirement is not fulfilled via costcompetitive service operation in the SME with the help of the SMP, the local maintenance provider has a good chance of making a contract directly with the customer, without the SME. The local maintenance provider's collaboration target is to provide local services as defined in the SLA by utilizing knowledge created by the SMP.

The vehicle system supplier must ensure the integration of the vehicle system and the SMP. It is important to have all the required data in the SMP, in order to manage the service operation and maintenance, as defined above. The vehicle system supplier's collaboration target is to provide an application program interface (API), that includes all of the data needed to optimize the operation and maintenance available to be connected to the SMP.

The consumers use the vehicle system and the quality of the system represents their expectations with regard to the collaboration targets. Vehicle systems that do not fulfil their quality requirements will have a low usage level, and ultimately, the SME will decline. In practice, this means that all vehicles must be in good condition to 


\section{Smart Mobility: Services, Platforms and Ecosystems \\ Jukka Pulkkinen, Jari Jussila, Atte Partanen, Igor Trotskii, Aki Laiho}

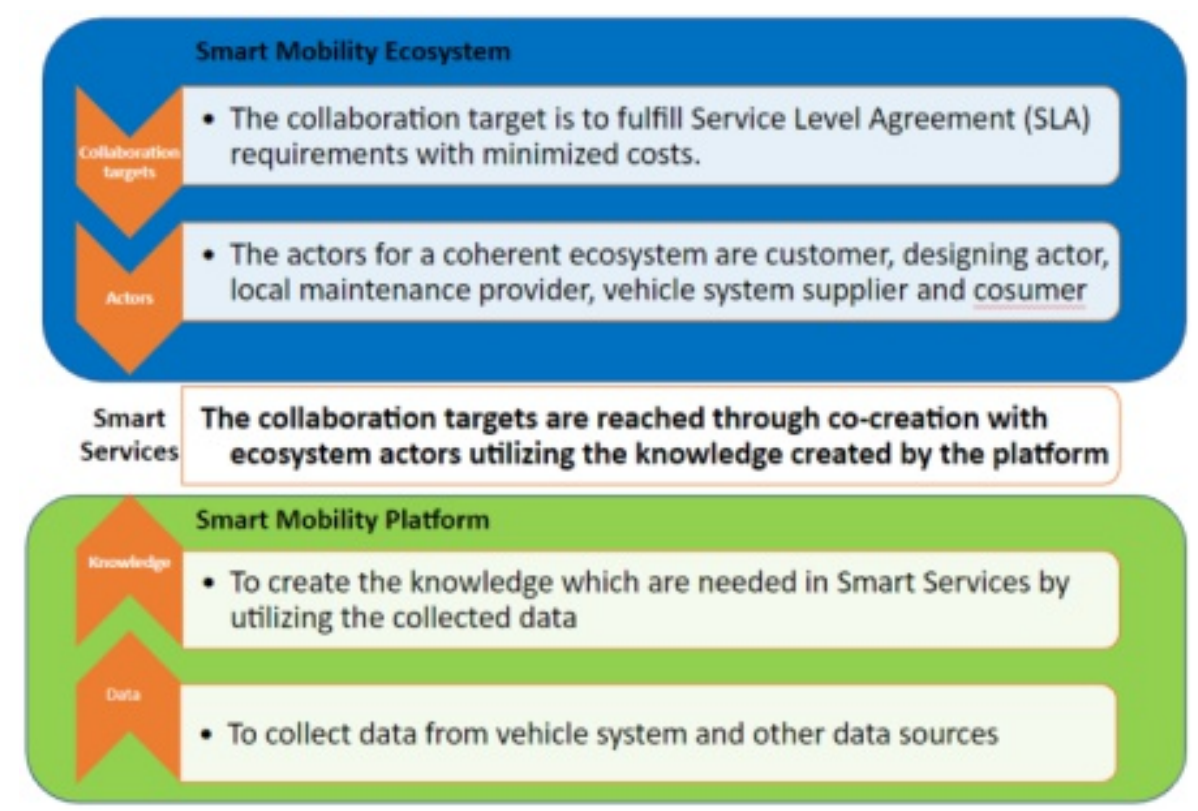

Figure 4. Smart Services needs to reach the collaboration targets by utilizing the knowledge created from data

drive, available when needed by consumers, and that there must be a place to easily leave vehicles after usage. Accordingly, the consumers' quality requirements need to be included in sufficient detail in the SLA requirements, which is the basis of the collaboration target for the SME.

\section{Smart Mobility Platform}

The SMP must provide a common application for the operation and maintenance of the vehicle fleet, as shown in Fig. 3. It defines the interactions of various actors within the SME and provides common interfaces for interacting in a well-defined way with the platform. The SMP must be capable of extending its functionality, as well as being easily integrated with other applications.

Based on the SMP's characteristics and functionality, general requirements were formulated. The provided requirements do not cover all the possible scenarios or required features, but they provide a solid guideline to follow, which considerably improves the probability of creating a coherent SME. On the other side, it also simplifies the design and life-cycle management of the systems.

1. The SMP must be highly modular. This means that different parts of the platform must be completely independent of each other. For example, the user interface for maintenance personnel must be independent of the platform's core logic. This requirement guarantees the ease of deployment and integration of the system, and increases its adaptability.

2. The SMP must provide well-documented and consistent APIs, both for integrating different internal modules into a single application and for connecting to external services. This requirement is essentially an extension of the first requirement.

3. The SMP must provide methods for automatic task generation, management and assignment to proper maintenance teams, based on the current state of the vehicle fleet. This requirement drastically increases the efficiency of operation and maintenance, and helps to ensure that the provided services fulfil the SLA requirements. This relies heavily on data collected from the vehicles and requirements defined by the SLA.

4. The SMP must provide all relevant information about maintenance tasks and the state of the vehicle fleet, and should be utilized for reporting.

5. The SMP must provide dedicated user interfaces for different actors.

6. The SMP must define and provide a common interface for easy extension of the platform to cover new types of vehicles.

\section{Smart Mobility Services}

The anchoring point in answering our research question: "What is the best way to build and manage a sustainable and expanding ecosystem for the vehicle fleet operation and maintenance?", relates to the SMS 


\section{Smart Mobility: Services, Platforms and Ecosystems Jukka Pulkkinen, Jari Jussila, Atte Partanen, Igor Trotskii, Aki Laiho}

that glue the ecosystem and platform together, and create the ecosystem outcome. SMS have built a new method of providing services for vehicle fleet operation and maintenance that is needed to fulfil the defined targets of greater efficiency and easier expansion meet the quality requirements, and utilize the knowledge created by the SMP.

In this new way of providing services, the actors' resources are applied so that the ecosystem is successful, expanding, and sustainable in the long run. This is called a coherent ecosystem. In practice, it means that the smart services outcome fulfils the collaboration targets by utilizing the unique knowledge created by the platform, as described in Fig. 4 . Accordingly, smart services can be defined so that the collaboration targets are reached through co-creation with ecosystem actors utilizing the knowledge created by the platform.

\section{Discussion}

The smart mobility market is a typical example of a relatively young industry which is growing fast. This means that there are relatively young companies in the industry, and tjat many are still in the start-up phase, waiting to penetrate the market. The leading vehicle system suppliers are not focusing on service business, but are instead giving full attention to the delivery of their smart mobility systems as a response to the growing demand. The service market is still very young and there is not yet any dominant player in the global market.

Based on our research, the biggest challenge in the creation of an SME is the integration of different vehicles on the SMP. This means that the vehicle system suppliers do not have API interfaces with all of the necessary data for vehicle operation and maintenance. In fact, they often have API interfaces, but these interfaces support only the connection of consumers to the system. Without an SMP that can connect and integrate data from different vehicle system suppliers, it will remain difficult to develop a robust (Iansiti \& Levien, 2004) and sustainable (Figay et al., 2012) SME.

The further development of this industry will be interesting. The importance of effective operation and maintenance will grow when the industry becomes more mature and undoubtedly, the vehicle system suppliers' interests in new services will increase in the future, as has been the case in many other industries. Obviously, the player who creates the first SMP and coherent ecosystem on top of the platform, will come to occupy the dominant position in this fast-growing service market. A real roadmap to building a SME is still missing, because the vehicle system suppliers' data is mandatory, and their interest in opening this type of interface is not yet in place. How this will be solved is not yet clear, but it is likely that cities, just like customers, could have some role to play, by requiring these interfaces early in the bidding phase of new smart mobility systems. In this way, the vehicle system suppliers would need to open their interfaces to the community of users.

Smart services as defined in this paper represent a dynamic, continuing narrative of value co-creation through resource integration and service exchange. Accordingly, this paper provides one use case using S-D logic in a real world scenario. Our research has presented concrete guidelines to create a coherent ecosystem in one specific industry and identified practical problems that need to be solved in order to obtain a major benefit from the ecosystem.

\section{Conclusion}

A new approach to services was presented with regard to the operation and maintenance of a heterogeneous and expanding vehicle fleet, in the new booming smart mobility market. The new method of providing services consists of an SME and an SMP, connected through SMS to co-create value for ecosystem customers.

A coherent SME, where the decision-making and behaviour of all actors supports the common collaboration targets is sustainable and can expand. The ecosystem is restricted and one actor in particular has a strategic intention to ensure its development; the commercial actor operating and maintaining the whole vehicle fleet. Other actors in the ecosystem comprise the local maintenance providers, vehicle system suppliers, customers, and consumers. In this article, the requirements were presented from each actor's point of view in order to create a coherent, sustainable and expanding ecosystem in the smart mobility environment. Empirical evidence from one case was presented regarding how designing actors can manage knowledge creation and sustainability of the ecosystem. Another result was the identification of technical requirements for the SMP as a basis for the sustainable and expanding ecosystem, thus ensuring a coherent ecosystem from the platform perspective.

Technical integration of different types of vehicles 


\section{Smart Mobility: Services, Platforms and Ecosystems}

Jukka Pulkkinen, Jari Jussila, Atte Partanen, Igor Trotskii, Aki Laiho

within a SMP is first needed to build a coherent ecosystem. Currently, vehicle system suppliers are not yet ready to open the required interfaces. Therefore further development is required to enable the full benefit from the above defined smart services to be obtained. On the other hand, the smart mobility market is currently developing at a rapid pace, and it will be interesting to discover who will succeed in creating a new ecosystem first and how this will be achieved.

\section{References}

Acquier, A., Carbone, V. \& Massé, D. 2019. How to Create Value (s) in the Sharing Economy: Business Models, Scalability, and Sustainability. Technology Innovation Management Review, 9(2). https://timreview.ca/article/1215.

Alt, R., Demirkan, H., Ehmke, J. F., Moen, A. \& Winter, A. 2019. Smart services: The move to customer orientation. Electronic Markets, 29(1): 1-6.

Anttiroiko, A.-V., Valkama, P. \& Bailey, S. J. 2014. Smart cities in the new service economy: building platforms for smart services. AI \& SOCIETY, 29(3): 323-334.

Docherty, I., Marsden, G. \& Anable, J. 2018. The governance of smart mobility. Transportation Research Part A: Policy and Practice, 115: 114-125.

Faber, A., Rehm, S. V., Hernandez-Mendez, A. \& Matthes, F. 2018. Modeling and visualizing smart city mobility business ecosystems: Insights from a case study. Information (Switzerland), 9(11).

https://doi.org/10.3390/info9110270.

Figay, N., Ghodous, P., Khalfallah, M. \& Barhamgi, M. 2012. Interoperability framework for dynamic manufacturing networks. Computers in Industry, 63(8): 749-755.

Graç, P. \& Camarinha-Matos, L. M. 2017. Performance indicators for collaborative business ecosystems Literature review and trends. Technological Forecasting and Social Change, 116: 237-255.

Hamari, J., Sjöklint, M. \& Ukkonen, A. 2016. The sharing economy: Why people participate in collaborative consumption. Journal of the Association for Information Science and Technology, 67(9): 2047-2059.

Hevner, A., Chatterjee, S., Park, J. \& Ram, S. 2004. Design Science Research in Information Systems. MIS Quarterly, 28(1): 75-105.

Iansiti, M. \& Levien, R. 2004. The keystone advantage: what the new dynamics of business ecosystems mean for strategy, innovation, and sustainability. Harvard Business School Press.

Jacobides, M. G., Cennamo, C. \& Gawer, A. 2018. Towards a theory of ecosystems. Strategic Management Journal, 39(8): 2255-2276.

Järvi, K. \& Kortelainen, S. 2017. Taking stock of empirical research on business ecosystems: a literature review. International Journal of Business and Systems Research, 11(3): 215-228.

Ji, S., Cherry, C. R., Han, L. D. \& Jordan, D. A. 2014. Electric bike sharing: Simulation of user demand and system availability. Journal of Cleaner Production, 85: 250-257.

Joo, J. \& Shin, M. M. 2018. Building sustainable business ecosystems through customer participation: A lesson from South Korean cases. Asia Pacific Management Review, 23(1): 1-11.

Ketonen-Oksi, S. \& Valkokari, K. 2019. Innovation Ecosystems as Structures for Value Co-Creation. Technology Innovation Management Review, 9(2). https://timreview.ca/article/1216.

Korpela, K., Kuusiholma, U., Taipale, O. \& Hallikas, J. 2013. A framework for exploring digital business ecosystems. 46th Hawaii International Conference on System Sciences, 3838-3847. IEEE.

Loidl, M., Witzmann-Müller, U. \& Zagel, B. 2019. A spatial framework for planning station-based bike sharing systems. European Transport Research Review, 11(1).

https://doi.org/10.1186/s12544-019-0347-7.

Lusch, R. F., Vargo, S. L. \& Fisher, R. 2014. Drawing on service-dominant logic to expand the frontier of physical distribution and logistics management. International Journal of Physical Distribution \& Logistics Management, 44(1/2): IJPDLM-07-20130209.

Moore, J. 1993. Predators and prey: a new ecology of competition. Harvard Business Review, 71(3): 75-86.

Nachira, F., Dini, P. \& Nicolai, A. 2007. A network of digital business ecosystems for Europe: roots, processes and perspectives. Introductory Paper. Bruxelles.

http://www.digitalecosystems.org/book/pdf/0.3.pdf.

Peffers, K., Tuunanen, T., Rothenberger, M. A. \& Chatterjee, S. 2007. A Design Science Research Methodology for Information Systems Research. Journal of Management Information Systems, 24(3): $45-77$.

Pulkkinen, J., Jussila, J., Partanen, A. \& Trotskii, I. 2019. Data strategy framework in servitization: Case study of service development for a vehicle fleet. Springer Proceedings in Complexity.

Ruohomaa, H. J. \& Salminen, V. K. 2019. Mobility as a service in smart cities - new concept for smart mobility in Industry 4.0 framework. ISPIM Ottawa Connects, Conference Proceedings, (April): 1-12.

Selma, K., Ilyès, B., Ladjel, B., Eric, S., Stéphane, J. et al. 2012. Ontology-based structured web data warehouses for sustainable interoperability: Requirement modeling, design methodology and tool. Computers in Industry, 63(8): 799-812.

Senyo, P. K., Liu, K. \& Effah, J. 2019. Digital business ecosystem: Literature review and a framework for future research. International Journal of Information 


\section{Smart Mobility: Services, Platforms and Ecosystems}

\section{Jukka Pulkkinen, Jari Jussila, Atte Partanen, Igor Trotskii, Aki Laiho}

Management, 47(June 2018): 52-64.

Tsujimoto, M., Kajikawa, Y., Tomita, J. \& Matsumoto, Y. 2018. A review of the ecosystem concept - Towards coherent ecosystem design. Technological Forecasting and Social Change, 136(June 2017): 49-58.

Vargo, S. L. \& Lusch, R. F. 2017. Service-dominant logic 2025. International Journal of Research in Marketing, 34(1): 46-67.

Vernadat, F. B. 2009. Technical, semantic and organizational issues of enterprise interoperability and networking. IFAC Proceedings Volumes (IFACPapersOnline), 13(PART 1): 728-733.

Wieland, H., Hartmann, N. N. \& Vargo, S. L. 2017. Business models as service strategy. Journal of the Academy of Marketing Science, 45(6): 925-943.

Yin, J., Qian, L. \& Shen, J. 2018. From value co-creation to value co-destruction? The case of dockless bike sharing in China. Transportation Research Part D: Transport and Environment.

https://doi.org/10.1016/j.trd.2018.12.004.
Citation: Pulkkinen, J., Jussila, J., Partanen, A., Trotskii,

I., Laiho, A. 2019. Smart Mobility: Services, Platforms

and Ecosystems. Technology Innovation Management

Review, 9(9): 15-24.

http://doi.org/10.22215/timreview/1265

(cc) BY

Keywords: Smart Mobility, Smart Services, Digital Business Ecosystems, Digital Platforms.

\section{About the Authors}

Dr. Jukka Pulkkinen holds a PhD degree in control engineering from Helsinki University of Technology. Currently, he acts as a principal research scientist at Häme University of Applied Sciences (HAMK). His research is currently focused on strategic business management, digital servitization and service development, especially in industry and smart city environments. Before his academic career, he had a long career in various leadership positions in a global industrial company, leading the service business, the EMEA sales region and a global business unit.

Dr. Jari Jussila holds a PhD degree in information and knowledge management from Tampere University of Technology (TUT, 2015). Currently he acts as a principal research scientist at Häme University of Applied Sciences (HAMK). His research is currently focused on knowledge management, business intelligence, social media, big social data analytics, and health informatics. His work has been published in international journals such as IEEE Access, Computers in Human Behavior, Industrial Management \& Data Systems, the International Journal of Knowledge Management and Knowledge Management Research \& Practice.

Atte Partanen holds a bachelor's degree in electrical and automation engineering from Häme University of Applied Sciences (HAMK, 2017). He works as a project engineer in many projects focused on the Internet of Things, data management and information systems at Häme University of Applied Sciences (HAMK). His research is currently focused on information and data management systems. His work on information systems and smart cities has been published in journals.

Igor Trotskii graduated from Häme University of Applied Sciences with a degree in electrical and automation engineering. He works as a project engineer with responsibilities in data analysis, and the design and implementation of data-driven applications.

Dr. Aki Laiho holds a PhD degree from the Faculty of Industrial Engineering of Aalto University. $\mathrm{He}$ is a partner at Rolan Oy, which operates and maintains a shared-mobility vehicle fleet. 


\title{
Open Data and Open Source Enabling Smart City Development: A Case Study in Häme Region Jari Jussila, Joni Kukkamäki, Mikko Mäntyneva, Juuso Heinisuo
}

\author{
"In God we trust, all others bring data."
}

W. Edwards Deming

Father of quality management

\begin{abstract}
Open data offers possibilities to accelerate both innovations and co-creation activities in cities and regions. Likewise, open source software development is an efficient way to create new services. Open data can be used to promote better information sharing and offers various opportunities for third-party developers. Co-creation improves the commitment of different stakeholders and ensures that the created solutions are based on real needs. For these reasons, it is only logical that these two themes are linked together in smart city activities. This paper presents a practical open data and co-creation development made in the region of Häme, Finland.
\end{abstract}

This paper contributes to smart cities research by describing the development of two smart city services: the Tavastia Events API and "Hämeenlinna in pocket" smartphone application. It describes strategies that facilitate beneficial participation and collaboration in smart city open data initiatives. Based on Linked Events, an open source solution developed for the city of Helsinki, modification and implementation were made to create a centralized and open service, to collect and publish event-related data via an application programming interface (API) in the Häme region. A smartphone application was then developed, making use of the developed Events API and other data sources, to provide citizens with the most common digital services, and a platform for digital participation in Häme.

\section{Introduction}

The role of the city is expanding from being a producer and buyer of services to being an innovator of services (Ojasalo \& Kauppinen, 2018) and creator of ecosystems (Cotton, 2018). Digitalization and increasing demand for digital services are not only changing the way the citizens use public services (Jussila, Lehtonen, Sillanpää, Helander, \& Kallio, 2016), but also how value is co-created between public organizations, companies, citizens, and other value network partners. Public organizations are among the largest creators and collectors of data that is valuable to citizens, organizations, and businesses for participation, decision making, and creating innovative products and services (Janssen, 2011). Many government agencies, including cities, have established initiatives to make their data available for public consumption (Chan, 2013; McDermott, 2010) also called open data initiatives. Open data refers to data "that is technically and legally made available for reuse and republication
(Lindman \& Rossi, 2013). However, it is important to recognize that while open data initiatives function as an enabler for citizen and company participation and collaboration, there is no assurance that such initiatives actually result in any purposeful or beneficial participation and collaboration (Chan, 2013).

In parallel with open data initiatives, open source is also gaining traction with governments. Open source refers to software development that results in open source code. According to an internationally recognized Open Source Definition (https://opensource.org/definition), only software licensed and distributed that meets the ten criteria introduced in the definition should be labeled open source software (Lindman \& Nyman, 2014; Nelson, 2007). Open source has the potential to scale up by incorporating the work of many (Garzarelli, Limam, \& Thomassen, 2008), and provides cities, for example, with opportunities to learn and make use of solutions developed in other cities. Not only can a city save costs 


\section{Open Data and Open Source Enabling Smart City Development Jari Jussila, Joni Kukkamäki, Mikko Mäntyneva, Juuso Heinisuo}

by reusing and modifying existing solutions, but it can also gain additional development resources when multiple cities participate and collaborate in software development. Open source provides the opportunity to create smart city platforms, following the Triple Helix (Etzkowitz, 2003) model of an institutional triangle of government, business, and academia, as well as adding citizens and users to the mix, thereby forming a socalled Quadruple Helix model (Carayannis \& Campbell, 2010).

The development of smart city platforms suggests that, increasingly, new services may be offered to citizens and that their delivery will be more efficient in terms of time, cost, and the number of citizens reached (Visvizi \& Lytras, 2018). Citizens should not, however, be considered merely as users, but also as stakeholders having an active role as participants, collaborators, and developers in the city's activities (Kunttu, 2019).

The concept of a smart city has received considerable academic interest. Dameri (2013) attempted to create a comprehensive definition of the smart city and concluded that "a smart city is a well-defined geographical area, in which high technologies such as ICT, logistics, energy production, and so on, cooperate to create benefits for citizens in terms of well-being, inclusion and participation, environmental quality, and intelligent development; it is governed by a well-defined pool of subjects, able to state the rules and policy for the city government and development". Anthopoulos and Fitsilis (2014) define a smart city as an ICT-based infrastructure and services environment that enhance a city's intelligence, quality of life, and other attributes (i.e., environment, entrepreneurship, education, culture, transportation etc.) One interesting addition to the concept of the smart city is the concept of smart community. Giffinger and Gudrun (2010) define 'smart community' in the following way: "A smart community is a community that has made a conscious effort to use information technology to transform life and work within its region in significant and fundamental rather than incremental ways." The concept of the smart community could better serve the focus of this particular paper, since the main emphasis is on regional development, extending beyond the formal city limits. Chourabi et al. (2012) state that the success of smart city initiatives relies heavily on managerial factors. More and more cities are taking a strategic approach to become smart. However, most of them face the challenge of figuring out the overall entity of becoming smart, how to connect smaller projects with each other, and to steer the progress from end to end.
The research question to frame the case study is: "What strategies can foster beneficial participation and collaboration in smart city open data initiatives?" This study centers around two smart city services: the Tavastia Events smart city service, which provides cities, citizens, organizations, and other users with the opportunity to showcase events and make use of open data generated on the platform, and 'Hämeenlinna in pocket' ('Hämeenlinna taskussa') - a smartphone application that provides citizens with smart services and a platform for digital participation in Häme. Our aim is to describe strategies that can lead to successful smart city open data implementations. We first introduce co-creation and innovation with open data. We then present a case study of two smart city services developed in Häme, and finally discuss and summarize the lessons learned and the managerial implications of the development and implementation of smart city services.

\section{Co-creation and Innovation}

Innovation is related to interactive and dynamic cocreation processes with end users, customers, and other potential value network parties (Lusch \& Nambisan, 2015). It is seldom a straightforward activity. It can be characterized as uncertain, co-constructive, experimental, and interactive (Edvardsson, Tronvoll, \& Gruber, 2011; Vargo, Wieland, \& Akaka, 2015). Vargo and Lusch (2014) argue that the customer is always a cocreator of value. While attempting to study value cocreation in more detail, the opportunities of applying ICT and data to substantially transform service systems should be taken into account (Edvardsson et al., 2011; Rai \& Sambamurthy, 2006). Smart cities provide an environment for user-driven and open innovation (Schaffers et al., 2011), however, co-creation does not emerge itself, but requires active effort from smart city governments (Eden Strategy Institute, 2018). A report investigating a Top 50 list of smart city governments in the world emphasizes that citizens have shown great enthusiasm whey they are given the opportunity to participate in designing and deciding their cities' future (Eden Strategy Institute, 2018).

\section{Creating and Innovating Services with Open Data}

Ojo et al. (2015) have studied how open data and smart cities converge. They covered various attempts to cocreate digital public services by third parties in their coverage of 18 open data initiatives across five smart cities. Four of the smart cities selected for study were from Europe, namely, Barcelona, Manchester, Amsterdam, and Helsinki. Chicago was chosen to represent the other continents. Conradie et al. (2012) 


\section{Open Data and Open Source Enabling Smart City Development Jari Jussila, Joni Kukkamäki, Mikko Mäntyneva, Juuso Heinisuo}

argue that, when releasing public sector information through co-creation in the city of Rotterdam, there seemed to be promising collaboration through the cocreation approach. They see the use of co-creation as a platform with the intention to leverage the potential of released public sector information. Relevant partners can create a sustainable infrastructure on this platform to co-create public services. A more open approach to innovation, and real collaboration with stakeholders like end users and external partners make it possible for them to participate in innovation activities. Chesbrough (2003) and West \& Lu (2009) argue that a co-creation methodology can be applied to promote stronger interaction with citizens. Also, it can be applied in the design of public services (Hartman et al., 2010).

Lindman et al. (2013) suggest that open data promises an increased availability of data for service development. However, the related research is still emerging, and there are several interesting paths to pursue. Zuiderwijk et al. (2014) identify four essential elements that an open data ecosystem should capture: 1) releasing and publishing open data on the Internet, 2) searching, finding, evaluating, and viewing data and their related licenses, 3) cleansing, analyzing, enriching, combining, linking, and visualizing data, and 4) interpreting and discussing data, and providing feedback to the data provider and other stakeholders.

Ojo et al. (2015) suggest that open data sets supporting tourism are characterized among others by co-created services based on available open data, better information sharing, and open innovation for co-created services. Lindman et al. (2013) propose that open data can be bundled and repackaged as information services that can be provided to customers, citizens, and other stakeholders. Ojo et al. (2015) point out that there are initiatives like "Apps for Amsterdam" and "Helsinki Loves Developers", which aim to enable the co-creation of services addressing the needs of citizens and businesses. These co-created services are based on the availability of open data built applications. Lindman et al. (2013) propose that applying service APIs (Application Programming Interfaces) will provide a more stable platform on which to create and develop new services. They consider many available opportunities for linked, or real time, open data to be redistributed through service APIs.

\section{Toward the Case Study}

Ojo et al. (2015) mention that the majority of the studied smart city initiatives were related to governance issues.
Among these they list the following: "1) Better information sharing across local authorities through data standards; 2) Improved services across major sectors like transportation and public safety; 3) Enhanced transparency; 4) Co-created services that better address the needs of citizens and businesses; 5) Enabling open innovation in City Administration involving third-party developers; 6) Enhanced interoperation among a network of cities by sharing tools and methods (standardization); 7) Improved capacities of citizens and stakeholders to leverage open data; 8) Open engagement of citizens in policies; and 9) Significant improvement in internal decision-making".

The case study of this paper involves many of these aspects. The most emphasized issues in the case study are improved services, enabling open innovation involving third-party developers, inter-operation among a network of cities by sharing tools and methods, improved capability of stakeholders and citizens to leverage open data, and co-created services that better address the needs of citizens and event organizers. All in all, this implies that open data related co-creation and service innovation initiatives are multifaceted, and can be approached and studied from various perspectives.

\section{Case Study: Developing Häme Region with Open Data and Open Source}

Hämeenlinna is situated in the middle of Southern Finland. Of the five million people living in Finland, over two million have chosen to establish their homes and businesses within radius of 150 kilometers from Hämeenlinna.

Hämeenlinna is a balanced mix of a dense urban environment and a spacious and peaceful countryside, with flourishing rural centres. The most important companies in town are SSAB, Huhtamäki, Patria Vehicles, Konecranes and Kultakeskus. The Hämeenlinna ecosystem program, which started operating in 2019, involves companies, organizations, and citizens. Hämeenlinna has five designated ecosystems: tourism and events, bio-economy, enabling city, renewable industry, and smart services. The ecosystems use information and ICT to improve urban operations, services, and competitiveness. The goal of the ecosystems is to create value for the partners involved via a mutual roadmap. The impact can be shown as environmental, economic, social and communal, or with research and innovation value (Cotton, 2018). Open data assets should be used to provide information supporting analytics and thus drive improved services. Therefore, the creation and usage of 


\section{Open Data and Open Source Enabling Smart City Development Jari Jussila, Joni Kukkamäki, Mikko Mäntyneva, Juuso Heinisuo}

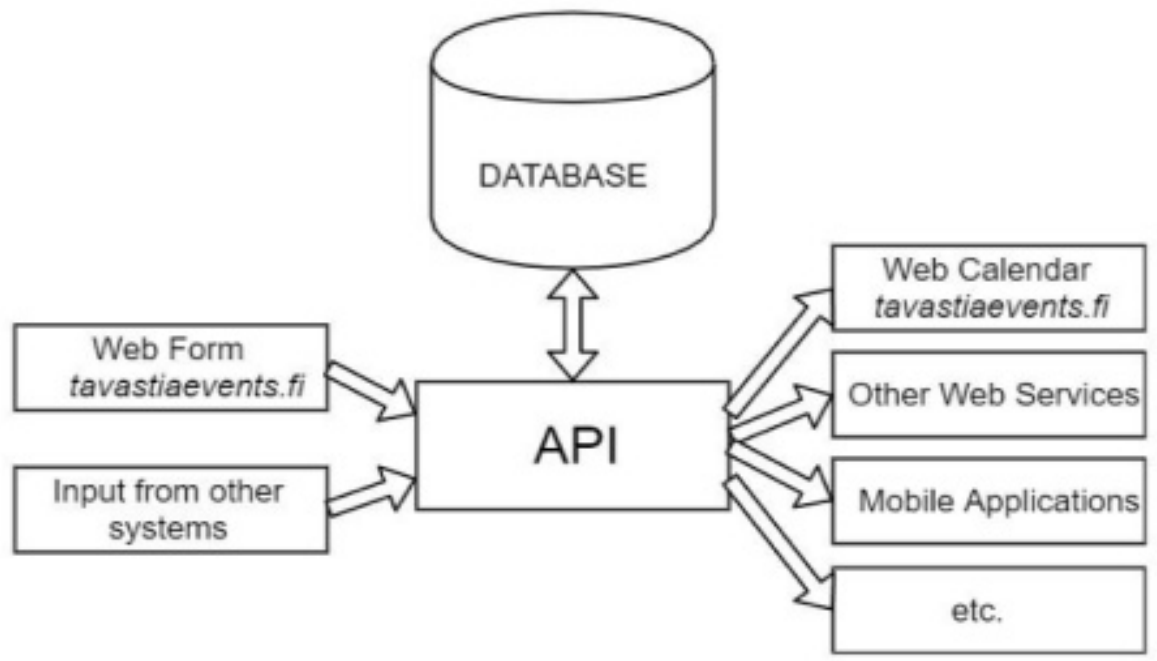

Figure 1. Structure of Tavastia Events API and Web service (Kukkamäki et al., 2019).

open data channels and openness should be included in a city's strategy (Cotton, 2018). The City of Hämeenlinna believes that openness is the key element in every path to future success. This includes for example open data, open meetings, open minds, open innovation, open decision making, open source, etc. This study centers around two projects that support ecosystem development in the Häme region: OpenHäme and Hämeenlinna in pocket.

The OpenHäme (AvoinHäme in Finnish) project was launched in May 2017. The main goal of the project is to develop open data possibilities and capabilities in the Häme region of Finland. In addition, the aim is to increase the amount of open data published in Häme. The project consists of different work packages for creating a collaboration network of different stakeholders, increasing knowledge and skills, and developing pilots to showcase the possibilities of open data. One of the results of the project is the Tavastia Events API.

As early as the application phase of the project, cocreation methods and open participation were used to gather critical information about the expectations of different stakeholders toward the project. Häme Region consists of three sub-regions around three major cities: Hämeenlinna, Riihimäki, and Forssa. In these cities, workshops open to everyone were organized. Especially companies, cities, and societies were invited. In these workshops, all the stakeholders had the opportunity to express all their needs, ideas, and doubts. This information was used when generating the final funding application for the project.

Additionally, in 2017 the City of Hämeenlinna made a strategic decision to provide all the municipal services for citizens in digital form by 2020, requiring rapid progress in practically all areas of smart city development. As part of this strategic goal, the City decided to design and create a smartphone application that provides citizens with the most commonly used digital services and a platform for digital participation. A development project was set up and named "Hämeenlinna in pocket", which was carried out jointly by the City and Häme University of Applied Sciences (HAMK) (Kunttu, 2019). The "Hämeenlinna in pocket" project utilized the development work done in OpenHäme, especially the Tavastia Events API, but also included development of several additional features that were not included in the OpenHäme project.

\section{Tavastia Events API}

Tavastia Events is an Event API created for the needs of the Häme region. The API is based on an open source solution called Linked Events (City of Helsinki, 2019), which was originally developed by the City of Helsinki. The modification and implementation of Linked Events for the needs of the Häme region was one of the activities in the OpenHäme project. The web service was developed from scratch to meet the Häme region's needs. From an early stage, Tavastia Events was recognized as the most important concrete development activity in the project. Different stakeholders pointed out the need for this kind of Event API and identified all the possibilities it would offer. 


\section{Open Data and Open Source Enabling Smart City Development Jari Jussila, Joni Kukkamäki, Mikko Mäntyneva, Juuso Heinisuo}

Tavastia Events consists of two main components, illustrated in Figure 1. The first is an event database and the API (HAMK Smart, 2019) itself, while the second component includes a website (tavastiaevents.fi) to make it easy to input and search for events taking place in the region (Kukkamäki, Jussila, \& Mäntyneva, 2019).

The most crucial elements of Tavastia Events are the database and the open API. This is what separates it from traditional web-based event calendars. The API receives inputs from various systems that send machinereadable messages in structured forms and saves them to the event database. In the same way, anyone can fetch event data programmatically from the database through the API and use the data in different ways: in a calendar, mobile application, or any other means they find suitable. This makes it possible for numerous event organizers and users of event information to automate these input and output processes.

This system brings many benefits. In the traditional model, event organizers have to input their events separately in every calendar where they want to gain visibility. This could amount to dozens of different inputs. If the event information changes or the event is cancelled, modifications need to be done again separately to all these calendars. Tavastia Events API makes it possible to gain visibility in multiple channels with only one input, not only in event calendars, but in other applications too. This is also the case when modifying information. Modification done through the API will pass it to every application in real time. This is the benefit of the Tavastia Event API: it gathers all the event information in one place and disseminates it to all the channels that utilize it.

The second major advantage relates to the multiple different stakeholders who use the event data. Cities can easily collect all the events from its area and display them to the citizens. The media, e.g., newspapers, can see at a glance all the interesting events happening and publish news about them. This publication process could even be automated thanks to the machinereadable API and structured format. Companies can also benefit from this data: hotels can tell their guests what is happening nearby, restaurants can prepare special offers, or taxis may reserve sufficient transport capacity. All the necessary information can be fetched and processed automatically.

The above examples already showcase the final advantage. When data is in a structured format, it is easy to create processes around it and handle all the actions in the same way with every event. The data structure is described in Table 1. This also ensures that any critical information such as location or time is present. Tavastia Events has the capability of inputting basic information in English and this supports the possibility to publicize events to tourists.

The API provides the possibility for automatic input or output from/to different existing systems and applications. However, from the point of view of small event organizers, they do not usually have this kind of existing system, and modifying their system would be too expensive. The web form for the manual input of calendar events was developed for this reason. This is a key element to support the usability and accessibility of this kind of service, which is meant to promote all events in the region regardless of the size of event or organizing party. The Tavastia Events website also allows users to search for all the events that are on the website.

\section{Hämeenlinna in Pocket Smartphone Application}

Development of the "Hämeenlinna in pocket" smartphone application was based on the use of the Open City Application platform, which provided a framework for the application's software development. In the first version of the application (see snapshot of the application in Figure 2), launched in March 2019, the following features were included (Kunttu, 2019):

Events: The application provides the user with a list of general and public events taking place in Hämeenlinna, including all cultural, educational, and sports-related events. The events can be viewed as a chronological list or located on a city map. The mobile application retrieves the event information from an open data based interface that collects all the event information in the Hämeenlinna area (Kukkamäki et al., 2019).

Topical information and news: The application includes a news channel giving the news, announcements, and information provided by the City. Users have an option to select the information they prefer to receive. The mobile platform can also provide targeted information for citizens based on their own neighborhood. This, in turn, enables collaborative activities and participation at the individual level on matters related to decision making and planning in the citizens' own neighborhood.

Public transportation information: The application contains a route planning tool for public transportation. The user submits the target address and receives a suggested easiest route to the target with bus times. The 


\section{Open Data and Open Source Enabling Smart City Development Jari Jussila, Joni Kukkamäki, Mikko Mäntyneva, Juuso Heinisuo}

Table 1. Data Structure of Tavastia Events

\begin{tabular}{|c|c|}
\hline Field ('mandatory) & Value \\
\hline \multicolumn{2}{|l|}{ Event } \\
\hline Event name (fi, en) ${ }^{*}$ & text, 255 characters \\
\hline Short description (fi, en) * & text, 140 characters \\
\hline Long description & text, 2000 characters \\
\hline Event web page (fi, en) & URL \\
\hline Date and time (single / multiple)* & datetime \\
\hline Target audience ${ }^{*}$ & text/keyword id \\
\hline Keywords * & text/keyword id \\
\hline Paid & $\mathrm{y} / \mathrm{n}$ \\
\hline Prices & text, 200 characters \\
\hline Detailed pricing information & text, 200 characters \\
\hline Link to ticket shop & URL \\
\hline Event language $^{*}$ & text/id \\
\hline External links & URLs \\
\hline Event organizer(s) * & text, 200 characters \\
\hline Accessibility & $\mathrm{y} / \mathrm{n}$ \\
\hline Picture & file \\
\hline Owner of picture & text \\
\hline Admin e-mail * & text \\
\hline PIN code ${ }^{*}$ & text, 64 characters \\
\hline \multicolumn{2}{|l|}{ Location } \\
\hline Location name & text, 255 characters \\
\hline Position (lat/lon) * & WGS84 coordinates \\
\hline Street address * & text \\
\hline City ${ }^{*}$ & text \\
\hline Postal code & text \\
\hline Detailed information & text \\
\hline
\end{tabular}

application also reports possible delays or changes in the public transportation system.

Digital library card: The application enables the user to take out a digital library card, which replaces the traditional loan card used in public libraries. The user can install the digital card in the application by logging into the library system through an interface. The user can then use the digital card by showing the barcode from the screen of the mobile phone to the library's user interface (see Figure 2).

My health platform (Oma olo): Through the application interface, the user has access to the digital health portal provided by theCity. The portal provides a variety of instructions for self-diagnosis and care, and also access to consultation with a nurse.
Schedules for free-time sports activities (Liikuntalukkari): The application provides weekly schedules of the free-time after-school sports activities for school-age children organized by the City.

Care-time allocations for nurseries: Through the application interface, parents of small children can book their weekly care-times in nurseries.

Feedback channel: The user can send feedback, questions, or comments to the City authorities through the application. The system classifies the feedback and sends it to the appropriate City authority for further analysis and actions. The user can link the feedback to location information. This is particularly helpful when users report, e.g., faults or problems in their living environment. 


\section{Open Data and Open Source Enabling Smart City Development Jari Jussila, Joni Kukkamäki, Mikko Mäntyneva, Juuso Heinisuo}
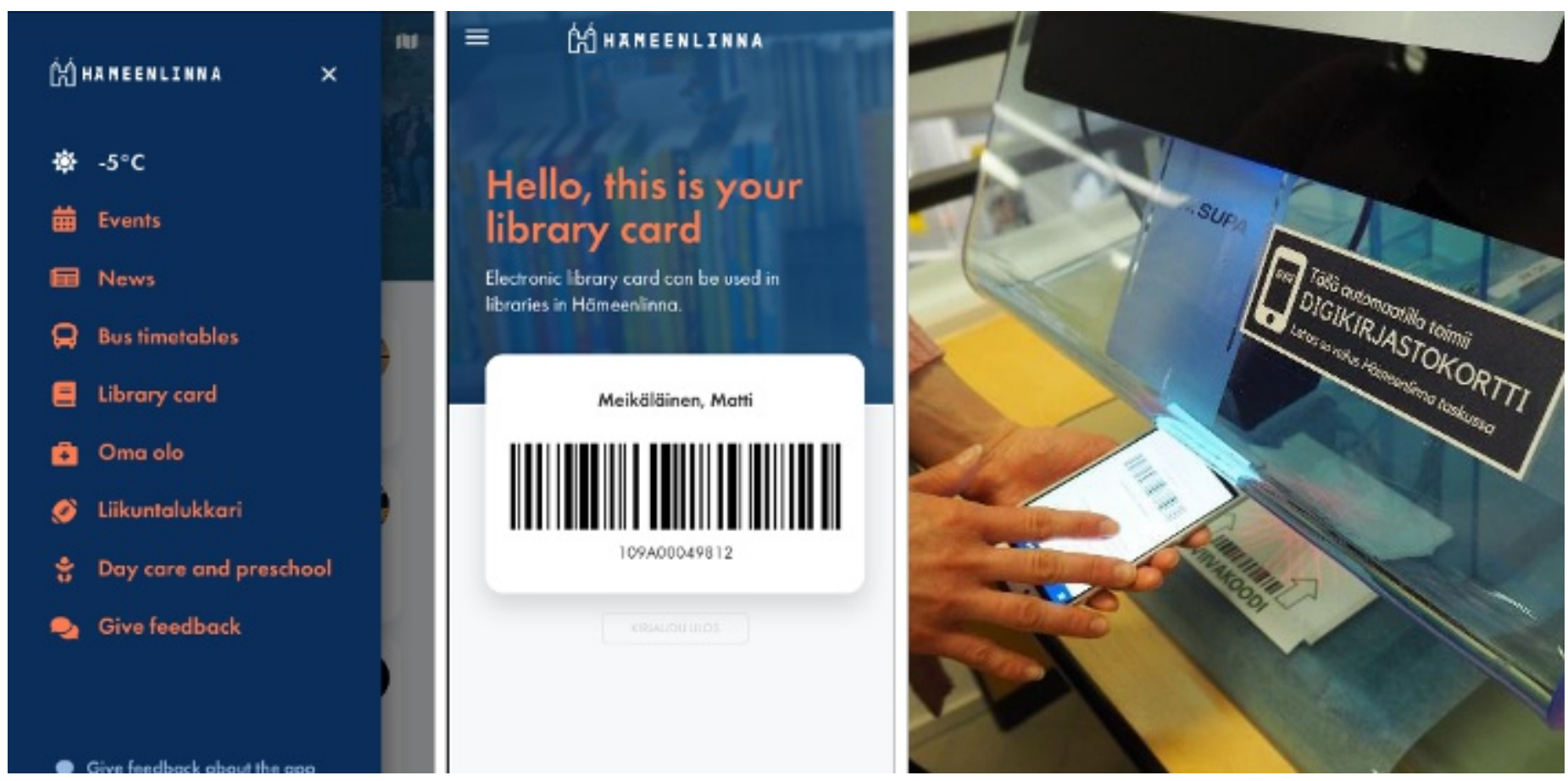

Figure 2. From left to right, the main menu of the mobile application, a snapshot of the digital library card available in the mobile application, and the library card being used on the self-service user interface in the library.

Digital participation tool: The application includes a digital participation tool that allows users to participate in decision making and planning, as part of municipal governance.

\section{Conclusion}

Open data that is shared in an effective and open way offers increased possibilities for different stakeholders to innovate together toward shared goals. This case study focused on open data and open source related to events, transportation, and digital libraries in smart city context. Many of the issues raised by Ojo et al. (2015) can be developed through open data, such as improved services, enabling open innovation involving third-party developers, and inter-operation among a network of cities by sharing tools and methods. In addition, the improved capability of companies and citizens in cocreating services is supported.

Making event information available for everyone enables more efficient promotion of regional events for organizers, programmers, and even for private persons. For example, anyone can develop a mobile application to show all the upcoming events and combine them with other information there, such as public transportation, nearby restaurants, or hotel information based on this data. It is obvious that an increased number of different kinds of open APIs would support the formation of new improved services even more. The benefit of expanding on existing open source also highlights the importance of breaking organizational silos, not only inside a city (Ojasalo \& Kauppinen, 2018), but also between cities as well. By releasing the developed software code as open source, several cities can take advantage of solutions built for the needs of one city, and thus use resources more smartly. Therefore, whenever evaluating the success of a smart city project, it is recommended to consider replicability and scalability of the smart city project solutions at a wider scale (cf. Bosch et al., 2017).

The first concrete example of a smart city service making use of the Tavastia Events API is the "Hämeenlinna in pocket" application developed jointly by Häme University of Applied Sciences (HAMK) and the City of Hämeenlinna. It offers citizens public transportation information, news, a digital library card, and a list of events occurring in the city (Kunttu, 2019).

From the very beginning it was clear that Tavastia Events would be created to serve the whole region and all stakeholders rather than a single city. It is recognized that some cities in the region have bigger interest than others in Tavastia Events. Still, it is wise to offer services, tools, and methods to everyone, even if the demand is not so high yet. This supports the future development of the whole region and might bring new innovations and 


\section{Open Data and Open Source Enabling Smart City Development Jari Jussila, Joni Kukkamäki, Mikko Mäntyneva, Juuso Heinisuo}

point out different kinds of needs that would not be recognized in a closed development process. This applies not only to open data, but also to open source code. When the first stakeholders can point out the opportunities and benefits, it usually activates others, too.

The participation of various stakeholders from the early stage of development of Tavastia Events brought many valuable benefits. It is clear that it improved the possibility to gain different insights to be taken into account in development, so there were no unexpected major surprises when it was released. It also committed certain stakeholders to use Tavastia Events instantly after release, as it is crucial for this kind of service to achieve a critical mass of users as fast as possible. Another important observation is that this type of cocreation not only improved the quality of this service, but also committed people to getting together to innovate other solutions that would help to build smarter cities and a smarter region.

Both Tavastia Events event API and "Hämeenlinna in pocket" mobile application have received increasing attention from several stakeholders. It is important to understand the role that open source plays in this development. Even cities, for instance, Helsinki that was ranked 5th place on the top 50 smart city governments (Eden Strategy Institute, 2018), which have been participating in original development of the frameworks are interested about the new and improved features that have been developed in Häme region, extending the original source code. Development has also been noticed in other cities in Finland and source code, experiences and guidance have been shared across Finland by different stakeholders. To get impact from open source or open data, it is important to have channels for open communication, make results visible, and collaborate actively between different parties. Häme University of Applied Sciences, especially it's OpenHäme project has put lot of effort for these activities to promote the possibilities of open technologies.

Experiences and results achieved in these two cases have had impact in development towards a smarter and more open region. Especially, the City of Hämeenlinna has started many activities to improve their capability to benefit from open technologies and to support their usage and development. It takes time before companies are widely ready to implement open technologies in their business. Likewise, it is a long-term process to raise citizen awareness of all the possibilities, even when both services have received positive feedback from companies and citizens. Meanwhile, it is critical to bring out these kinds of showcases, which helps accelerate the penetration of open source to market. The future aim for the Häme region is to support usage of open technologies, update educational curricula, and facilitate knowledge, learning and skills that are required to create new businesses around open technologies.

\section{Acknowledgments}

The financial support from the Regional Council of Häme is gratefully acknowledged.

\section{References}

Anthopoulos, L., \& Fitsilis, P.-. 2014. Exploring architectural and organizational features in smart cities. 16th International Conference on Advanced Communication Technology. IEEE.

https://ieeexplore.ieee.org/abstract/document/67789 47\%.

Bosch, P., Jongeneel, S., Rovers, V., Neumann, H. M., Airaksinen, M., et al. 2017. CITYkeys indicators for smart city projects and smart cities. CITYkeys report. https://www.researchgate.net/profile/Aapo_Huovila/ publication/326266723_CITYkeys_indicators_for_sma rt_city_projects_and_smart_cities/links/5b434e4fof7e 9bb59b187e77/C̄ITYkeys-indicators-for-smart-cityprojects-and-smart-cities.pdf.

Carayannis, E., \& Campbell, D. 2010. Triple Helix, Quadruple Helix and Quintuple Helix and how do knowledge, innovation and the environment relate to each other?: a proposed framework for a transdisciplinary analysis of sustainable development and social ecology. International Journal of Social Ecology and Sustainable Development (IJSESD), 1(1): 41-69.

Chan, C. 2013. From open data to open innovation strategies: Creating e-services using open government data. 46th Hawaii International Conference on System Sciences, 1890-1899. IEEE.

Chesbrough, H. 2003. The Logic of Open Innovation. California Management Review, 45(3): 33-58.

Chourabi, H., Nam, T., Walker, S., Gil-Garcia, J., Mellouli, S., et al. 2012. Understanding smart cities: An integrative framework. 45th Hawaii international conference on system sciences, 2289-2297. IEEE.

City of Helsinki. 2019. Linked Events. https://github.com/City-of-Helsinki/linkedevents.

Conradie, P., Mulder, I., \& Choenni, S. 2012. Rotterdam open data: Exploring the release of public sector information through co-creation. 18th International ICE Conference on Engineering, 1-10. IEEE.

Cotton, N. 2018. The Smart City Cookbook. Tampere: City of Tampere, Department of International Affairs. 


\section{Open Data and Open Source Enabling Smart City Development Jari Jussila, Joni Kukkamäki, Mikko Mäntyneva, Juuso Heinisuo}

Dameri, R. P. 2013. Searching for Smart City definition: a comprehensive proposal. International Journal of Computers \& Technology, 11(5): 2544-2551.

Eden Strategy Institute. 2018. Top 50 Smart City Governments.

https://static1.squarespace.com/static/5b3c517fec4e b767a04e73ff/t/5b513c57aa4a99f62d168e60/1532050

650562/Eden-

OXD_Top+50+Smart+City+Governments.pdf.

Edvardsson, B., Tronvoll, B., \& Gruber, T. 2011. Expanding understanding of service exchange and value co-creation: a social construction approach. Journal of the Academy of Marketing Science, 39(2): 327-339.

Etzkowitz, H. 2003. Innovation in Innovation: The Triple Helix of University-Industry-Government Relations. Social Science Information, 42(3): 293-337.

Garzarelli, G., Limam, Y. R., \& Thomassen, B. 2008. Open source software and economic growth: A classical division of labor perspective. Information Technology for Development, 14(2): 116-135.

Giffinger, R., \& Gudrun, H. 2010. Smart cities ranking: an effective instrument for the positioning of the cities? ACE: Architecture, City and Environment, 4(12): 7-26.

HAMK Smart. 2019. Tavastia Events API. http://api.tavastiaevents.fi/vl/.

Hartman, A., Jain, A. N., Ramanathan, J., Ramfos, A., Van der Heuvel, W.-J., et al. 2010. Participatory Design of Public Sector Services. International Conference on Electronic Government and the Information Systems Perspective, 219-233. Berlin: Springer.

Janssen, K. 2011. The influence of the PSI directive on open government data: An overview of recent developments. Government Information Quarterly, 28(4): 446-456.

Jussila, J., Lehtonen, T., Sillanpää, V., Helander, N., \& Kallio, J. 2016. Can e-government solutions enhance the work in municipalities?: empirical evidence from case lupapiste. Proceedings of the 20th International Academic Mindtrek Conferenc, 20-25. ACM.

Kukkamäki, J., Jussila, J., \& Mäntyneva, M. 2019. Open data enabling networked e-government: Case Tavastia Events. ISPIM Connects Ottawa Innovation Conference. Ottawa, Canada.

Kunttu, I. 2019. Developing smart city services by mobile application. ISPIM Ottawa Connects Conference Proceedings.

https://www.researchgate.net/profile/Iivari_Kunttu/ publication/332257651_Developing_smart_city_servi ces_by_mobile_application/links/5ca9ef2e92851c64b d566863/Developing-smart-city-services-by-mobileapplication.pdf.

Lindman, J., \& Nyman, L. 2014. The businesses of open data and open source: Some key similarities and differences. Technology Innovation Management Review, 4(1).

https://timreview.ca/article/757.
Lindman, J., \& Rossi, M. 2013. Open data services: Research agenda. 46th Hawaii International Conference on System Sciences, 1239-1246. IEEE.

Lusch, R., \& Nambisan, S. 2015. Service innovation: A service-dominant logic perspective. MIS Quarterly, $39(1)$.

http://plaza.sdlogic.net/uploads/3/4/0/3/34033484/ si_luschnambisan-3.pdf.

Lusch, R., \& Vargo, S. 2014. Evolving to a new dominant logic for marketing. Service-Dominant Logic of Marketing. Routledge.

https://www.taylorfrancis.com/books/e/9781317454 649/chapters/10.4324/9781315699035-9.

McDermott, P. 2010. Building open government. Government Information Quarterly, 27(4): 401-413.

Nelson, R. 2007. Defining Open Source. Open Source Business Resource, (September 2017). https://timreview.ca/article/74.

Ojasalo, J., \& Kauppinen, H. 2018. Collaborative Innovation with External Actors: An Empirical Study on Open Innovation Platforms in Smart Cities. Technology Innovation Management Review, 6(12): 49-60.

Ojo, A., Curry, E., \& FA Zeleti. 2015. A tale of open data innovations in five smart cities. 48th Hawaii International Conference on System Sciences, 2326-2335. IEEE.

Rai, A., \& Sambamurthy, V. 2006. Editorial Notes- The Growth of Interest in Services Management: Opportunities for Information Systems Scholars. Information Systems Research, 17(4): 327-331.

Schaffers, H., Komninos, N., Pallot, M., Trousse, B., Nilsson, M., et al. 2011. Smart Cities and the Future Internet: Towards Cooperation Frameworks for Open Innovation. In The future internet assembly: 431-446. Berlin: Springer.

Vargo, S., Wieland, H., \& Akaka, M. 2015. Innovation through institutionalization: A service ecosystems perspective. Industrial Marketing Management, 44: $63-72$.

Visvizi, A., \& Lytras, M. D. 2018. Rescaling and refocusing smart cities research: from mega cities to smart villages. Journal of Science and Technology Policy Management, 9(2): 134-145.

West, D., \& Lu, J. 2009. Comparing technology innovation in the private and public sectors. http://www188.pair.com/next1/Comparingtech innovation in public and private sectors.pdf.

Zuiderwijk, A., Janssen, M., \& Davis, C. 2014. Innovation with open data: Essential elements of open data ecosystems. Information Polity, 19(1,2): 17-33. 


\title{
Open Data and Open Source Enabling Smart City Development Jari Jussila, Joni Kukkamäki, Mikko Mäntyneva, Juuso Heinisuo
}

\begin{abstract}
About the Authors
Dr. Jari Jussila holds a PhD degree in Information and Knowledge Management from Tampere University of Technology (TUT, 2015). Currently he is working as Principal Research Scientist at HAMK Smart Research Unit. His research is currently focused on knowledge management, business intelligence, social media, big social data analytics, and health informatics.

Mr. Joni Kukkamäki is a Research Manager in the HAMK Smart Research Unit. He runs the DISP (Digital Solutions \& Platforms) team whose role is to provide technology-based research \& development activities for the needs of HAMK Research and also for industry. Focus areas for the team are software development, Internet of Things, game engines, and data analytics. Kukkamäki holds a Bachelor of Business Administration (IT) degree and is currently working for his M.Sc (Computer Science) at Tampere University.
\end{abstract}

Dr. Mikko Mäntyneva holds a $\mathrm{PhD}$ degree in Strategic Management from Tampere University of Technology (TUT, 2004). Currently he is the Principal Research Scientist at Häme University of Applied Sciences (HAMK). His research is currently focused on smart services, innovation management, knowledge management, and customer relationship management. He has authored several scientific articles as well as six books on various management topics.

Dr. Juuso Heinisuo holds a $\mathrm{PhD}$ degree from the Faculty of Business and Built Environment of Tampere University of Technology (TUT, 2013). Currently he is the Strategy Manager for the City offl Hämeenlinna. His work is currently focused on knowledge management, ecosystems, data analytics, strategy, and urban planning. His works have been recognized in such international communities as TED.

Citation: Jussila, J., Kukkamäki, J., Mäntyneva, M., \& Heinisuo, J.. 2019.

Open Data and Open Source Enabling Smart City Development: A Case Study in Häme Region. Technology Innovation Management Review, 9(9): 25-34.

http://doi.org/10.22215/timreview/1266

(cc) BY

Keywords: Smart city, Smart cities, Smart service, Open data, Open source, E-government, Innovation, Co-creation, Events, Application programming interface 


\title{
Open Strategy in a Smart City Suvi Einola, Marko Kohtamäki \& Harri Hietikko
}

\author{
"Human creativity is the ultimate economic resource." \\ Richard Florida \\ Urban studies theorist
}

\begin{abstract}
To attract new companies and a talented workforce in a way that increases income streams, cities are searching for strategic capabilities by using a variety of strategic practices. The present study participates in the theoretical debate between micro- and macro-strategizing by focusing on the interplay between the city organization and its institutional environment. As such, the study elucidates the open strategy process used in the strategy work of a medium-sized city in Finland. To make the strategy work open and encourage citizens' participation, the city decided to utilize crowdsourcing as a tool that was part of a broader strategy process to develop a city strategy in a participative manner. The present study analyzes the responses of almost 2000 citizens to address the role of an open strategy in developing a smart city. The study contributes by depicting how the open strategy was utilized in practice and what types of outcomes it produced.
\end{abstract}

\section{Introduction}

Strategic planning has traditionally been seen as a business of the upper echelons and top management, whereas the "lower" levels of the organization are charged with taking care of the implementation. The open strategy concept challenges this view by demanding transparency and the involvement of broader communities as a component of the success of the strategy work (Whittington, Cailluet, \& YakisDouglas, 2011). Although open strategy work has incontestable advantages, it has also been argued that "the directive, focused, convergent qualities of traditional conceptions of strategy and the nonhierarchical, expansive and often divergent nature of dialogic approaches" (Heracleous, Gößwein, \& Beaudette, 2018), raise tensions that are novel to organizations. While previous studies of open strategy researchers have mostly focused on shareholders, employees, or various partner communities, the newest stream of open strategy work builds on open innovation by applying the concept of crowdsourcing to strategy work (Aten \& Thomas, 2016; Dobusch \& Kapeller, 2018). The word "crowdsourcing" is used for multiple activities and practices that have crowd-participating elements (Estellés-Arolas \& González-Ladrón-de-Guevara, 2012; Howe, 2006). Crowdsourcing has many definitions, but in this study the definition from Aitamurto, Chen, Cherif, Galli and Santana (2016) is taken: "Crowdsourcing is an open call for anyone to participate in an online task by sharing information, knowledge, or talent". As Schenk and Guittard (2009: 5) put it: "crowdsourcing is a form of outsourcing not directed to other companies but to the crowd by means of an open tender (open call) via an Internet platform". Crowdsourcing has the potential to improve the engagement of citizens in policy-making, even between elections, and because of this ability, it is increasingly used also in public sector organizations (Aitamurto et al., 2016). Although crowdsourcing itself as a method is not new, it provides meaningful opportunities for the more effective use of citizens' opinions in strategy work (Bauer \& Gegenhuber, 2015).

In addition to the increasing use of the concept of crowdsourcing in development work by public sector organizations, the smart city concept has gained massive attention in the last decade in the European Union (Schuurman, Baccarne, Marez, \& Mechant, 2012). The smart city concept includes both technology- and human-driven approaches (Kummitha \& Crutzen, 2017) in which the role of citizen participation is one of the key elements of the effective development of cities (Schuurman et al., 2012). Whereas the technology-driven approach highlights the role of ICT and IoT in the development of cities, human-driven approaches emphasize the idea that smart cities "can also include human capital investments that are aimed at fostering a city's capacity for learning and innovation" (Neirotti, De Marco, Cagliano, Mangano, \& Scorrano, 2014: 26).

There is a need for empirical studies about how to foster learning and innovation in cities through citizen involvement (Schuurman et al., 2012). The present study contributes by suggesting that an integrated interplay exists between the technology- and human-driven approaches and use the concept of sociomateriality to 


\section{Open Strategy in a Smart City}

\section{Suvi Einola, Marko Kohtamäki \& Harri Hietikko}

discuss this interplay in the context of open strategizing. Furthermore, this study depicts both how an open strategy was utilized in practice, and what types of outcomes the use of the open strategy produced. As such, the present study participates in the theoretical debate between micro- and macro-strategizing by focusing on the interplay between the city organization and its institutional environment. By involving citizens in open strategizing, the organization crafts a micropractice that enables citizens to participate in strategic activity.

\section{Key Insights from the Literature}

\section{Open Strategy}

The open strategy concept includes two key features of strategy work: participation and transparency. The former reflects upon the people involved in the actual strategy work, and the latter refers to the transparency of the strategy process and communicating the strategy; both of these are favored by new social media technologies (Whittington et al., 2011). An open strategy that includes the participation of external and internal stakeholders has many undeniable benefits: increasing collective commitment and, through commitment, enabling more effective strategic actions and joint sensemaking (Ashmos, Duchon, McDaniel, \& Huonker, 2002; Doz \& Kosonen, 2008; Kellermanns, Walter, Lechner, \& Floyd, 2005). Furthermore, open strategizing can improve creativity by capturing more diverse views (Stieger, Matzler, Chatterjee, \& Ladstaetter-Fussenegger, 2012).

Despite the many positive aspects of open strategy, researchers have also discussed the negative effects of openness: having more participants in strategy work is time-consuming for management teams and requires the top management team (TMT) to relinquish some control (Birkinshaw, 2017), to enhance participation and transparency. This easily leads to situations in which an organization struggles with tensions "between flexibility and openness on the one hand versus structure and control on the other; broad participation of stakeholders versus selection of particular contributors to lead parts of the process and integrate ideas; aiming for a collective creation, but within clear, directed parameters" (Heracleous et al., 2018: 25). Crowdsourcing as an open strategy tool can be a good solution to balance time, collective strategy creation and effective decision making, as shown in a few previous studies (Aitamurto et al., 2016; Aten \& Thomas, 2016; Malhotra, Majchrzak, \& Niemiec, 2017; Schuurman et al., 2012).

\section{Crowdsourcing as a Sociomaterial Tool}

Sociomateriality has attracted growing interest in the field of management and information studies in recent decades (Orlikowski, 2007; Orlikowski \& Scott, 2008). Sociomateriality is defined as "the constitutive entanglement of the social and the material in everyday organizational life" (Orlikowski, 2007: 1438). Researchers aim to understand the entanglement, or the intertwined interaction, between the social and material (Balogun, Jacobs, Jarzabkowski, Mantere, \& Vaara, 2014). For a long time, organization studies overlooked the role of the material in organizing (Orlikowski, 2007) and in strategy research, before the field of sociomateriality enabled us to combine and elaborate technological aspects with actors and practices (Balogun et al., 2014). Research on sociomateriality is interested in the interaction between actors and objects. These material artifacts can be strategy tools, presentation tools, sticky notes, frameworks, or analytical software (Jarzabkowski \& Kaplan, 2015). Strategy-as-practice research is particularly intrigued "with the way that sociomaterial aspects such as tools, locations, and spatial arrangement configure strategic interaction between bodies and things" (Balogun et al., 2014: 185).

In this study, our special interest lies in crowdsourcing and how it can be used as a sociomaterial tool to improve the involvement of citizens in a city's strategy work. Although crowdsourcing has been tightly coupled with the Internet of Things (IoT), its roots can be traced back as early as the attempts by the 18th century British government to find solutions for positioning ships at sea, as well as in Wild West movies where sheriffs offer rewards to bring suspects to justice (Afuah \& Tucci, 2012). Crowdsourcing has spread quickly, with much emphasis in areas such as creating, organizing and sharing knowledge (Bauer \& Gegenhuber, 2015: 661). Crowdsourcing has also been used in the context of open strategizing (Aten \& Thomas, 2016; Malhotra et al., 2017). Crowdsourcing enables a large number of stakeholders to take part in strategy work through virtual environments (Aten \& Thomas, 2016), which are seen as an important engagement tool to improve the involvement of citizens in the context of public organizations (Aitamurto et al., 2016). Although crowdsourcing has incontestable positive effects for the inclusion of citizens, some have also warned that it creates problems in sharing and integrating knowledge because of contentious conflict risk and self-promotion risk (Malhotra et al., 2017). To mitigate these risks, Malhotra and colleagues (2017) suggest framing the strategic challenge appropriately using a 2-phase guided crowdsourcing process, discouraging self-promotion in instructions, and posting answers anonymously. 


\section{Open Strategy in a Smart City}

\section{Suvi Einola, Marko Kohtamäki \& Harri Hietikko}

\section{Research Methodology}

This single case study aims to understand the role of crowdsourcing in an open strategy in the context of a medium-sized city in the western part of Finland. The present study uses single case research for an improved understanding of the case context (Eriksson \& Kovalainen, 2016) and the rich processes of open strategy, which should be studied in detail (Patton, 2015). The case is relevant and valuable as such, and the meaningful findings of this case will be conceptually interesting for a broad readership (Stake, 1995).

The city started its participative strategy work in 2013, and all three researchers have been facilitating the strategy process and strategy workshops since inception. In 2017, new city counselors were elected, and a new strategy round was started. Because it was the first time new councilors took part in strategy work

and because the purpose was to develop a completely new strategy instead of updating an existing one, it was considered important to provide sufficient background information to support decision making. The idea of citizen participation had also been discussed in previous strategy rounds, and this time, the top management team and city councilors took up the challenge. Crowdsourcing was chosen as a form of inclusion because the city, Vaasa, has nearly 70,000 citizens, which makes face-to-face participation impossible. The crowdsourcing was carried out in cooperation with an external actor, but the city of Vaasa was closely involved in all stages of the preparation. One of the authors built the questions together with the external actor.

As such, the case city was involved in a large EU project IRIS (Integrated and Replicable Solutions for

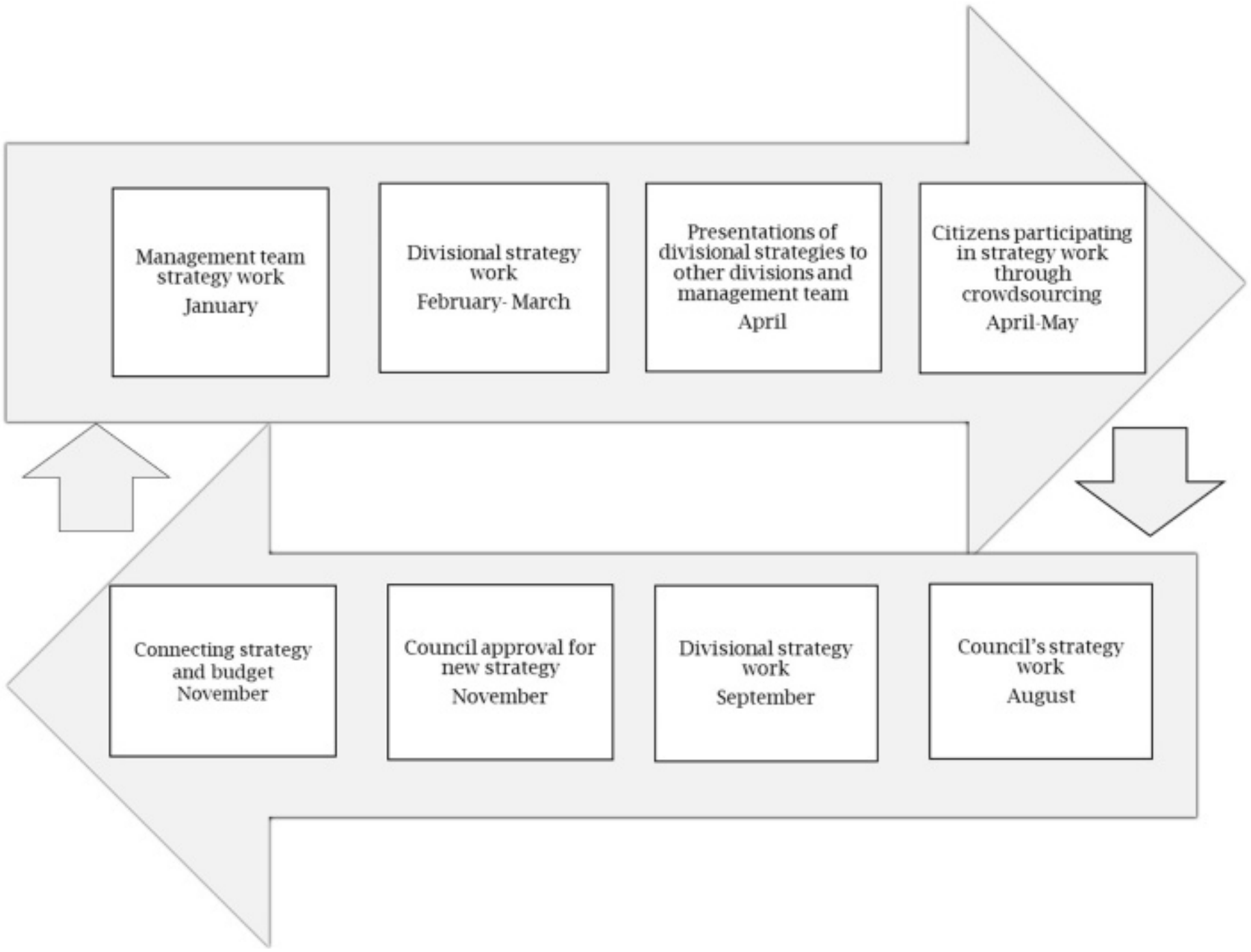

Figure 1. Strategy process in the city of Vaasa 2017. 


\section{Open Strategy in a Smart City Suvi Einola, Marko Kohtamäki \& Harri Hietikko}

Sustainable Cities), which focuses on five key themes: 1) energy-positive regions, 2) smart energy handling, 3) smart e-mobility, 4) an innovation platform for digital cities, and 5) citizen participation and co-creation. The project aimed at developing sustainable business models and innovations as well as seizing the opportunity to implement and disseminate the entities developed within the project. The project also aimed to change the behavior of residents by producing innovative solutions based on digital applications and exploiting the possibilities of open knowledge. In this study, we focus on the role of participation and cocreation (see also Mattoni, Gugliermetti, \& Bisegna, 2015).

The research data was collected through a crowdsourcing tool, which was used 1971 times during one month between 29.3.2017-1.5.2017. Respondents' background variables included gender, age, and assigned role as citizen, city employee, company representative, community representative, or political decision-maker. It was possible to respond to the survey in Finnish, Swedish or English. The survey consisted of six different sections, entitled 1) How did Vaasa manage to serve you last year?, 2) What do you think are the most important service roles in Vaasa?, 3) In your opinion, what kind of city is future Vaasa, where it is good to live, act, and influence?, 4) What is a good direction for Vaasa?, 5) In the future, where should the city invest?, and, 6) What should be done in practice? In some sections, statements were prepared in response to the questions, and the respondents could assess their accuracy and significance. But for a significant portion of the questionnaire the response options were empty, and the respondents could raise completely unclassified themes that were recorded in order to be the subject of peer review by other respondents. In this case, it was possible to confirm or refute the importance of the topics based on the other respondents' thoughts and experiences (see also Malhotra et al. 2017). The most important observation from the point of view of executing the survey can be considered a great interest in the possibility of citizens to present their views on the future of Vaasa. With approximately two thousand responses, the survey clearly became more popular than many other similar surveys carried out at the same time in Finland, both by public and private organizations. When looking at the crowdsourcing results, each single theme was looked at from two different perspectives: 1) How many times the topic was mentioned, and 2) How important the theme was evaluated as being. A high ranking in one perspective did not necessarily mean a similar ranking in the other.
During the analysis process, the data were initially studied by an external actor. The researchers subsequently obtained the raw data from the external actor for analysis and crosschecked their interpretations of the data to ensure its trustworthiness (Lincoln \& Guba, 1985). All three researchers were closely connected to the case organization during data collection because of the ongoing strategy process. Although the findings of the study emerge from a specific context of a single case study, the results provide some more common concepts and ideas that can be used to study these issues in other case contexts (Corley \& Gioia, 2004; Lincoln \& Guba, 1985)

\section{Results}

The strategy process in the city of Vaasa 2017 (Figure 1) included management team level strategy work, divisional strategy work, the participation of citizens through crowdsourcing, council-level strategy work, and decision making. Four strategy tools were used in all internal strategy workshops: 1) the strategic capabilities framework, 2) a value curve, 3) a strategy map, and 4) a goals, measures, and initiatives -table. The same strategy tools have been used in the city's strategy process since 2013, so most of the organizational members were familiar with the tools. This enabled the organization to take the next step and emphasize the inclusion of citizens in the strategy process. Each of the workshops built on the outputs of previous workshops, enabling the deepening of city strategy and a shared understanding of the organization's future.

\section{Engaging in open strategy in the city of Vaasa through crowdsourcing}

The results of this article elucidate the role of crowdsourcing as a tool for enabling co-creation and innovation in the strategy process of the city of Vaasa. The crowdsourcing process took place in May 2017, after the management team and divisions began a new strategy process at the beginning of the year. With crowdsourcing, it was important to the case organization that they could also give sufficient background information to participants to ensure that people had a somewhat similar understanding of the questions. In addition, the crowdsourcing tool enabled citizens to "discuss" the topics by emphasizing each other's responses so that the topics evolved through the crowdsourcing process.

In the city of Vaasa, the most important topics that were discussed in the citizens' responses were as follows: 1) supporting employment and entrepreneurship, 2) 


\section{Open Strategy in a Smart City}

\section{Suvi Einola, Marko Kohtamäki \& Harri Hietikko}

Table 1. Targets, indicators and actions in the city of Vaasa strategy 2017.

\begin{tabular}{|c|c|c|}
\hline TARGETS & INDICATORS & ACTIONS \\
\hline \multicolumn{3}{|l|}{ WELL-BEING } \\
\hline $\begin{array}{l}\text { Well-being of the } \\
\text { population }\end{array}$ & $\begin{array}{l}\text { - TEA indicators for } \\
\text { how actively health } \\
\text { and well-being are } \\
\text { promoted } \\
\text { - Sense of security }\end{array}$ & $\begin{array}{l}\text { - The city center school campus } \\
\text { - More efficiently integrating of new residents } \\
\text { - Transferring services online } \\
\text { - Encouraging the network of associations to participate and promoting the visibility of } \\
\text { services } \\
\text { - H-building, establishing a well-being and health care unit } \\
\text { - Methodically using of impact assessment in decision-making } \\
\text { - Supporting and developing bilingualism and creating a language strategy as soon as } \\
\text { possible }\end{array}$ \\
\hline $\begin{array}{l}\text { Strengthening } \\
\text { representative } \\
\text { and direct } \\
\text { democracy }\end{array}$ & $\begin{array}{l}\text { - Number of appeals } \\
\text { on municipal } \\
\text { decisions }\end{array}$ & $\begin{array}{l}\text { - Implementing the City's Participation Programme - making use of resident surveys } \\
\text { - Improving utilisation of the feedback service }\end{array}$ \\
\hline $\begin{array}{l}\text { Carbon neutral } \\
\text { Vaasa } 2035\end{array}$ & $\begin{array}{l}\text { - Carbon dioxide } \\
\text { emissions }\end{array}$ & - Implementing the energy and climate programme \\
\hline \multicolumn{3}{|l|}{ ATTRACTION } \\
\hline $\begin{array}{l}\text { Improving } \\
\text { competitiveness; } \\
\text { Tax revenue } \\
\text { among the TOP } \\
6 \text { cities }\end{array}$ & $\begin{array}{l}\text { - Corporation tax } \\
\text { revenue } \\
\text { - Tax revenue in } \\
\text { comparison to other } \\
\text { cities } \\
\text { - Company } \\
\text { dynamics (changes } \\
\text { in company base) }\end{array}$ & $\begin{array}{l}\text { - Implementing of municipal mergers in a controlled and efficient way, while taking } \\
\text { bilingualism into account } \\
\text { - Acting as the platform for events, developing and designing "Vaasa Events" } \\
\text { - Selling Vaasa and nurturing its connections to the world; Increasing tax revenue through } \\
\text { new business acquisitions; Strengthening connections to Asia } \\
\text { - Strengthening the operations of the Vaasa University Campus }\end{array}$ \\
\hline $\begin{array}{l}\text { Population } \\
\text { growth } \\
>100,000 \\
\text { inhabitants by } \\
2021 \\
\end{array}$ & $\begin{array}{l}\text { - Population growth } \\
\text { cp. previous year } \\
\text { - Rate of migration } \\
\text { to other } \\
\text { municipalities }\end{array}$ & $\begin{array}{l}\text { - Investments in the living environment and infrastructure, inel. both new projects and the } \\
\text { maintenance of existing structures } \\
\text { - Investments in preventative work }\end{array}$ \\
\hline $\begin{array}{l}\text { Employment rate } \\
>75 \%\end{array}$ & $\begin{array}{l}\text { Number of } \\
\text { employed persons } \\
\text { (18-64-year old) per } \\
\text { capita }\end{array}$ & $\begin{array}{l}\text { - Activation of innovation activities } \\
\text { - Supporting the employment of experts and helping them to grow roots here }\end{array}$ \\
\hline $\begin{array}{l}\text { Competitive } \\
\text { urban structure }\end{array}$ & $\begin{array}{l}\text { - Number of plot } \\
\text { and plan reserves } \\
\text { - The lead time of } \\
\text { building permits } \\
\text { - The lead time of } \\
\text { town plans }\end{array}$ & $\begin{array}{l}\text { - Strengthening air, rail and shipping traffic } \\
\text { - Developing innovative public procurements } \\
\text { - Developing public transport and the bicycle network } \\
\text { - Implementing the Kurikka groundwater project } \\
\text { - Extending the pedestrian precinct to the shore and university campus } \\
\text { - Developing and revitalising the city centre and market place }\end{array}$ \\
\hline \multicolumn{3}{|l|}{$\begin{array}{l}\text { STRONG } \\
\text { ECONOMY }\end{array}$} \\
\hline $\begin{array}{l}\text { Balanced } \\
\text { economy }\end{array}$ & $\begin{array}{l}\text { - Accrued surplus } \\
\text { - Debt } \\
\text { collection/inhabitant } \\
\text { - Annual margin } \\
\text { - Person-work-ycars } \\
\text { - Operating } \\
\text { revenues }\end{array}$ & $\begin{array}{l}\text { - Strict compliance with the binding balancing plan } \\
\text { - Taking private funding/crowdfunding into account in investments, public-private } \\
\text { partnerships } \\
\text { - Developing monitoring and reporting procedures, opening up realised financial out-turns }\end{array}$ \\
\hline
\end{tabular}




\section{Open Strategy in a Smart City}

\section{Suvi Einola, Marko Kohtamäki \& Harri Hietikko}

\begin{tabular}{|c|c|c|}
\hline $\begin{array}{l}\text { Smart and } \\
\text { effective asset } \\
\text { management }\end{array}$ & $\begin{array}{l}\text { - Development of } \\
\text { premises }\end{array}$ & $\begin{array}{l}\text { - Increasing the occupancy rate of properties, abandoning external rental properties, } \\
\text { anticipatory management of the use of premises } \\
\text { - Developing contract management } \\
\text { - Developing corporate governance }\end{array}$ \\
\hline $\begin{array}{l}\text { PERSONNEL, } \\
\text { COMPETENCE } \\
\text { AND } \\
\text { MANAGEMEN }\end{array}$ & & \\
\hline $\begin{array}{l}\text { Employee well- } \\
\text { being and } \\
\text { productivity }\end{array}$ & $\begin{array}{l}\text { - Number of sick } \\
\text { leave absences } \\
\text { - Results of job } \\
\text { satisfaction survey }\end{array}$ & $\begin{array}{l}\text { - Developing leadership and management skills: Coaching-style management and workplace } \\
\text { well-being management } \\
\text { - Developing the management system } \\
\text { - Developing competence and work community skills in the workplace } \\
\text { - New models for work (digitisation, automation of routine tasks) }\end{array}$ \\
\hline
\end{tabular}

safety, 3) education, 4) exploiting expertise, 5) nearby services, 6) preventative action, 7) environment and sustainable development, 8) transparency and communication, 9) experiencing equality, and 10) opportunities to influence. The first of these, support for employment and entrepreneurship, became particularly significant because great importance among the respondents legitimized the ideological basis of the strategy work among policy makers: in the city of Vaasa, one of the basic elements of strategy work since 2013 had been increasing attractiveness and social development through employment and job creation. In addition, education was raised as an important area in which the city should target future investment. The answers also raised visible tensions that have smoldered between political parties; e.g., Vaasa has been active in accepting asylum seekers, which has caused debates between the right and left parties. This is also reflected in safety being highlighted. Furthermore, Vaasa is a compact area where there have been many nearby services (e.g., 7 health care stations in a $10 \mathrm{~km}$ radius from the city centre). Pruning nearby services caused a wave of protests and is visible in citizens' answers. Additionally, transparency, communication, equality and influencing opportunities were seen as important. When looking at the actions the city committed in its strategy (Table 2), it reflects quite well the emphasis of citizens' opinions.

The topics citizens highlighted in their answers as the most important emerged significantly in Vaasa's strategy. In Figure 2, left side, are the ten most important areas where Vaasa should invest in the future, listed in the order they were ranked in the data. The right side of the figure shows how these emerged in strategic actions the city committed in its 2017 strategy process. As shown, the topics citizens evaluated as important were emphasized heavily in the organizational strategy work. Naturally, the responses also contained a large number of sub-proposals, views and suggestions, which were utilized for divisional level strategy work, as well as suggestions that were ultimately not included in the final strategy work. The conclusions of the crowdsourcing process were included in the background material and presented to city councilors in the strategy workshop of August 2017. Each of the divisional directors in the city facilitated a strategy workshop with a group of councilors, which enabled building a shared understanding of city strategy through dialogical discussions. These discussions were condensed in the final strategy, which was approved in November 2017.

Both citizens and city officials stressed employment and competitiveness in their opinions. It was seen as extremely important that the city be able to attract new companies to the area, and thereby create new jobs and increase tax revenue. Furthermore, as citizens were worried about city safety, officials addressed the issue from many different angles: they highlighted the significance of efficient integration of new residents, invested in preventative work, and aimed to develop public transportation and the bicycle network. Investments in education are highlighted in the new city centre school campus strategy, and by strengthening operations at the Vaasa University campus. In addition, investments in the environment and in sustainable development were of special interest to both groups. Implementation of a broad energy and climate program and strengthening air, rail and shipping traffic are actions committed to in its strategy.

\section{Conclusion}

This study set out to analyze the role of crowdsourcing as a sociomaterial tool enabling co-creation and innovation to improve citizen involvement in a city's strategy work. As an alternative to traditional strategy work for the upper echelons, we propose opening strategy work in the spirit of smart city development. As 


\section{Open Strategy in a Smart City}

\section{Suvi Einola, Marko Kohtamäki \& Harri Hietikko}

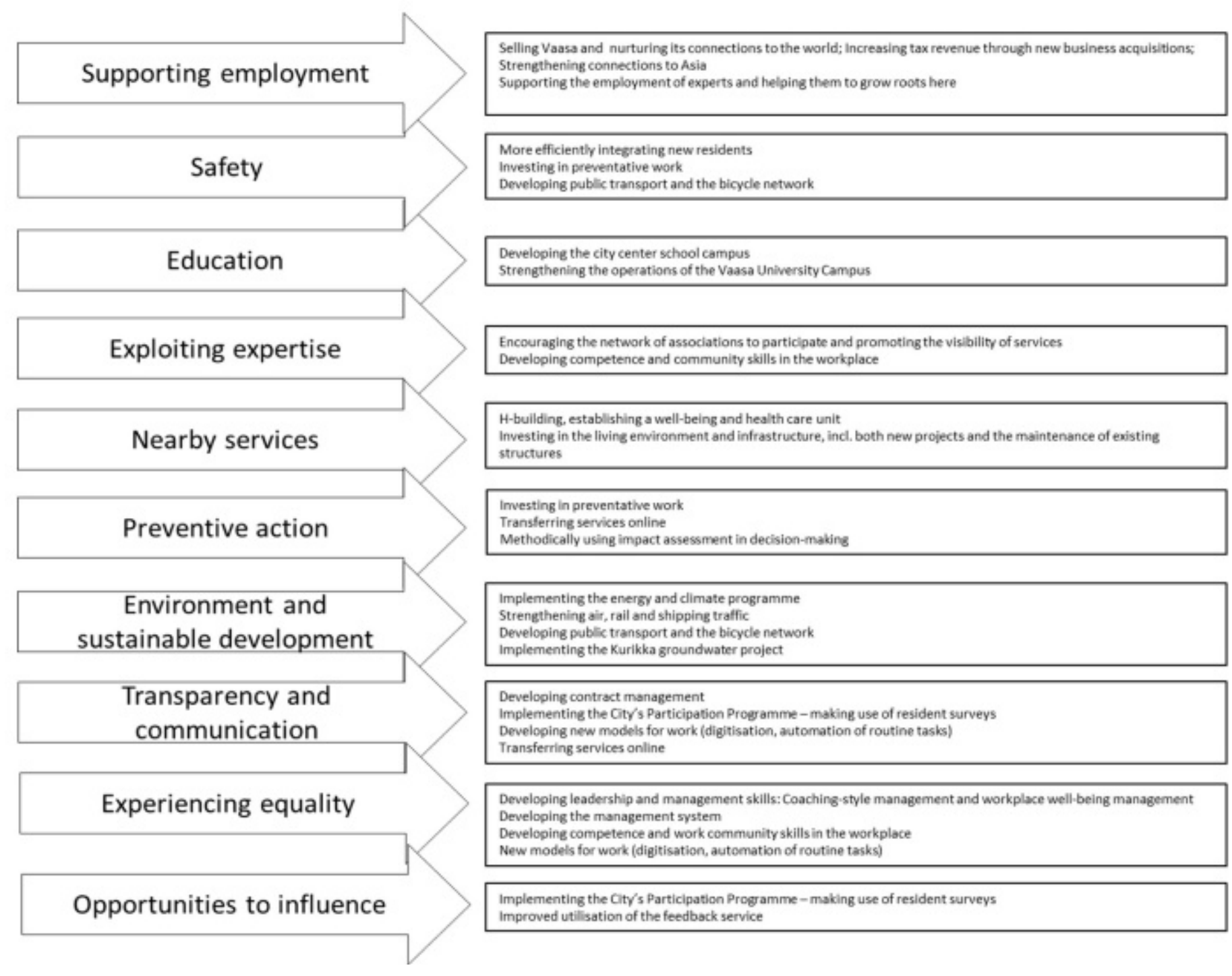

Figure 2. Connections between the top ten areas Vaasa should invest as defined by citizens and the strategic actions the city committed in its strategy work.

shown in the results of the present study, citizen opinions feed strategy work and should be taken into account if the top management team is ready to relinquish some part of its control and power to other stakeholders. Giving any amount of control away is not an easy task, but one that requires an open mind and confidence in fellow citizens' co-creative capacity. As such, opening strategy work to all, not only provides a rich variety of ideas, but also may help facilitate implementation when the time comes (Birkinshaw, 2017; Felin, Lakhani, \& Tushman, 2017; Whittington et al., 2011). Involvement is the way to gear the city towards the implementing smart city initiatives.

In retrospect, the route taken by research's case organization towards open strategy and smart city development has progressed bit by bit: first, councilor participating in strategy work, then employees from different organizational levels, and finally citizens. This type of baby-step progression provided a means for opening the strategy work to a broader range of participants (Whittington et al., 2011) and might be one reason why the strategy work development has been successful (Heracleous et al., 2018). It has allowed sufficient time for organizational members to have meaningful discussions with each other and build a shared understanding in and around strategy, with sociality at the centre of open strategizing (Felin et al., 2017). In this way, the organization was ready and open to accept insightful ideas from citizens. As such, this participative working method has facilitated knowledge integration and reduced conflicts (Malhotra et al., 2017). 


\section{Open Strategy in a Smart City}

Suvi Einola, Marko Kohtamäki \& Harri Hietikko

The present study demonstrated both a process and some micro-level outcomes of a smart city using crowdsourcing as a means of open strategizing.

\section{References}

Afuah, A., \& Tucci, C. L. 2012. Crowsourcing as a solution to distant search. Academy of Management Review, 37(3): 355-375.

Aitamurto, T., Chen, K., Cherif, A., Galli, J. S., \& Santana, L. 2016. Civic Crowd Analytics: Making sense of crowdsourced civic input with big data tools. Academic Mindtrek'16, October 16.

Ashmos, D., Duchon, D., McDaniel, R., \& Huonker, J. 2002. What a mess! participation as a simple managerial rule to "complexify" organizations. Journal of Management Studies, 39(2): 189-206.

Aten, K., \& Thomas, G. F. 2016. Crowdsourcing strategizing: Communication technology affordances and the communicative constitution of organizational strategy. International Journal of Business Communication, 53(2): 148-180.

Balogun, J., Jacobs, C., Jarzabkowski, P., Mantere, S., \& Vaara, E. 2014. Placing strategy discourse in context: Sociomateriality, sensemaking, and power. Journal of Management Studies, 51(2): 175-201.

Bauer, R. M., \& Gegenhuber, T. 2015. Crowdsourcing: Global search and the twisted roles of consumers and producers. Organization, 22(5): 661-681.

Birkinshaw, J. 2017. Reflections on open strategy. Long Range Planning, 50(3): 423-426.

Corley, K., \& Gioia, D. 2004. Identity ambiguity and change in the wake of a corporate spin-off. Administrative Science Quarterly, 49(2): 173-208.

Dobusch, L., \& Kapeller, J. 2018. Open strategy-making with crowds and communities: Comparing Wikimedia and Creative Commons. Long Range Planning, 51(4): 561-579.

Doz, Y., \& Kosonen, M. 2008. The dynamics of strategic agility: Nokia's rollercoaster experience. California Management Review, 50(3): 95-118.

Eriksson, P., \& Kovalainen, A. 2016. Qualitative methods in business research. London: Sage.

Estellés-Arolas, E., \& González-Ladrón-de-Guevara, F. 2012. Towards an integrated crowdsourcing definition. Journal of Information Science, 38(2): $189-200$.

Felin, T., Lakhani, K. R., \& Tushman, M. L. 2017. Firms, crowds, and innovation. Strategic Organization, 15(2): 119-140.

Heracleous, L., Gößwein, J., \& Beaudette, P. 2018. Open Strategy-Making at the Wikimedia Foundation: A Dialogic Perspective. Journal of Applied Behavioral Science, 54(1): 5-35.
Howe, B. J. 2006. The Rise of crowdsourcing. Wired Magazine, 14(6): 1-5.

Jarzabkowski, P., \& Kaplan, S. 2015. Strategy tools-inuse: A framework for understanding "technologies of rationality" in practice. Strategic Management Journal, 36: 537-558.

Kellermanns, F. W., Walter, J., Lechner, C., \& Floyd, S. W. 2005. The lack of consensus about strategic consensus\%: Advancing theory and research. Journal of Management, 31(5): 719-737.

Kummitha, R. K. R., \& Crutzen, N. 2017. How do we understand smart cities? An evolutionary perspective. Cities, 67(July 2016): 43-52.

Lincoln, Y. S., \& Guba, E. G. 1985. Naturalistic Inquiry. Thousand Oaks: Sage Publications.

Malhotra, A., Majchrzak, A., \& Niemiec, R. M. 2017. Using public crowds for open strategy formulation: Mitigating the risks of knowledge gaps. Long Range Planning, 50(3): 397-410.

Mattoni, B., Gugliermetti, F., \& Bisegna, F. 2015. A multilevel method to assess and design the renovation and integration of Smart Cities. Sustainable Cities and Society, 15: 105-119.

Neirotti, P., De Marco, A., Cagliano, A. C., Mangano, G., \& Scorrano, F. 2014. Current trends in smart city initiatives: Some stylised facts. Cities, 38: 25-36.

Orlikowski, W. J. 2007. Sociomaterial practices: Exploring technology at work. Organization Studies, 28(9): 1435-1448.

Orlikowski, W. J., \& Scott, S. V. 2008. Sociomateriality: Challenging the separation of technology, work and organization. Academy of Management Annals, 2(1): 433-474.

Patton, M. Q. 2015. Qualitative research and evaluation methods. Sage.

Schenk, E., \& Guittard, C. 2009. Crowdsourcing: What can be outsourced to the crowd, and why? Technical Report, 1-29.

Schuurman, D., Baccarne, B., Marez, L. De, \& Mechant, P. 2012. Smart ideas for smart cities: Investigating crowdsourcing for generating and selecting ideas for ICT innovation in a city context. Journal of Theoretical and Applied Electronic Commerce Research, 7(3): 49-62.

Stake, R. E. 1995. The art of case study research. Thousand Oaks, CA: Sage.

Stieger, R., Matzler, K., Chatterjee, S., \& LadstaetterFussenegger, F. 2012. Democratizing strategy: how crowdsourcing can be used for strategy dialogues. California Management Review, 54(4): 44-68.

Whittington, R., Cailluet, L., \& Yakis-Douglas, B. 2011. Opening strategy: Evolution of a precarious profession. British Journal of Management, 22(3): $531-544$ 


\title{
Open Strategy in a Smart City
}

Suvi Einola, Marko Kohtamäki \& Harri Hietikko

\begin{abstract}
About the Authors
D.Sc. (Admin) Suvi Einola is Assistant Professor at the University of Vaasa. She acts as a program manager of the Master's Programme in Strategic Business Development. Before joining academia, she worked in the public sector for fifteen years, holding managerial, training, and development responsibilities. In her research, Einola focuses on strategic practices and servitization challenges both in public and private organizations. Her articles have been published in journals and books focused on both the public sector and industrial marketing.

D.Sc. (Econ) Marko Kohtamäki is Professor of Strategy and Director of the 'Strategic Business Development' (SBD) research group at the University of Vaasa. Professor Kohtamäki is also an Adjunct Professor at the University of South-Eastern Norway (USN). He takes special interest in industrial service business or servitization, strategic practices, and business intelligence in technology companies. He has published in several distinguished international journals, such as Strategic Management Journal, International Journal of Operations and Production Management, Strategic Entrepreneurship Journal, and Industrial Marketing Management, among others.
\end{abstract}

D.Sc. (Admin) Harri Hietikko is Development Manager at the City of Vaasa and a published author of several works. He has written crime fiction, nonfiction and plays that have been performed on several theater stages. In 2008, Hietikko received his doctorate from the University of Tampere on the subject "Power, Leadership, Destruction and Hope in J.R.R. Tolkien's Lord of the Rings." In 2010, a Finnish publisher launched Hietikko's nonfiction work Management by Sauron - The Lord of the Rings Guide to Leadership, a guidebook on the practicalities of working life and leadership skills that draws on the characters and events of Tolkien's famous novel. In 2018, this work was also published in Germany by Franz Vahlen.

Citation: Einola, S., Kohtamäki, M. \& Hietikko, H. 2019. Open Strategy in a Smart City. Technology Innovation Management Review, 9(9): 35-43.

http://doi.org/10.22215/timreview/1267

Keywords: Strategy-as-practice (SAP), open strategy, crowdsourcing in open innovation, sociomaterial strategy tools, participative strategy process, smart city. 


\title{
World Heritage meets Smart City in an Urban- Educational Hackathon in Rauma
}

\author{
Anu Helena Suominen, Seija Halvari, Jari Jussila
}

\author{
" The world as we have created it is a process of our thinking. It \\ cannot be changed without changing our thinking." \\ Albert Einstein \\ Nobel Prize in Physics (1921)
}

\begin{abstract}
UNESCO World Heritage cities can become smart cities if they take into account their cultural heritage and integrate diverse actors, including universities in their innovation practices. This article addresses the hackathon as an innovation contest method in the urban and educational context. Specifically, it concentrates on hackathon design, particularly the focus of the event, as well as the outputs. Although the design plays an integral part in a hackathon, particularly in goal achievement, design has not yet been thoroughly studied in mainly descriptive hackathon research. To address the subject, this article presents a case study of a dual-focused, i.e., combined urban and educational hackathon in the City of Rauma, which has a World Heritage Old Town that aims to integrate its historical uniqueness with modern city services. As a result, the article portrays the process and outputs of a hackathon carried out with the collaboration of two higher education institutions (HEIs) and the Entrepreneur Association of Rauma. Presenting conclusions for both academics and the public sector, the article contributes to the literature on urban and educational hackathons in smart cities with a heritage context.
\end{abstract}

\section{Introduction}

During recent years, the 'smart city' concept has emerged in literature (e.g., Kunttu, 2019; Markkula \& Kune, 2018; Öberg, Graham, \& Hennelly, 2017; Visvizi \& Lytras, 2018). Inherently, the smart city concept includes urban innovation; therefore, simply developing and applying technology is not enough for success. For cities to be 'smart,' they also have to be innovative, apply new ways of thinking among businesses, citizens, and academia, as well as integrate diverse actors, especially universities, in their innovation practices (Kunttu, 2019; Markkula \& Kune, 2018).

At their best, smart cities incorporate two views: technology and people. People are the biggest challenge, since what is required is the creation of an open mindset and a participatory attitude toward rethinking the future (Mulder, 2014). When properly managed, cultural heritage may enhance the livability of the surrounding areas and sustain productivity (Roders \& van Oers, 2011). Thus, inhabited UNESCO World Heritage cities can also become smart only if they take their cultural heritage into account in their smart city concept and integrate diverse actors, including universities, in their innovation practices. Thus, there is a need for participatory methods that would bring together multiple stakeholders, especially universities, to innovate the smart future of inhabited urban cities with invaluable cultural heritage.

As a participatory method, hackathons, provide a promising methodology and have spread from IT to other sectors. Hackathons are used in education, the corporate sector, and by city organizations, for example, as an innovative exploration method for idea generation, selection, and prototyping (Granados \& ParejaEastaway, 2019; Pe-Than et al., 2019). Hackathons as a type of innovation contest have been defined as "a short bounded-time event of creation and ceremony processes of innovation, carried out in radical collocation and coopetition of teams to solve a challenge" (Halvari et al. 2019, p. 12). The public sector has also used innovative methods in so-called civic hackathons (e.g., Almirall, Lee, \& Majchrzak, 2014) and urban hackathons (e.g., Pogačar \& Žižek, 2016).

However, hackathon design elements and their effects 


\title{
World Heritage meets Smart City in an Urban-Educational Hackathon in Rauma
}

\author{
Anu Helena Suominen, Seija Halvari \& Jari Jussila
}

on event goal achievement is still under-researched (PeThan et al., 2019). This article studies hackathon design elements, the event process, and its outputs, particularly from the viewpoint of one hackathon design element, i.e. focus. We aim to clarify how hackathons are designed with multiple foci, especially the dual focus of urban-educational hackathons, to derive set goals. The study describes a case in the Finnish UNESCO World Heritage town of Rauma, with a student group of higher education institutions (HEIs) participating in a hackathon in the city context generating novel ideas. The event did not involve coding.

Our research questions are:

What kind of process and practises did a hackathon event, designed with a dual-focus, i.e., combined educational-urban hackathon, consist of?

What kind of output did a combined educationalurban hackathon achieve in terms of its dual-focus and goal setting?

In the pursuit of our research aims, the article is structured as follows. In the introduction, we first acknowledge the need to study the hackathon with a multiple focus in the educational and urban context. In the second section, the literature regarding smart cities and hackathons is discussed. The method and case description involve the presentation of, as well as grounds for, an empirical case study with students innovating in the smart city context. In the results, we describe the process and innovation outputs of a dualfocus hackathon. In the conclusions, we contemplate the results of a multi-focus, educational-urban hackathon in a smart city with a heritage context, and its significance to innovation methodology.

\section{Smart Cities and Hackathons}

\section{Smart city concept}

During recent years, the 'smart city' concept has emerged in the literature. A smart city may refer to a city as a geographical location, or as a municipal administration (Öberg et al., 2017), and the concept has been used in contexts ranging from megacities, with total populations of 10 million people or more, to a town or a village (Visvizi \& Lytras, 2018). Dameri (2013, p. 2549) defines a smart city as: “a well-defined geographical area, in which high technologies such as ICT, logistics, energy production, and so on, cooperate to create benefits for citizens in terms of well-being, inclusion and participation, environmental quality, intelligent development; it is governed by a well-defined pool of subjects, able to state the rules and policy for the city government and development." However, some cities that were established some time ago and have preserved their cultural heritage are listed as UNESCO World Heritage cities.

There are three types of heritage cities: 1) towns that are no longer inhabited, i.e., urban archaeological sites such as Palmyra in Syria, 2) inhabited historic towns, such as Djenne in Mali, Macau in China, and 3) new towns of the twentieth century, such as Brasilia in Brazil (Roders \& van Oers, 2011). Naturally, the inhabited cities must strike a balance between their heritage and the urban demands of their inhabitants and visitors. Yet, acknowledging the cultural heritage and including it in the smart city concept, World Heritage cities can also be smart cities. According to Ojasalo and Kauppinen (2018), urban innovation is at the heart of the smart city concept. Moreover, "the 'smartness' of a region relates to its capacity to leverage its human, structural, and relational capital, and its ability to integrate diverse actors in the region's innovation practice." (Markkula \& Kune 2018, p. 7) At best, a smart city combines two worlds: it is people-centered, values-active citizenship that embraces community-driven innovation, and is new technology-oriented. However, although participatory innovation is needed, the biggest challenges are the creation of an open mindset and a participatory attitude to rethink the future. (Mulder, 2014)

\section{Hackathon as an innovation contest}

Hackathons have their roots in programming in the 1960s (Leckart, 2012; Pe-Than \& Herbsleb, 2019; Zukin \& Papadantonakis, 2017). The current hackathon approach is a relatively novel one (Pe-Than et al., 2019), which focuses on the rapid and iterative development of small but scalable projects, and is considered a bottom-up approach (Chowdhury, 2018). The spread of the concept to other domains has caused proliferation (Angarita \& Nolte, 2019), but generally, hackathons are regarded as innovation contests (Hartmann, Mainka, \& Stock, 2019a), or competitions (Hartmann, Mainka, \& Stock, 2019b). Moreover, hackathons are regarded as innovation practices, which contribute to innovation in two ways: by promoting exploration activities, such as new external solutions, and by enhancing some preconditions of innovation, e.g., attracting talent or building a community of experts (Granados \& ParejaEastaway, 2019). In their conceptualization of the hackathon (Halvari et al., 2019), have identified the core attributes of hackathons. The first attribute is coopetition, i.e., simultaneous competition and 


\section{World Heritage meets Smart City in an Urban-Educational Hackathon in Rauma}

\section{Anu Helena Suominen, Seija Halvari \& Jari Jussila}

collaboration, which can exist on the organizational level as well as the individual, team, or network level (Bouncken, Gast, Kraus, \& Bogers, 2015). Besides competition, collaboration is an inherent characteristic of hackathons (Almirall et al., 2014; Briscoe \& Mulligan, 2014; Granados \& Pareja-Eastaway, 2019; Hartmann et al., 2019a, 2019b; Kienzler \& Fontanesi, 2017; Leckart, 2012; Pe-Than et al., 2019; Rosell, Kumar, \& Shepherd, 2014). Furthermore, hackathons are regarded as one of the most widespread collaborative practices (Granados \& Pareja-Eastaway, 2019). The second attribute is radical collocation, a situation where team members are together in a physical space for the duration of the project (Pe-Than et al., 2019; Pe-Than \& Herbsleb, 2019; Teasley, Covi, Krishnan, \& Olson, 2000). The concept of radical collocation also incorporates cooperation in teams. The third attribute is the hackathon's duration as an intense, short-term, time-bound event (Chowdhury, 2018; Kienzler \& Fontanesi, 2017; Lodato \& DiSalvo, 2015; Pe-Than et al., 2019; Pe-Than \& Herbsleb, 2019). As the fourth and fifth attributes, the hackathon event includes two processes: it starts with a creation process and is followed by a ceremony process (Halvari et al., 2019). The ceremony incorporates the presentation of the output with a pitch for example, as well as recognition of the results, sometimes including rewards ranging from non-monetary to monetary (Kienzler \& Fontanesi, 2017; Pe-Than et al., 2019). Hackathons have been adopted in many domains and for multiple usages besides only coding (Leckart, 2012; Zukin \& Papadantonakis, 2017): as an educational method (Porras et al., 2019), a way to crowdsource solutions (Gama, 2017), to find new potential employees (Komssi et al., 2015; Pe-Than \& Herbsleb, 2019), to attain public engagement and collaboration between citizens (Gama, 2017), the creation of prototypes, and possible new business formation (Komssi et al., 2015). As events, they yield learning, create new social connections, and have the potential to foster innovation.

The features of hackathons that cultivate creativity and innovation are: the diverse expertise and experience of participants; interruption-free and focused work hours; processes, goals, and management, which occur outside the usual constraints; opportunity to run a project, assess its feasibility, and uncover potential pitfalls with minimal risk to daily operations; and a chance for participants to work on something they are passionate about (Pe-Than et al., 2019). The entire hackathon process is divided into the pre-hackathon, the hackathon event itself, and post-hackathon processes (Granados \& Pareja-Eastaway, 2019; Komssi et al., 2015; Rosell et al., 2014), and as a process, hackathons have both inputs and outputs (Komssi et al., 2015). Due to its attributes, a hackathon event has particular design choices (Pe-Than et al., 2019), or design elements (Adamczyk, Bullinger, \& Möslein, 2012), such as focus, (e.g., educational, urban, civic, industrial), goals (e.g., learning, prototyping, problem solving), task setting (e.g., bounded or unbounded tasks of the event), participants, team formation, etc., which act as the hackathon event inputs. Team or group formation in educational events may occur as random selection and development, either by self-grouping, the educator's choice, or in addition, by applying specific criteria that can vary in terms of background, personality, ethnicity, and gender etc. (Dascalu, Bodea, Lytras, De Pablos, \& Burlacu, 2014).

\section{Issue-oriented, Urban and Civic hackathons}

Societal and environmental change together with the development of information technologies are changing urban planning. Pogačar and Žižek (2016) emphasize that today, due to the requirements of flexibility, usability, and openness in urban space, new alternative approaches to urban planning are emerging, especially in the context of urban renewal. Open data for strategic planning and day-to-day operations, as well as stakeholder involvement are both necessary (Pogačar and Žižek, 2016).

Corporate hackathons are considered to favor the production of technical solutions for business opportunities, whereas issue-oriented events put social questions at the centre, such as environmental conditions or food systems. Civic hackathons are regarded as one subset of issue-oriented hackathons, which focus on governance and public life. In civic hackathons, activists, citizens, entrepreneurs, and coders are drawn together to address social conditions and their consequences. (DiSalvo, Gregg, \& Lodato, 2014) Civic hackathons are open to the broad public and participation is via an accessible platform (Pogačar \& Žižek, 2016). Civic hackathons provide ad-hoc experiments in new conceptions of citizenship, with audience outputs and applications that envision citizenship. (DiSalvo et al., 2014) Pogačar \& Žižek (2016) consider urban hackathons as a form of civic hackathon, which use a similar approach in the field of urban development and renewal.

The focus of an urban hackathon is exclusively on the problems of the urban environment, acknowledging the importance of open data, public participation, and community collaboration. As with the general term of hackathon, there is also a proliferation in the use of civic hackathon as a term, but at their core, they are similar events of diverse groups of people, e.g., IT specialists, 


\section{World Heritage meets Smart City in an Urban-Educational Hackathon in Rauma}

\section{Anu Helena Suominen, Seija Halvari \& Jari Jussila}

communicators, community organizers, other specialists, and activists creatively and collaboratively contributing to problem solving in the domain. Similarly, as with general hackathons, civic hackathons vary in focus, event format, topics, and approaches (Pogačar \& Žižek, 2016). In the view of Pogačar and Žižek, the aim of urban hackathons may range from pure coding to "decision making, generating public initiatives with concrete proposals, compiling document drafts with solid argumentation based on open data and strategic foresight, etc." (Pogačar \& Žižek 2016, p. 1973). In the literature, both positive and negative views have been presented regarding civic hackathons. The positive aspects are the output of valuable open data crowdsourced apps with the investment of prizes and publicity. The utility and quality of the apps, and the hackathon process or scope have received criticism, yet this is mostly based on anecdotal evidence, and rigorous empirical evidence on the claims has not been found. However, it has been verified that the developers' experience affects the requirements and compromises the utility and relevance of applications (Gama, 2017). Many researchers neveretheless point out that the research on civic hackathons is scarce and limited, hence evidence of hackathon outputs is also scarce. Therefore, more research is needed to assess the impacts, outcomes, and value of their deployment, as well as the stakeholders that derive value from them (Gama, 2017; Johnson \& Robinson, 2014). This suggests that one simple way to measure value is through descriptive statistics surrounding contest inputs and outputs (Johnson \& Robinson, 2014).

\section{Methods and Case Description}

We chose the case study approach (e.g., Siggelkow, 2007) to study the innovation contest of a hackathon with a dual educational and urban focus. In our case study, the theory of smart cities and hackathons was identified via literature. Next, a single case study was carried out in 2018 using action research methodology in an educational hackathon where urban issues were innovated in Rauma, a town of 39,360 inhabitants in Finland (Statistics Finland, 2018). The town of Rauma was established in 1442, and the Old Town of Rauma with its wooden buildings received UNESCO World heritage status in 1991. The participants of the hackathon were students from one Research, Development and Innovation (RDI) class in an HEI, majoring in either technical or business subjects. The research material consisted of field notes of observations made before, during, and after the hackathon. The hackathon was arranged in collaboration between two HEIs and the Entrepreneur Association of Rauma.
The purpose of the empirical research was to study a hackathon with the dual focus of a combined educational and urban hackathon, its design, process, and outputs. The hackathon concerned the development needs of a city with an inhabited cultural heritage, i.e., Old Rauma, with the new commercial centre planned in the proximity. The case was chosen due to its idiosyncrasy: there are only a few descriptive reports on hackathons with multiple foci, firstly in an educational context, and secondly in the context of smart cities with cultural heritage where innovation is carried out beyond coding. Therefore, the case is interesting for theory building regarding the hackathon type of innovation contest, as a way to enhance innovation management within both HEIs and cities.

\section{Results of the Case Study}

\section{Hackathon with dual focus in Rauma}

When the observed hackathon is described in terms of attributes and themes (Table 1), the dual focus of the hackathon is revealed. It has the training elements of an educational hackathon, yet the task setting is aimed at solving urban issues.

\section{Hackathon process}

Figure 1 describes the entire hackathon process in three phases: pre-hackathon, hackathon event itself, and posthackathon. In the pre-hackathon phase, the design elements were planned according to the focus of the hackathon. Due to the dual focus, both educational and urban hackathon characteristics had to be taken into account in the pre-hackathon phase design. As the focus was two-fold: educational and urban, likewise the goals of the hackathon were dual. They were to, 1) produce learning of innovation, and, 2) yield innovations that benefit the city aiming to combine its World Heritage with its urban needs.

As an educational hackathon, learning elements had to be incorporated. Since the hackathon event duration was designed to be short, training for the participants was provided in the pre-hackathon phase via innovation lectures and short video clips of four creative methods prepared by lecturers. The four creative methods presented were: 1) Transformation technique (Cross, 2008), 2) Synectics with fantasy analogies (Cross, 2008), an analogy method which is particularly a type of the distant analogy method, 3) Trace matrix for business chains (Kärkkäinen, Piippo, \& Tuominen, 2001), which helps to describe complex business chains and trace back requirements for the company from even a remote customer's stakeholders and trends, and 4) a novel 3+1 


\title{
World Heritage meets Smart City in an Urban-Educational Hackathon in Rauma
}

\author{
Anu Helena Suominen, Seija Halvari \& Jari Jussila
}

Table 1. The Old Rauma Hackathon presented with hackathon concept attributes and themes

\begin{tabular}{|c|c|c|c|}
\hline \multicolumn{4}{|c|}{ Old Rauma Hackathon } \\
\hline Theme & & Attribute & Old Rauma Case \\
\hline \multirow[t]{4}{*}{ Coopetition } & 1 & Team & $\begin{array}{l}\text { - } 2 \text { teams with } 4 \text { participants, } 1 \text { team with } 3 \text { participants: total } 3 \text { teams } \\
\text { with } 11 \text { participants }\end{array}$ \\
\hline & 2 & Challenge & $\begin{array}{l}\text { - To create ideas for Old Rauma to add value to its users with a new } \\
\text { commercial centre to be built in the proximity } \\
\text { - To learn innovation methods }\end{array}$ \\
\hline & 3 & $\begin{array}{l}\text { Creation } \\
\text { process }\end{array}$ & $\begin{array}{l}\text { - Background information from an Old Rauma entrepreneur who is the } \\
\text { chairman of The Entrepreneur Association of Rauma } \\
\text { - Innovation exercises used for drafting the final ideas } \\
\text { - Pitching exercise } \\
\text { - Team formation } \\
\text { - Continual Ideation process }\end{array}$ \\
\hline & 4 & $\begin{array}{l}\text { Ceremony } \\
\text { process }\end{array}$ & $\begin{array}{l}\text { - Idea pitching by each group } \\
\text { - Jury: comments on each presentation } \\
\text { - Winner: voting by each participant based on pre-defined criteria }\end{array}$ \\
\hline \multirow{2}{*}{$\begin{array}{r}\text { Radical } \\
\text { Collocation }\end{array}$} & 5 & Collaboration & $\begin{array}{l}\text { - Participants/teams: Students } \\
\text { - Organizers: } 2 \text { HEIs in cooperation } \\
\text { - Domain: Entrepreneur Association }\end{array}$ \\
\hline & 6 & $\begin{array}{l}\text { Collocation } \\
\text { Consistency }\end{array}$ & $\begin{array}{l}\text { - Public library in close proximity of Old Rauma } \\
\text { - Coffee/tea and fruits as a complimentary snack } \\
\text { - Intensive and consistent }\end{array}$ \\
\hline $\begin{array}{r}\text { Short time- } \\
\text { bounded event }\end{array}$ & 8 & $\begin{array}{l}\text { Short } \\
\text { duration }\end{array}$ & $\begin{array}{l}\text { - Duration } 10 \text { hours + preliminary innovation exercise, as well as reading } \\
\text { and report writing after the event }\end{array}$ \\
\hline
\end{tabular}

method, where an idea is examined via four views (Suominen, Jussila, Lundell, Mikkola, \& AramoImmonen, 2018). Training sessions were also provided during the event, i.e., there was a pitch training, an 'Idea Walk' (Slåen, Mantere, Tollet, \& Karisto, 2003), and an 'Open Space', which were designed in the prehackathon phase. The event was designed to be held in the facilities of the Rauma public library. This location was chosen due to its close proximity to Old Rauma, and the library's open and free space, which provides both concrete and online knowledge that manifests the 'smart city' activities. The participants were predetermined as they were students of one HEI's RDIcourse. The students participating were from various cities outside Rauma, and were mostly unfamiliar with each other prior to the event. Both the team formation and sizes were voluntary, and team formation was designed to occur during the hackathon event.

In the event phase, the hackathon started with innovation exercises, a warm-up and pitch training with the NABC model (Carlson \& Wilmot, 2006). The aim of this was to allow the participants to get to know each other, while embarking on the ideation process. Team formation was merged into the innovation exercises, and team sizes were voluntarily formed. The goal setting aimed at fulfilling the domain's real-life need to make Old Rauma more viable. As the participants were students, the set task was bounded.

Background information for the task was given by the Chairman of the Rauma Entrepreneur Association, who has been an entrepreneur in Old Rauma for four decades. He described the urban challenges of a World Heritage city with the modern needs of inhabitants and visitors. As the main challenges, he listed the change of generations, the revolution in retail, digitalization and e-commerce, and a changing environment. Thereafter, the task was described by the organizing HEI lecturers as follows:

What kind of solution for Rauma city centre would produce added value for some user group? Or, Develop a novel solution that would create value for some user groups of the city centre of Rauma. The solution may be physical, intangible, digital, or a combination. 


\section{World Heritage meets Smart City in an Urban-Educational Hackathon in Rauma}

\section{Anu Helena Suominen, Seija Halvari \& Jari Jussila}

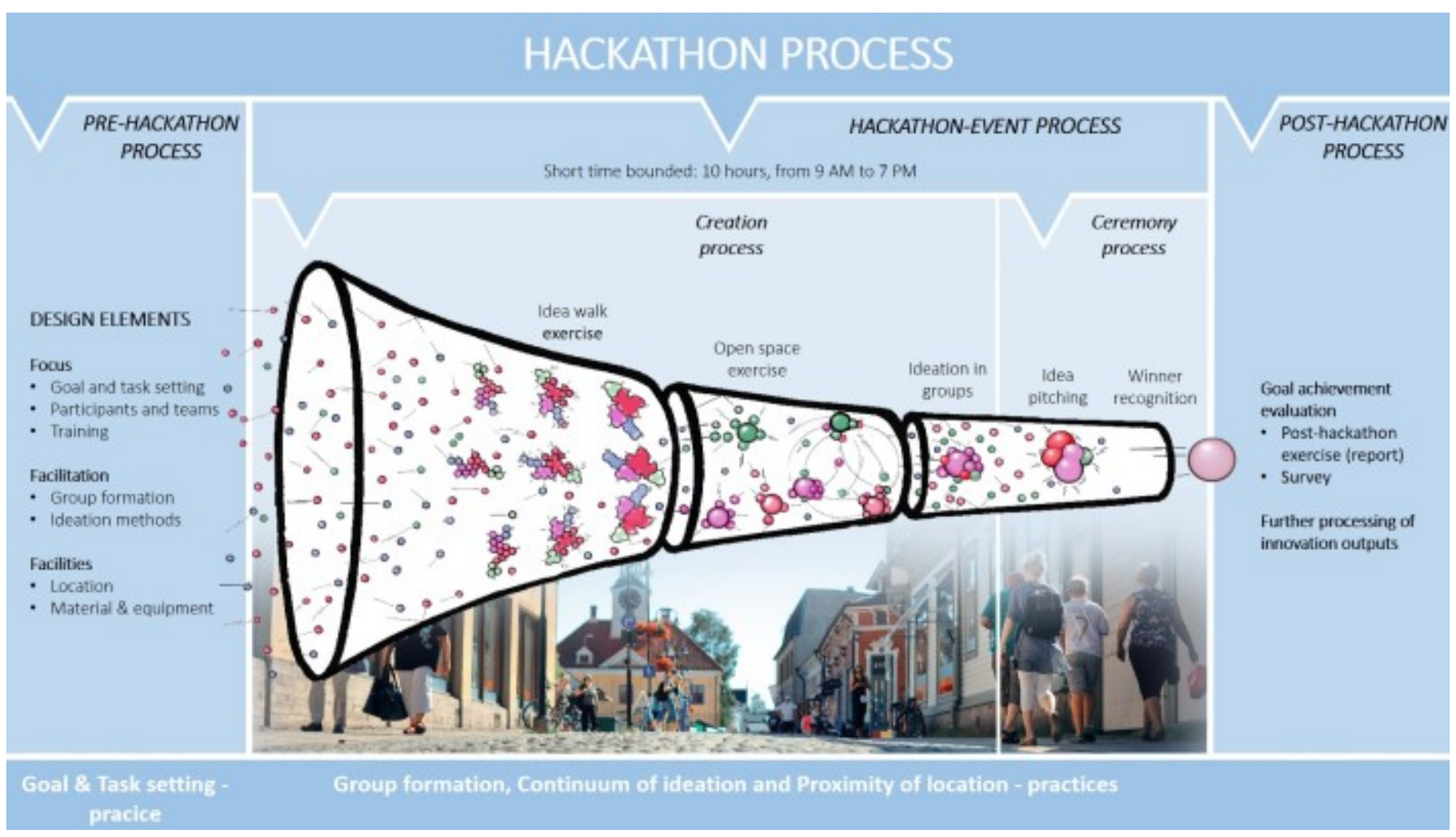

Figure 1. Hackathon process

The creation process started with the Idea Walk. The Idea Walk method is a version of brainstorming, where ideation is carried out individually or in small groups. The aim of an Idea Walk is to support the broadening of views, and to yield as many approaches toward the problem as possible. The hackathon's Idea Walk started with large empty sheets, each of which had a different topic, such as possibilities, threats, and potential users. Each participant wandered around to the sheets, and added their ideas on top of others'. The method produced lots of ideas, which were grouped, without evaluation, and presented to all of the participants, as well as left on display for inspiration during the event. The Idea Walk produced seven idea areas (Table 2), and was followed by using the Open Space method, where voluntary students presented their idea and invited others to join their team. Initially, four teams formed in the Open Space period. Yet only two teams joined forces in the end, after students were able to discuss all of the presented topics. Thus, the essence of these event methods is self-direction. In the Open Space, the students discussed five ideas (Table 2). After the Open Space, the Rauma hackathon continued with three teams working towards their final solutions.

The work on the hackathon task was then continued with the possibility for facilitation and mentoring with the lecturers. The students had three hours to work on their solutions. Some students used the opportunity to do a walkabout in Old Rauma, and test their ideas in an authentic environment. The celebration process was started three hours later, after the participants returned

Table 2. The ideas results of Idea Walk and Open Space ideations

\begin{tabular}{lc}
\hline Idea Walk ideas & Open Space ideas \\
\hline 1. User segments and their services & 1. Glass-topped walking area \\
2.\& 3. Threats and Opportunities of the area & 2. Transportation portal \\
4. Reasons for people to gather in certain areas & 3. City walking tour with an app \\
$\begin{array}{l}\text { 5. Technology for value creation } \\
\text { 6. Needs to be satisfied }\end{array}$ & $4 . \quad$ Community and collaborational mass \\
7. Organizations to benefit from the area & 5. Pop-up days \\
\hline
\end{tabular}




\section{World Heritage meets Smart City in an Urban-Educational Hackathon in Rauma}

\section{Anu Helena Suominen, Seija Halvari \& Jari Jussila}

to the library to pitch their ideas to a three-person jury, with two members from the Entrepreneur Association and one observing lecturer. The length of the pitch was a maximum of three minutes. After the pitches, each of the groups collected a small reward, and the winning team received a gift card for a restaurant located in Old Rauma. In the post-hackathon phase, the student teams produced a report, which was then evaluated by the lecturers, as part of the educational hackathon goal was learning. Furthermore, a post-hackathon survey was prepared by the lecturers and filled in by the students right after the event. Moreover, a summary of the event and its outputs was delivered to the Rauma Entrepreneur Association, although a follow-up of the later process of innovation outputs is beyond the scope of this study.

\section{Hackathon design elements driven practices}

As various hackathon events include design elements, these elements require also practices to be applied from the hackathon organizer viewpoint, since they may enhance the hackathon's success (Figure 1). There are at least four essential general practices that were identified during the Urban-Educational hackathon case:

1. Goal and task-setting practices include the specification of the hackathon's goals, and furthermore the task or tasks the hackathon aims to address.

2. Ideation continuum practices signify the benefits of design thinking throughout the hackathon process from pre-hackathon to post-hackathon phases. Thus, the tasks and the exercises do not appear unattached, but rather flow in a way that constitutes a solid experience to the participant.

3. Team formation practices incorporate social learning among participants and their various characteristics, thus choosing the most beneficial team formation method for the event.

4. Forming a proximity of location means that the object of the hackathon, e.g. a city aiming at getting 'smarter', should be familiarized to the participants with physical, mental or spiritual artifacts.

\section{Hackathon outputs}

The three student groups generated different conceptual innovations. Two of the innovations were technological, combining service product concepts, and the third combined logistics and service concepts.

\section{Conclusions}

This article contributes to the literature of innovation management methods, particularly to the concept and method of the hackathon as an innovation contest. More specifically, by responding to the call by Pe-Than et al. (2019) to study different design elements and their effectiveness with respect to the intended event goals, this article contributes to the design of dual-focus hackathons, combining educational and urban hackathons, and their innovation outputs. By answering our first research question, "What kind of process and practices did a hackathon event, designed with a dualfocus, i.e. combined educational-urban hackathon, consist of?", we contribute by describing the process and design elements of a dual-focus hackathon, which aimed at both learning, and the creation of innovations to benefit the city in question.

As an educational hackathon, the hackathon process was designed to include training both in the prehackathon phase, as well as in the hackathon event itself, and additionally during the event with coaching. As an urban hackathon, the task was set for a city domain, aiming to create value-adding solutions for the city centre users, either physical, intangible, digital, or a combination of them. Therefore, our results add to the previous studies of general, civic, and urban hackathons by Almirall et al. (2014), Granados and Pareja-Eastaway (2019), Komssi et al. (2015), Pogačar and Žižek (2016), and Rosell et al. (2014), by clarifying the significance that the hackathon design element of focus, and especially

Table 3. The three innovations generated in the educational-urban hackathon in Rauma

\begin{tabular}{lll}
\hline Generated innovations & Innovation type \\
\hline 1. & $\begin{array}{l}\text { Smartphone application } \\
\text { Displays entertainment in Rauma e.g., events, restaurants } \\
\text { with their menus, hotels, and shopping opportunities. }\end{array}$ & $\begin{array}{l}\text { Combines technology and service product } \\
\text { concept innovation }\end{array}$ \\
2. $\begin{array}{l}\text { Gamified smartphone application built on Rauma map } \\
\text { The application would apply augmented reality, including } \\
\text { stories and games of local historical events. }\end{array}$ & $\begin{array}{l}\text { Combines technology and service concept } \\
\text { product innovation }\end{array}$ \\
3. Non-stop electric bus route \& gateway & $\begin{array}{l}\text { Connects Old Rauma with rest of the city. Improves the Old } \\
\text { Rauma entry with a prestige gateway }\end{array}$ & innovation \\
\hline
\end{tabular}




\section{Anu Helena Suominen, Seija Halvari \& Jari Jussila}

dual-focus, has on the goals and process of the hackathon event.

In addition, we identified four practices that are connected to and driven by hackathon design elements: 1) Goal and task-setting, 2) Formation of the ideation continuum, 3) Team formation, and 4) Forming the proximity of location. From the organizer viewpoint, at least these four practices should be adopted while designing an Educational-Urban hackathon, since they may enhance the hackathon's success. Moreover, this article responds to the call for more research to assess the impacts and outcomes of hackathons by Gama (2017), and Johnson and Robinson (2014). By answering our second research question, "What kind of output did a combined educational-urban hackathon achieve in terms of its dual focus and goal setting?", we make a contribution by presenting the three urban innovation outputs generated by the students of an RDI course during a hackathon. The outputs were two different smartphone application concepts, as well as one logistics and service concept. Therefore, our results add to the previous civic and urban hackathon studies by Lodato and DiSalvo (2015) and Pogačar and Žižek (2016), particularly by describing a generated urban innovation output. Secondly, the results consolidate the view of Pogačar and Žižek (2016) that urban hackathons have moved away from pure coding, toward concrete proposals.

In general, scientific research on hackathons is scarce and mainly descriptive, concerning software solutions and applications. According to Pe-Than et al. (2019), the study of hackathon design elements in particular is practically non-existent. Our results showed that hackathons could have a dual focus, and thus multiple goals. Therefore, we believe educational and urban hackathons can be combined to produce multiple goals. However, in task setting, both of these focuses have to be considered when designing the event.

Firstly, with students as participants, innovation training is an important part of the event design, in order to achieve the targeted learning outcome. Secondly, when the goal is to achieve urban innovations that truly benefit the city domain, the task should be bounded in order to gain innovations with the targeted level of sophistication. Yet, just as students used their education and knowledge to create innovations, the hackathon as a method could very well also be adopted in city collaboration with the public. Taking into account the fact that participants may have various backgrounds and carefully designing the task accordingly, it would be more likely that public output could achieve the goals set by the city.

Our hackathon case was carried out in the context of an inhabited World Heritage city, which aims to stay competitive in face of challenges from modern urban cities. Therefore, our results benefit both lecturers in HEIs teaching innovation, as well as cities aiming to collaborate with HEIs for urban innovation. Our results present an encouraging example for other cities to use participatory methods, such as hackathons, especially dual-focus educational-urban hackathons, in collaboration with HEIs to generate not only learning, but also usable urban innovations. Therefore, our results give a vivid example of how cities can integrate universities in particular into their innovation practices, as suggested by Kunttu (2019), and Markkula and Kune (2018), using the hackathon method. From an innovation management standpoint, having functioning methods for innovation, and especially idea generation and evaluation, is an essential feature of teaching and utilizing innovation in various domains. Thus, we claim that the dual-focus educational-urban hackathon, when designed properly, is a practical functioning method for cities aiming at urban innovations and smart city development. 


\section{World Heritage meets Smart City in an Urban-Educational Hackathon in Rauma}

\section{Anu Helena Suominen, Seija Halvari \& Jari Jussila}

\section{References}

Adamczyk, S., Bullinger, A. C., \& Möslein, K. M. 2012. Innovation Contests: A Review, Classification and Outlook. Creativity and Innovation Management, 21(4): 335-360.

Almirall, E., Lee, M., \& Majchrzak, A. 2014. Open innovation requires integrated competitioncommunity ecosystems: Lessons learned from civic open innovation. Business Horizons, 57(3): 391-400.

Angarita, A. M. M., \& Nolte, A. 2019. Does it matter why we hack? -Exploring the impact of goal alignment in hackathons. Proceedings of the 17th European Conference on Computer- Supported Cooperative Work: The International Venue on Practice-centred Computing and the Design of Cooperation Technologies - Exploratory Papers, Reports of the European Society for Socially Embedd, 1-15.

Bouncken, R. B., Gast, J., Kraus, S., \& Bogers, M. 2015. Coopetition: a systematic review, synthesis, and future research directions. Review of Managerial Science, 9(3): 577-601.

Briscoe, G., \& Mulligan, C. 2014. Digital Innovation: The Hackathon Phenomenon. Creativeworks London, (6): $1-13$.

Carlson, C.R., \& Wilmot, W. W. 2006. Innovation: the five disciplines for creating what customers want. Crown Business.

Chowdhury, J. 2018. Hacking Health: Bottom-up Innovation for Healthcare. Technology Innovation Management Review, 2(7): 31-35.

Cities - Organization of World Heritage Cities. n.d.. https://www.ovpm.org/cities/, May 21, 2019.

Cross, N. 2008. Engineering design methods: Strategies for product design (4th ed.).

https://doi.org/10.1016/0261-3069(95)90023-3.

Dameri, R. P. 2013. Searching for Smart City definition: a comprehensive proposal. International Journal of Computers \& Technology, 11(5): 2544-2551.

Dascalu, M. I., Bodea, C. N., Lytras, M., De Pablos, P. O., \& Burlacu, A. 2014. Improving e-learning communities through optimal composition of multidisciplinary learning groups. Computers in Human Behavior, 30: 362-371.

DiSalvo, C., Gregg, M., \& Lodato, T. 2014. Building belonging. Interactions, 21(4): 58-61.

Gama, K. 2017. Preliminary ndings on Software Engineering Practices in Civic Hackathons. IEEE 4th International Workshop on CrowdSourcing in Software Engineering (CSI-SE), 14-20.

Granados, C., \& Pareja-Eastaway, M. 2019. How do collaborative practices contribute to innovation in large organisations? The case of hackathons. Innovation, 00(00): 1-19.

Halvari, S., Suominen, A., Jussila, J., Jonsson, V., \& Bäckman, J. 2019. Conceptualization of hackathon for innovation management. The ISPIM Innovation Conference - Celebrating Innovation: 500 Years Since daVinci. ISPIM.
Hartmann, S., Mainka, A., \& Stock, W. G. 2019a. Innovation contests: how to engage citizens in solving urban problems? Civic engagement and politics: concepts, methodologies, tools, and applications: 58-77. IGI Global.

Hartmann, S., Mainka, A., \& Stock, W. G. 2019b. Opportunities and Challenges for Civic Engagement: A Global Investigation of Innovation Competitions. Civic engagement and politics: concepts, methodologies, tools, and applications: 607-623.

Johnson, P., \& Robinson, P. 2014. Civic Hackathons: Innovation, procurement, or civic engagement? Review of Policy Research, 31(4): 349-357.

Kärkkäinen, H., Piippo, P., \& Tuominen, M. 2001. Ten tools for customer-driven product development in industrial companies. International Journal of Production Economics, 69: 161-176.

Kienzler, H., \& Fontanesi, C. 2017. Learning through inquiry: a Global Health Hackathon. Teaching in Higher Education, 22(2): 129-142.

Komssi, M., Pichlis, D., Raatikainen, M., Kindstrom, K., Jarvinen, J., et al. 2015. What are Hackathons for? IEEE Software, 32(5): 60-67.

Kunttu, I. 2019. Developing smart city services by mobile application. ISPIM Florence Conference Proceedings.

Leckart, S. 2012. The Hackathon Is On: Pitching and Programming the Next Killer App. Wired. https://www.wired.com/2012/02/ff_hackathons/.

Lodato, T.J., \& DiSalvo, C. 2015. Issue-oriented hackathons as material participation. New Media and Society, 18(4): 539-557.

Markkula, M., \& Kune, H. 2018. Making Smart Regions Smarter: Smart Specialization and the Role of Universities in Regional Innovation Ecosystems. Technology Innovation Management Review, 5(10): $7-15$.

Mulder, I. 2014. Sociable Smart Cities: Rethinking Our Future through Co-creative Partnerships. In N. Streitz \& P. Markopoulos (Eds.), Distributed, ambient, and pervasive interactions: Sedonc international conference, DAPI 2014 held as part of Heraklion, Crete, Greece, June 22-27, 2014, 566-574. Springer.

Öberg, C., Graham, G., \& Hennelly, P. 2017. Smart cities: A literature review and business network approach discussion on the management of organisations. IMP Journal, 11(3): 468-484.

Ojasalo, J., \& Kauppinen, H. 2018. Collaborative Innovation with External Actors: An Empirical Study on Open Innovation Platforms in Smart Cities. Technology Innovation Management Review, 6(12): $49-60$.

Pe-Than, E. P. P., \& Herbsleb, J. D. 2019. Understanding Hackathons for Science: Collaboration, Affordances, and Outcomes. In N. G. Taylor, C. Christian-Lamb, M. H. Martin, \& B. Nardi (Eds.), Information in Contemporary Society, Proceedings of 14th International Conference, iConference, 27-37. Washington, DC, USA: Springer. 


\section{World Heritage meets Smart City in an Urban-Educational Hackathon in Rauma}

\section{Anu Helena Suominen, Seija Halvari \& Jari Jussila}

Pe-Than, E. P. P., Nolte, A., Filippova, A., Bird, C., Scallen, S., et al. 2019. Designing Corporate Hackathons With a Purpose. IEEE Software, (January): $15-22$.

Pogačar, K., \& Žižek, A. 2016. Urban Hackathon Alternative Information Based and Participatory Approach to Urban Development. Procedia Engineering, 161: 1971-1976.

Porras, J., Knutas, A., Ikonen, J., Happonen, A., Khakurel, J., et al. 2019. Code camps and hackathons in education-literature review and lessons learned. Proceedings of the 52nd Hawaii International Conference on System Sciences, 7750-7759.

Roders, A. P., \& van Oers, R. 2011. World Heritage cities management. Facilities, 29(7): 276-285.

Rosell, B., Kumar, S., \& Shepherd, J. 2014. Unleashing innovation through internal hackathons. Digest of Technical Papers - InnoTek 2014: 2014 IEEE Innovations in Technology Conference. https://doi.org/10.1109/InnoTek.2014.6877369.

Siggelkow, N. 2007. Persuation with Case Studies. Academy of Management Journal, 50(1): 20-24.

Slåen, T., Mantere, V., Tollet, L., \& Karisto. 2003. Opera: a guide for more efficient meetings. Innotiimi. https://books.google.fi/books/about/Opera.html?id= h78zAwAACAAJ\&redir_esc=y.

Statistics Finland. 2018. Population, Statistics Finland.

Suominen, A. H., Jussila, J., Lundell, T., Mikkola, M., \& Aramo-Immonen, H. 2018. Educational Hackathon: Innovation Contest for Innovation Pedagogy. In I. Bitran, S. Conn, K. R. E. Huizingh, O. Kokshagina, M. Torkkeli, et al. (Eds.), XXIX ISPIM Conference "The Name of the Game." Stockholm.

Teasley, S., Covi, L., Krishnan, M. S., \& Olson, J. S. 2000. How does radical collocation help a team succeed? $A M C$ conference on CSCW 2000, 339-346. Philadelphia, PA, USA.

Visvizi, A., \& Lytras, M. D. 2018. Rescaling and refocusing smart cities research: from mega cities to smart villages. Journal of Science and Technology Policy Management, 9(2): 134-145.

Zukin, S., \& Papadantonakis, M. 2017. Hackathons as Co-optation Ritual: Socializing Workers and Institutionalizing Innovation in the "New" Economy. Precarious Work.

https://doi.org/http://dx.doi.org/10.1108/VINE-102013-0063.

\section{About the Authors}

Anu Helena Suominen, D.Sc. (Tech.), is a university teacher at Tampere University, Finland. She defended her doctoral thesis on legitimacy building in inter-organizational networks in 2017. Besides working for years in the field of research and education, Anu has several years of practical working experience in industry: in export, managing networking, and training projects. Anu is responsible for teaching four Master's level courses in Knowledge Management, Innovation, Procurement, and Project Business Management. Her research is currently focused on hackathons for both industrial and educational purposes, knowledge sharing and integration, and innovation in inter-organizational networks.

Seija Halvari, M.Sc. (Tech.) and B.Eng., is a lecturer in Häme University of Applied Sciences (HAMK). Her research has focused on startup companies' business model evolution and innovations. In addition, she has studied hackathons in an industrial and educational context. Seija has a strong industrial background and over a decade of experience in external and internal project management in various positions, together with experience in IT systems and business process improvement.

Dr. Jari Jussila holds a $\mathrm{PhD}$ in Knowledge Management from Tampere University of Technology (TUT, 2015). At present, he is Principal Research Scientist at Häme University of Applied Sciences (HAMK). His research is currently focused on knowledge management, business intelligence, social media, big social data analytics, and health informatics. His works have been published in such international journals as Computers in Human Behavior, Industrial Management \& Data Systems, International Journal of Knowledge Management, and Knowledge Management Research \& Practice.

Citation: Suominen, A.H., Halvari, S. \& Jussila, J. 2019 World Heritage meets Smart City in an Urban-Educational Hackathon in Rauma. Technology Innovation Management Review, 9(9): 44-53.

http://doi.org/10.22215/timreview/1268/

(cc) BY

Keywords: Innovation contest, Hackathon, Urban

hackathon, Educational hackathon, Smart city 


\section{Author Guidelines}

These guidelines should assist in the process of translating your expertise into a focused article that adds to the knowledge resources available through the Technology Innovation Management Review. Prior to writing an article, we recommend that you contact the Editor to discuss your article topic, the author guidelines, upcoming editorial themes, and the submission process: timreview.ca/contact

\section{Topic}

Start by asking yourself:

- Does my research or experience provide any new insights or perspectives?

- Do I often find myself having to explain this topic when I meet people as they are unaware of its relevance?

- Do I believe that I could have saved myself time, money, and frustration if someone had explained to me the issues surrounding this topic?

-Am I constantly correcting misconceptions regarding this topic?

- Am I considered to be an expert in this field? For example, do I present my research or experience at conferences?

If your answer is "yes" to any of these questions, your topic is likely of interest to readers of the TIM Review.

When writing your article, keep the following points in mind:

- Emphasize the practical application of your insights or research.

- Thoroughly examine the topic; don't leave the reader wishing for more.

- Know your central theme and stick to it.

- Demonstrate your depth of understanding for the topic, and that you have considered its benefits, possible outcomes, and applicability.

- Write in a formal, analytical style. Third-person voice is recommended; first-person voice may also be acceptable depending on the perspective of your article.

\section{Format}

1. Use an article template: .doc .odt

2. Indicate if your submission has been previously published elsewhere. This is to ensure that we don't infringe upon another publisher's copyright policy.

3. Do not send articles shorter than 2000 words or longer than 5000 words.

4. Begin with a thought-provoking quotation that matches the spirit of the article. Research the source of your quotation in order to provide proper attribution.

5. Include an abstract that provides the key messages you will be presenting in the article.

6. Provide a 2-3 paragraph conclusion that summarizes the article's main points and leaves the reader with the most important messages.

7. Include a 75-150 word biography.

8. List the references at the end of the article.

9. If there are any texts that would be of particular interest to readers, include their full title and URL in a "Recommended Reading" section.

10. Include 5 keywords for the article's metadata to assist search engines in finding your article.

11. Include any figures at the appropriate locations in the article, but also send separate graphic files at maximum resolution available for each figure. 
Issue Sponsor

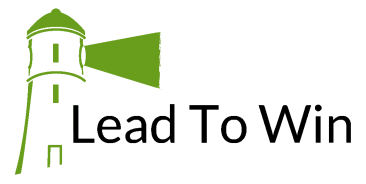

\section{Do you want to start a new business? Do you want to grow your existing business?}

Lead To Win is a free business-development program to help establish and grow businesses in Canada's Capital Region.

Benefits to company founders:

- Knowledge to establish and grow a successful businesses

- Confidence, encouragement, and motivation to succeed

- Stronger business opportunity quickly

- Foundation to sell to first customers, raise funds, and attract talent

- Access to large and diverse business network

\section{Apply Now}

E Eventbrite

f Facebook

Linkedin

Slideshare

- YouTube 


\section{TIM Technology Innovation Management Review

\section{Academic Affiliations and Funding Acknowledgements}
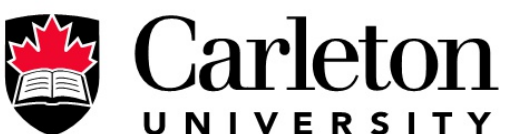
U N I V E R S I T Y

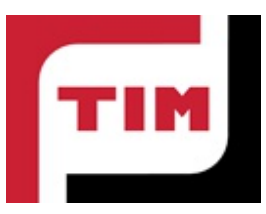

Technology Innovation Management (TIM; timprogram.ca) is an international master's level program at Carleton University in Ottawa, Canada. It leads to a Master of Applied Science (M.A.Sc.) degree, a Master of Engineering (M.Eng.) degree, or a Master of Entrepreneurship (M.Ent.) degree. The objective of this program is to train aspiring entrepreneurs on creating wealth at the early stages of company or opportunity lifecycles.

The TIM Review is published in association with and receives partial funding from the TIM program.

The TIM Review team is a key partner and contributor to the Scale Early, Rapidly and Securely (SERS) Project: https://globalgers.org/. Scale Early, Rapidly and Securely (SERS) is a global community actively collaborating to advance and disseminate high-quality educational resources to scale companies.

The SERS community contributes to, and leverages the resources of, the TIM Review (timreview.ca). The authors, readers and reviewers of the TIM Review worldwide contribute to the SERS project. Carleton University's Technology Innovation Management (TIM) launched the SERS Project in 2019.

We are currently engaged in a project focusing on identifying research and knowledge gaps related to how to scale companies. We are inviting international scholars to join the team and work on shaping Calls for Papers in the TIM Review addressing research and knowledge gaps that highly relevant to both academics and practitioners. Please contact the Editor-inChief, Dr. Stoyan Tanev (stoyan.tanev@carleton.ca) if you want to become part of this international open source knowledge development project. 